\title{
ANEMIA FERROPRIVA NA INFÂNCIA: \\ PREVALÊNCIA E FATORES ASSOCIADOS \\ NA AMAZÔNIA OCIDENTAL BRASILEIRA
}

\section{TERESA GONTIJO DE CASTRO}

Tese apresentada na área de concentração de Nutrição da Faculdade de Saúde Pública da Universidade de São Paulo para obtenção do Grau de Doutor.

Área de concentração: Nutrição

Orientadora: Profa. Dra. Marly Augusto Cardoso

São Paulo

2007 
Autorizo, exclusivamente para fins acadêmicos e científicos, a reprodução total ou parcial desta tese, por processos fotocopiadores.

Assinatura: 
Dedico este momento de minha passagem: A meu pai, Jurany Castro Rezende Andrade A minha mãe, France Maria Gontijo Coelho Pela eterna presença na luta em prol das minorias sociais de nosso país. 


\section{AGRADECIMENTOS}

A minha querida orientadora, Marly Augusto Cardoso, pela amizade, confiança e por toda a aprendizagem e amadurecimento propiciados nos últimos 5 anos. Muito obrigada!

Ao Wolney Lisboa Conde, pela amizade, pela co-orientação desta tese e pela motivação de novos caminhos de investigação.

Ao Pascoal Torres Muniz e sua família, pela oportunidade e recepção durante os trabalhos de campo no Acre.

À equipe de campo (pesquisadores da USP e UFAC, agentes de saúde do PSF, profissionais de saúde e estudantes da UFAC). Em especial à Erika Hellena Hoffmann, Mônica Silva-Nunes, Tiago Santos de Araújo, Nara Barros Nunes e ao Huck.

A Fran (Francisca Souza Santiago), pela amizade e pela ajuda perfeita nos inquéritos alimentares. Meu carinho.

Ao Marcelo Urbano Ferreira pelo auxílio indispensável nas análises estatísticas e bioquímicas.

Ao companheiro de análises Orivaldo Florêncio de Souza pela amizade. A Larissa Baraldi pelo auxílio nos inquéritos alimentares.

Ao Carlos Augusto Monteiro, Sônia Isoyama Venâncio, Pedro Israel Lira e José Maria Pacheco de Souza, pela apreciação so trabalho e sugestões.

A minha família (France, Jura, Maria, Chicão e Vó Chica) e, em especial, aos meus queridos tios Maria de Lourdes e Joany pelo apoio em São Paulo. Muito obrigada!

Aos amigos queridos pelo afeto fundamental: Giana Longo, Daniela Sartorelli, Daniela Schoeps, Gisele Bento, Flora, Renata Damião, Chiara Reyes e Márcio Juliboni.

À Fundação de Amparo à Pesquisa do Esatdo de São Paulo (FAPESP) pela bolsa de doutorado concedida.

Ao Conselho Nacional de Pesquisa (CNPq) pelo suporte financeiro da pesquisa.

Enfim, à população dos municipios de Assis Brasil e Acrelândia, em especial à D. Nilce e sua familia, que me receberam com tanto apreço e carinho em Assis.

E claro, a Deus, por ter me acompanhado em mais esta caminhada. 


\section{RESUMO}

\section{Castro TG. Anemia ferropriva na infância: prevalência e fatores} associados na Amazônia Ocidental Brasileira. São Paulo: 2007. [ Tese de Doutorado - Faculdade de Saúde Pública da USP]

Objetivo: Descrever o estado nutricional de crianças menores de 5 anos residentes em 2 municípios da Amazônia Brasileira.

Métodos: Inquérito transversal de base populacional em crianças residentes na área urbana de Assis Brasil $(\mathrm{n}=200)$ e Acrelândia $(\mathrm{n}=$ 477), Estado do Acre, Brasil.

Resultados: Os resultados foram apresentados na forma de 3 artigos:

1) Saúde e nutrição infantil na Amazônia Ocidental Brasileira: inquéritos de base populacional em dois municípios acreanos; 2) Prevalência e fatores associados ao risco para anemia ferropriva entre pré-escolares da Amazônia brasileira; 3) Dietary practices and nutritional status of 0-24-month-old children from Brazilian Amazonia.

Conclusões principais: Diagnosticaram-se déficits nutricionais, segundo os índices P/E, P/I e E/I, em 3,7\%, 8,7\% e 7,5\% das crianças examinadas, respectivamente. As prevalências gerais de anemia, deficiência de ferro e anemia ferropriva foram de 30,6\%, 43,5\% e $20,9 \%$, respectivamente. Ser menor de 24 meses [Razão das Chances$(\mathrm{RC})=13,72$; Intervalo com 95\% de confiança $(\mathrm{IC} 95 \%)=5,66-33,27] \mathrm{e}$ história de episódio recente de diarréia $(\mathrm{RC}=1,57$; IC95\%=1,01-2,45) foram associados ao risco para anemia ferropriva; porém, pertencer ao maior tercil do índice de riqueza foi associado à proteção $(\mathrm{RC}=0,48$; IC95\%=0,28-0,82). Entre as crianças menores de 2 anos, o aleitamento materno foi iniciado por $97,3 \%$ das mães. Foi observada precoce introdução de alimentos (prevalência de aleitamento materno exclusivo entre menores de 6 meses: $31,4 \%$ ). O padrão alimentar da dieta de desmame foi caracterizado por alta ingestão de alimentos ricos 
em carboidratos e leite de vaca, com ingestão insuficiente de frutas, vegetais e carnes. Todas as crianças de 6-12 meses e 92,3\% das crianças de 12 a 24 meses estavam em risco de consumo inadequado de ferro, sendo observado baixo consumo de ferro biodisponivel (ferro proveniente de alimentos de origem animal contribuiu em média com $0,5 \%$ do total de ferro entre crianças de 6-12 meses e com $14,3 \%$ entre crianças de 12-24 meses).

Descritores: Saúde Infantil. Nutrição Infantil. Anemia Ferropriva. Amazônia Brasileira. 


\section{ABSTRACT}

\section{Castro TG. Iron deficiency anemia in childhood: prevalence and} associated factors in Brazilian Amazonia. São Paulo: 2007. [Doctor Thesis - Faculdade de Saúde Pública da USP]

Objective: To describe the nutritional status of preschool children living in Brazilian Amazonia.

Methods: A population-based cross-sectional study was carried out in the urban area of the towns of Acrelândia ( $\mathrm{n}=477)$ e Assis Brasil $(\mathrm{n}=200)$, Acre State.

Results: The results are presented in 3 articles: 1) Child health and nutrition in Western Brazilian Amazon: population-based surveys in two towns in Acre State; 2) Prevalence and associated factors with iron deficiency anemia in preschool children in Brazilian Amazonia; 3) Dietary practices and nutritional status of 0-24-month-old children from Brazilian Amazonia.

Conclusions: The overall prevalence rates of low weight-for-height, low weight-for-age and low height-for-age were respectively $3.7 \%$, $8.7 \%$ and $7.5 \%$, with similar figures in both towns. Anemia, iron deficiency, and iron deficiency anemia were diagnosed in $30.6 \%$, $43.5 \%$, and $20.9 \%$ of the children, respectively. Age under 24 months (Odds Ratio $-\mathrm{OR}=13.7 ;$ 95\% Confidence Interval $-\mathrm{CI}=5.66-33.27$ ) and history of a recent diarrhea episode $(\mathrm{OR}=1.57$; 95\% CI $=1.01$ 2.45) were associated with a risk for iron deficiency anemia; however; the highest tertile of wealth index was a protector factor for iron deficiency anemia. Among under-twos, breastfeeding was initiated by 97.3\% of mothers. Early feeding with complementary foods was observed (prevalence of exclusive breastfeeding in babies under 6 months: $31.4 \%$ ). Dietary pattern reflected a high intake of carbohydrate-rich foods and cow's milk, with irregular intakes of 
fruit, vegetables and meat. All infants and $92.3 \%$ of toddlers were at risk of inadequate iron intakes. Iron from animal foods contributed on average $0.5 \%$ and $14.3 \%$ of total dietary iron among infants and toddlers, respectively.

Descriptors: Child Health. Childhood Nutrition. Iron Deficiency Anemia. Brazilian Amazonia. 


\section{APRESENTAÇÃO}

Esta tese compõe-se de uma breve INTRODUÇÃO, dividida em três partes, seguida de uma seção de OBJETIVOS. A seguir, encontram-se os ARTIGOS, que incluem um artigo publicado e dois artigos a serem submetidos à publicação. Cada artigo inclui os seguintes tópicos: RESUMO, INTRODUÇÃO, MATERIAIS E MÉTOdOS, RESULTADOS e DISCUSSÃO. Depois dos artigos, encontra-se uma seção para DISCUSSÃo FINAL. A BIBLIOGRAFIA encontra-se no final deste volume, seguida dos ANEXOS. 


\section{ÍNDICE}

Pág.

\section{INTRODUÇÃO}

1.1 Epidemiologia da anemia ferropriva 01

1.2 Fatores associados ao risco de anemia ferropriva na 05 infância

1.3 Estratégias de prevenção e controle da anemia 11 ferropriva na infância

2 JUSTIFICATIVA

3. OBJETIVOS

4. ARTIGOS

3.1 Artigo 1: Saúde e nutrição infantil na Amazônia 20 Ocidental Brasileira: inquéritos de base populacional em dois municipios acreanos.

3.2 Artigo 2: Prevalência e fatores associados ao risco de anemia ferropriva entre pré-escolares da Amazônia brasileira.

3.3 Artigo 3: Dietary practices and nutritional status of 77 0-24-month-old children from Brazilian Amazon.

\section{DISCUSSÃO}




\section{ANEXOS}

\section{Anexo 1}

Termo de Consentimento e Parecer do Comitê de Ética em Pesquisa da Faculdade de Saúde Pública (CEP/FSP/USP) sobre o projeto

Anexo 2

Questionários utilizados para coleta das informações

epidemiológicas da população de estudo

\section{Anexo 3}

Registro fotográfico do trabalho de campo. 


\section{INDICE DE TABELAS}

Pág.

\section{INTRODUÇÃO}

Tabela 1. Estimativa do percentual de anemia (anos de 1990- 02 1995) entre diferentes grupos populacionais no mundo.

Tabela 2. Prevalência de anemia na infância verificada em 04 estudos transversais de base populacional brasileiros.

\section{ARTIGO 1}

Tabela 1. Distribuição de freqüência de características 34 demográficas, sócio-econômicas e ambientais segundo municipios estudados. Acre, 2003.

Tabela 2. Distribuição de freqüência de déficits nutricionais pelos índices $\mathrm{P} / \mathrm{I}, \mathrm{E} / \mathrm{I}, \mathrm{P} / \mathrm{E}$, obesidade pelo índice $\mathrm{P} / \mathrm{E}$, deficiência de ferro e anemia ferropriva segundo municípios estudados. Acre, 2003.

Tabela 3. Distribuição de freqüência de infecção por parasitas intestinais e morbidades referidas segundo municipios estudados. Acre, 2003.

\section{ARTIGO 2}

Tabela 1. Características de saúde, socioeconômicas e 62 ambientais da população de estudo, Acre, Brasil.

Tabela 2. Prevalência de anemia ferropriva entre crianças de 6-60 meses nas categorias das variáveis independentes e resultado da análise univariada, Acre, Brasil.

Tabela 3. Fatores associados à anemia ferropriva entre 66 crianças de 6-60 meses, Acre, Brasil. 


\section{ARTIGO 3}

Table 1. Characteristics of the nutritional status of infants (6- 86 12 month-old) and toddlers, Acre, Brazil.

Table 2. Median (interquartile ranges: 25 th; 75 th) of energy and selected nutrient intakes according to age categories (over 88 6-month-old children), Acre, Brazil. 


\section{ÍNDICE DE FIGURAS}

Pág.

\section{INTRODUÇÃO}

Figura 1. Diagrama conceitual da relação entre deficiência de 01 ferro e anemia em população hipotética.

Figura 2. Determinantes relacionados com a gênese da 06 anemia ferropriva na infância.

Figura 3. Localização dos municípios estudados, Acre, Brasil.

\section{ARTIGO 1}

Figura 1. Prevalência de desnutrição pelo índice E/I e anemia na população infantil de Assis Brasil e Acrelândia 40 segundo quartis do índice de riqueza. Acre, 2003 ( $n=674)$. Tendência estatisticamente significante de redução da prevalência de desnutrição e anemia com o aumento do índice de riqueza: qui-quadrado de tendência, $\mathrm{p}=0,006 \mathrm{e}$ $p=0,0005$, respectivamente.

\section{ARTIGO 2}

Figura 1. Prevalência de anemia, deficiência de ferro e 63 anemia ferropriva em crianças de 6-60 meses, Acre, Brasil.

\section{ARTIGO 3}

Figure 1 Contribution of food groups and breast milk to total energy intake among infants and toddlers, Acre, Brazil.

Figure 2 Percent of children (6-24-month-old) that met the 89 recommendation of energy and nutrients intake, Acre, Brazil. 


\section{LISTA DE SIGLAS}

\section{Em Português}

E/I - Índice Estatura/Idade

$\mathrm{Hb}$ - Hemoglobina ou Hemoglobin

IDH - Índice de Desenvolvimento Humano

IDI - Índice de Desenvolvimento Infantil

RC - Razão de Chances

$\mathrm{P} / \mathrm{E}$ - Índice Peso/Estatura

$\mathrm{P} / \mathrm{I}$ - Índice Peso/Idade

VCT - Valor Calórico Total

\section{Em Inglês}

HAZ - Height/Age escore Z Index

Hb- Hemoglobin

ID - Iron Deficiency

IDA - Iron Deficiency Anaemia

OR - Odds Ratio

SF - Serum Ferritin

STfR - Soluble Transferrin Receptor

WAZ - Weight/Age escore Z Index

WHZ - Weight/Height escore Z Index 


\section{INTRODUÇÃO}

\subsection{EPIDEMIOLOGIA DA ANEMIA FERROPRIVA}

Segundo definição da Organização Mundial de Saúde (OMS, 1968), existe anemia quando a concentração de hemoglobina está anormalmente baixa no organismo humano em conseqüência da carência de um ou mais nutrientes essenciais. Dentre os nutrientes implicados na gênese da anemia, a deficiência de ferro é apontada como a determinante causal principal da maioria dos casos, o que caracteriza a anemia ferropriva como a carência nutricional mais prevalente no mundo atual (VANNUCCHI et al., 1992; OSKI, 1993; GILLESPIE et al., 1991). A Figura 1 apresenta diagrama conceitual entre a relação de deficiência de ferro, anemia e anemia ferropriva em uma população hipotética.

Figura 1. Diagrama conceitual da relação entre deficiência de ferro e anemia em população hipotética (Fonte, WHO, 2001).

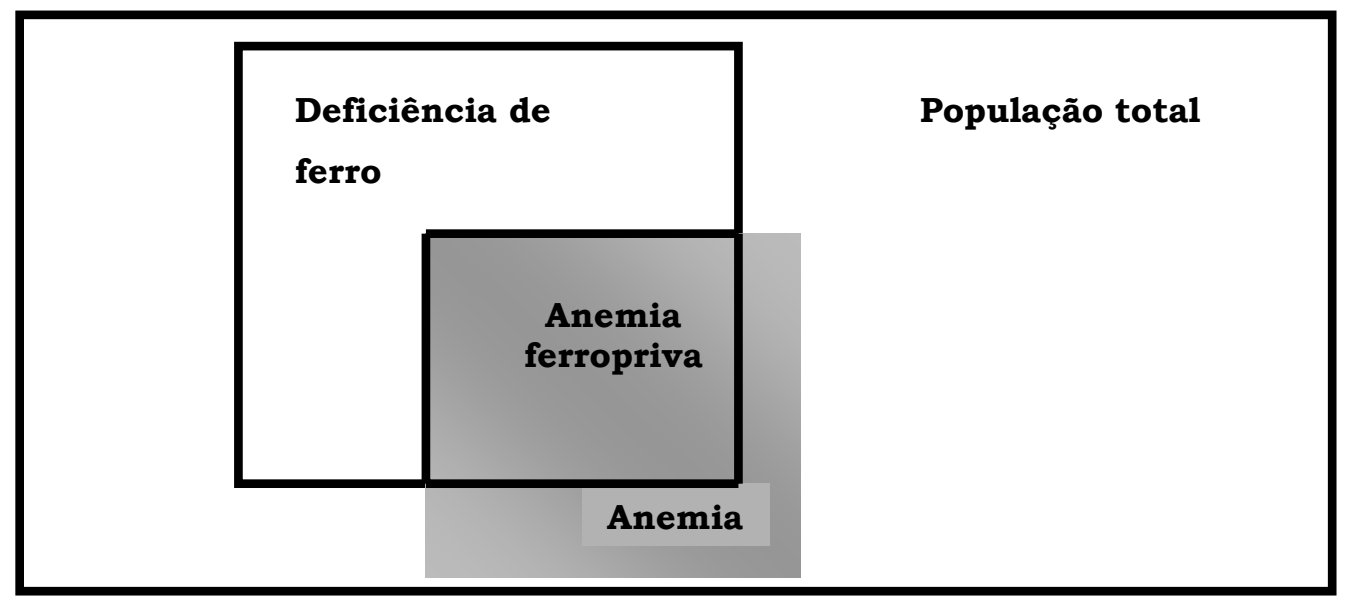


No mundo, a deficiência de ferro atinge mais de 2 bilhões de pessoas, estimando-se uma prevalência total de $40 \%$ da população. Os principais grupos de risco para esta carência são as gestantes e crianças em idade pré-escolar (GILLESPIE, 1998). Estima-se que a maioria das gestantes e pré-escolares nos países não industrializados e ao menos 30-40\% em países industrializados tenham anemia (WHO, 2001). A Tabela 1 apresenta as estimativas de prevalência de anemia segundo concentrações de hemoglobina entre diferentes grupos populacionais de países industrializados e não industrializados no mundo.

Tabela 1. Estimativa do percentual de anemia (anos de 1990-1995) entre diferentes grupos populacionais no mundo. (Fonte, WHO, 2001).

\begin{tabular}{lcc}
\hline & Países & Países não \\
& industrializados & industrializados \\
\hline Crianças 0-4 anos & 20,1 & 39,0 \\
Crianças 5-14 anos & 5,9 & 48,1 \\
Mulheres grávidas & 22,7 & 52,0 \\
Mulheres 15-59 anos & 10,3 & 42,3 \\
Homens 15-59 anos & 4,3 & 30,0 \\
Idosos 60+ anos & 12,0 & 45,2 \\
\hline
\end{tabular}

A deficiência de ferro entre crianças pré-escolares suscita grande preocupação em saúde pública pelos prejuízos que esta acarreta no desenvolvimento deste segmento populacional. Entre estas, os sintomas comuns da deficiência de ferro incluem: comprometimento do desenvolvimento mental e cognitivo, dificuldades no crescimento e desenvolvimento físico, reduzida atividade física e produtividade e 
menor resistência a infecções, com repercussões no aumento da freqüência de morbidades (GILLESPIE, 1998; WHO, 2001). As conseqüências econômicas da anemia ferropriva relacionam-se aos custos despendidos com tratamento dos casos prevalentes, e custos indiretos advindos do aumento da mortalidade materna (no caso de anemia grave durante a gestação), redução da produtividade e comprometimento do desenvolvimento cognitivo e mental na formação de capital humano (WHO, 2001). No Brasil, estima-se um custo anual de US\$ 605 milhões em tratamentos e perdas de produtividade e dias de trabalho e US\$ 2 bilhões com baixos rendimentos escolares (MINISTÉRIO DA SAÚDE, 2000).

Há diferenças discrepantes nas prevalências de anemia ferropriva entre crianças no mundo: nos países do oeste e leste europeu, a prevalência de anemia em pré-escolares é de 5\% e 10\%, respectivamente, sendo estimada em 53\% entre pré-escolares dos países em transição (UNICEF, 2000).

No Brasil, nas últimas três décadas, houve melhoria importante no quadro de saúde infantil, especialmente a redução na prevalência de desnutrição (MONTEIRO E BENÍCIO, 1997). No entanto, o declínio da desnutrição infantil não foi acompanhado por evolução favorável no quadro das anemias (FILHO E RISSIN, 2003), sendo apontado, inclusive, aumento em sua prevalência entre crianças (MONTEIRO, 2000; OLIVEIRA, 2002). É assinalado, ainda, que, embora a prevalência de anemia apresente gradiente entre crianças de diferentes estratos sócioeconômicos, esta se difunde no território nacional como um problema que afeta pobres e ricos, sem evidência de diferenças na ocorrência das anemias entre as macrorregiões do país (FILHO E RISSIN, 2003).

No entanto, no Brasil, são escassos os números de inquéritos de base populacionais acerca da prevalência da anemia (SOUZA et al., 1997). A maioria dos estudos disponíveis utiliza-se dos dados de 
usuários de serviços de saúde ou de grupos restritos, que não compõem uma amostra representativa da população (VANNUCCHI et al., 1992; SOUZA et al., 1997). Além disto, os estudos disponiveis avaliaram a prevalência da anemia com base na medição única de hemoglobina sanguínea, não havendo, até o presente momento, levantamentos que incluam informações sobre a situação das reservas orgânicas de ferro em grupos de risco. Sabe-se que parâmetros hematológicos e bioquímicos podem ser utilizados isoladamente ou associados no diagnóstico do estado nutricional de ferro em indivíduos ou populações. No entanto, quando utilizados de forma isolada, nenhum deles é suficientemente sensível ou específico (PAIVA et al., 2000).

A Tabela 2 apresenta as prevalências de anemia na infância encontradas em estudos populacionais transversais realizados no Brasil. Estes utilizaram o critério de classificação de anemia com base nos valores de hemoglobina sanguínea $(\mathrm{Hb}<11 \mathrm{~g} / \mathrm{dL})$, colhida por meio de punção digital e com leitura em aparelho de hemoglobinômetro portátil (Hemocue).

Tabela 2. Prevalência de anemia na infância verificada em estudos transversais de base populacional brasileiros.

\begin{tabular}{|c|c|c|c|}
\hline Estudo & Local & Grupo (N) & Prevalência de anemia ${ }^{\#}$ \\
\hline $\begin{array}{l}\text { Monteiro et al., } \\
2000\end{array}$ & São Paulo, SP & $\begin{array}{c}6 \text { meses a } 5 \text { anos } \\
(\mathrm{N}=1016 \text { na déc. de } \\
80 \text { e } \mathrm{N}=1280 \text { na déc. } \\
\text { de } 90)\end{array}$ & $\begin{array}{l}\text { Aumento entre as } \\
\text { décadas de } 80 \text { e } 90 \text { (de } \\
36 \% \text { para } 47 \% \text { ) }\end{array}$ \\
\hline Neuman et al., 2000 & Criciúma, SC & $\begin{array}{c}\text { Menores de } 3 \text { anos } \\
(\mathrm{N}=476)\end{array}$ & $54 \%$ \\
\hline Silva et al., 2001 & $\begin{array}{c}\text { Porto Alegre, } \\
\text { RS }\end{array}$ & $\begin{array}{l}\text { Menores de } 3 \text { anos } \\
\quad(\mathrm{N}=557)\end{array}$ & $47,8 \%$ \\
\hline Assis et al., 2004 & Salvador, BA & $\begin{array}{l}\text { Menores de } 5 \text { anos } \\
\quad(\mathrm{N}=553)\end{array}$ & $\begin{array}{c}46,4 \%(13,4 \% \text { de anemia } \\
\text { grave }-<9,5 \mathrm{~g} / \mathrm{dL})\end{array}$ \\
\hline Osório et al., 2004 & Pernambuco & $\begin{array}{l}\text { Menores de } 5 \text { anos } \\
\quad(\mathrm{N}=650)\end{array}$ & $\begin{array}{c}40,9 \%(61,8 \% \text { entre }<\text { de } \\
2 \text { anos e } 31,0 \% \text { entre } 2- \\
5 \text { anos })\end{array}$ \\
\hline Oliveira et al., 2002 & $\begin{array}{l}8 \text { cidades da } \\
\text { zona urbana } \\
\text { da Paraíba }\end{array}$ & $\begin{array}{l}6 \text { meses a } 5 \text { anos } \\
(\mathrm{N}=1287)\end{array}$ & $\begin{array}{c}36,4 \% \text { (em } 1982 \text { era de } \\
19,3 \%)\end{array}$ \\
\hline
\end{tabular}




\subsection{FATORES ASSOCIADOS AO RISCO DE ANEMIA FERROPRIVA NA INFÂNCIA}

O estado nutricional de uma população relaciona-se, entre outros fatores, à alimentação, educação, saneamento ambiental e acesso aos serviços básicos de saúde, caracterizando diferentes níveis causais de determinação (VICTORA et al., 1987; VICTORA et al., 1990). Portanto, assim como qualquer outro problema nutricional na sociedade, além das causas imediatas da anemia ferropriva, há as subjacentes que são claramente importantes. Estas incluem a habilidade das casas em adquirir alimentos em quantidade e qualidade para todos os membros da família, a capacidade e a prática de cuidados adequados da mãe para com a criança e o acesso da família a serviços de saúde de qualidade e ambiente saudável. Também, causas de nível mais básico, como a pobreza, baixo status (poder de decisão) e escolaridade da mulher e degradação ambiental atuam como determinantes importantes da deficiência de ferro e anemia ferropriva na infância (GILLESPIE, 1998).

Os determinantes proximais da deficiência de ferro e anemia ferropriva resultam da combinação de fatores que afetam ingestão de ferro e perdas deste mineral pelo organismo (RAMAKRISHNAN \& YIP, 2002). De maneira geral, seus determinantes imediatos estão principalmente relacionados às condições de gestação e nascimento, a variáveis biológicas, ao estado nutricional da criança, à ocorrência de morbidades na infância, às práticas de aleitamento materno e de consumo alimentar. A Figura 2 esquematiza, de forma genérica, os determinantes envolvidos na gênese da anemia ferropriva na infância. 
Figura 2. Determinantes relacionados com a gênese da anemia ferropriva na infância.

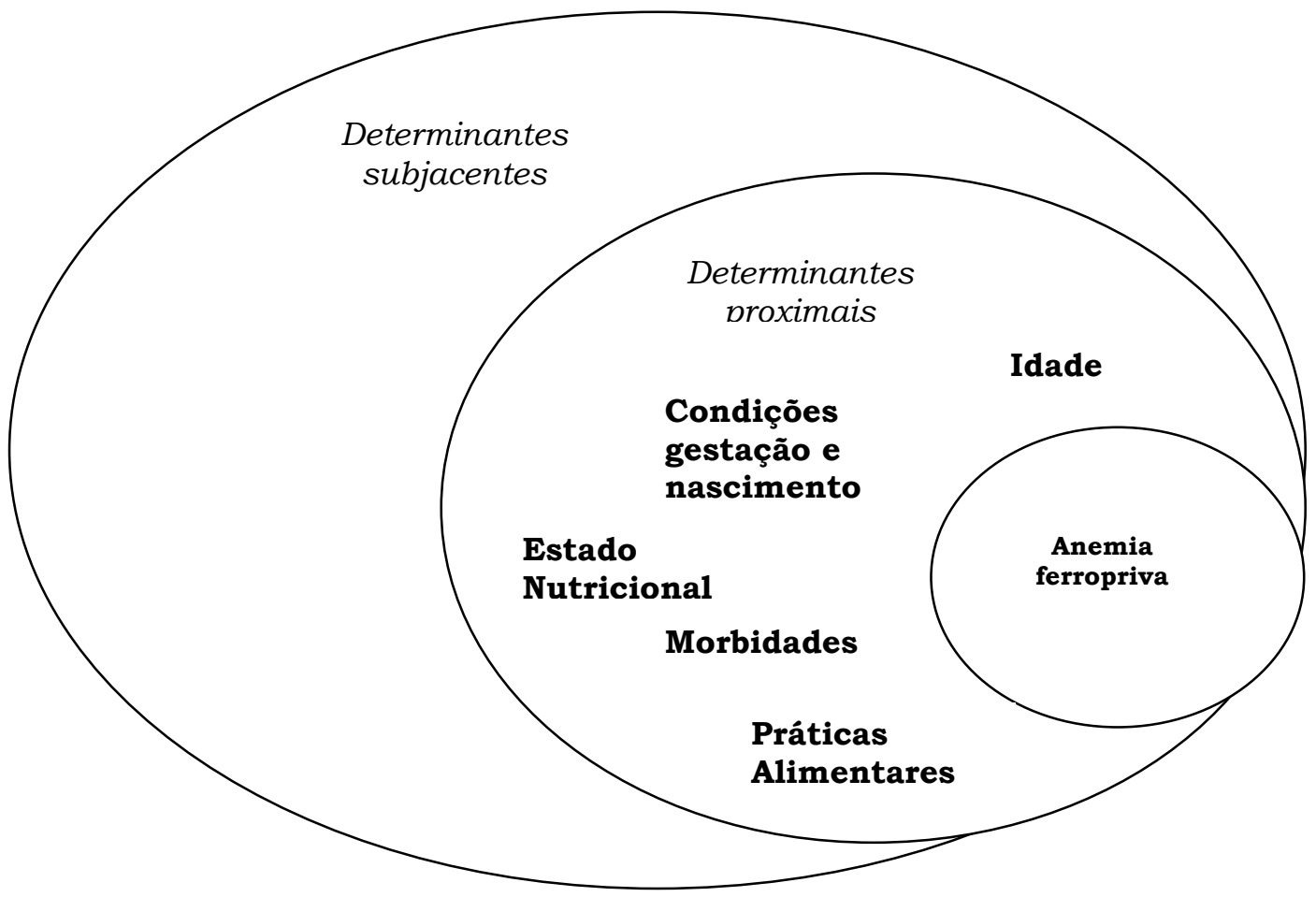

Com relação às condições de gestação e nascimento, estudos prévios sugerem que a anemia materna por deficiência de ferro durante a gestação aumenta o risco para a ocorrência de anemia ferropriva na infância (COLOMER et al., 1990; PEE et al., 2002). Há, também, evidências de associações entre a anemia materna e peso ao nascer da criança, a duração da gestação (idade gestacional) e a mortalidade neonatal ou perinatal (RASMUSSEN, 2001). No entanto, os desfechos desfavoráveis de uma gestação cuja mãe foi deficiente em ferro parece dependerem da gravidade da anemia materna. Em estudo de coorte conduzido com 918 gestantes adolescentes africanas em serviços de saúde não foi verificada associação significante entre a baixa concentração de hemoglobina sangüínea materna e desfechos de baixo peso ao nascer e prematuridade. Os autores atribuíram esse resultado, em parte, ao fato da maioria das mulheres terem 
apresentado anemia moderada durante a gestação (CHANG et al., 2003).

Por sua vez, ao nascimento, a ocorrência de baixo peso e prematuridade aumentam o risco de anemia ferropriva na infância, pois a transferência de ferro materno para a reserva de ferro fetal (estocado no figado e medula óssea) ocorre principalmente durante o último trimestre de gestação (ZLOTKIN, 2003). Além disso, aliado aos baixos estoques orgânicos de ferro, crianças prematuras e com baixo peso ao nascer apresentam maior taxa de crescimento pós-natal, o que aumenta o risco para ocorrência da carência deste mineral (OSKI, 1993; CESSIE et al., 2002). Outro fator associado ao risco de anemia ferropriva na infância, no momento do nascimento, diz respeito ao procedimento de clampeamento do cordão umbilical. O tempo gasto para o corte do cordão umbilical pode interferir nas reservas fetais de ferro. Em estudo de caso-controle randomizado foram avaliados os valores de hemoglobina e ferritina sérica aos 3 meses de idade de crianças que tiveram o corte precoce do cordão, comparado com o grupo onde o corte do cordão ocorreu mais tarde. Os valores médios de ferritina sérica e hemoglobina sangüinea foram significantemente maiores no grupo com maior tempo para corte do cordão $(118,4 \mathrm{mcg} / \mathrm{L}$ e $99 \mathrm{~g} / \mathrm{dL})$ do que no grupo com ruptura precoce do mesmo (73 mcg/L e $88 \mathrm{~g} / \mathrm{dL})$, após controle para variáveis de ajuste em modelo de regressão (GUPTA \& RAMJI, 2002).

A deficiência de ferro é mais prevalente em crianças de 6 a 12 meses de idade - período onde há aumento das necessidades de ferro para prover o crescimento de tecidos (da ordem de 50\% a $70 \%$ maiores). No primeiro ano de vida, a necessidade de ferro a ser absorvido é comparável à estimada para um homem adulto, sugerindo um risco de deficiência maior, dado que a ingestão de ferro tende a ser proporcional à ingestão de energia, que por sua vez é proporcional ao tamanho corporal (GILLESPIE, 1998). 
O estado nutricional da criança também se mostra associado ao risco para anemia ferropriva. A desnutrição protéico-calórica é ainda um problema de saúde pública em áreas tropicais, devido tanto a sua magnitude como também ao efeito catastrófico para a sobrevivência e o desenvolvimento de crianças e mães. Estimativas mundiais provenientes da World Health Organization Global Database on Child Growth and Malnutrition apontam para o ano de 2005 a existência de cerca de 149,1 milhões de crianças com baixa estatura para idade e 127,2 milhões com baixo peso para idade (ONIS et al, 2004). Nos países em desenvolvimento, cerca de $36 \%$ das crianças menores de cinco anos apresentam baixo peso para idade e $43 \%$ têm déficit de altura (ONís et al., 1993). No Brasil, análises da evolução do estado de saúde da população infantil nas últimas décadas demonstraram melhorias substanciais e contínuas em vários indicadores de saúde associados à pobreza, com redução da mortalidade e desnutrição infantil em nível nacional. No entanto, essas melhorias foram menos intensas nas Regiões Norte e Nordeste, o que determinou a exacerbação das desigualdades existentes entre essas regiões e o Centro-Sul do país (MONTEIRO E BENÍCIO, 1997). $\mathrm{O}$ estado marginal de vitamina A também se associa ao risco para anemia ferropriva, pois esta vitamina tem papel importante na hematopoiese, relacionado à absorção e mobilização de ferro corpóreo (BLOEM, 1995). OSÓRIO et al (2004), em estudo transversal com menores de 5 anos no estado de Pernambuco, encontraram associação positiva entre valores séricos de retinol e niveis de hemoglobina sanguínea, em modelo de regressão linear múltiplo.

Morbidades comuns na infância, como as infecções, exercem papel negativo no estado nutricional de ferro (GILLESPIE, 1998, WHO, 2001). Em áreas tropicais, as infestações parasitárias podem desempenhar, também, importante papel na etiologia da anemia ferropriva. Em infecções pesadas por Trichuris trichiura, pode-se 
observar anemia severa, acentuada perda de peso, diarréia abundante com laivos de sangue, prolapso retal, baqueteamento de dedos e eosinofilia moderada (HOLLAND, 1987). Estudo com préescolares na República Unida da Tanzânia detectou uma alta prevalência de anemia (54\%), particularmente nas crianças com esquistossomose e infecção por helmintos. Análise estratificada estimou que a infecção por helmintos e a esquistossomose foram responsáveis por $6 \%$ e $15 \%$ dos casos de anemia, respectivamente (GUYATT et al., 2001). Em estudo realizado com crianças escolares no Zanzibar diagnosticou-se uma prevalência de $51 \%$ de anemia ferropriva, sendo $35 \%$ e $75 \%$ dos casos de anemia ferropriva moderada e grave, respectivamente, atribuídos à infecção por parasitas espoliadores de sangue. Neste estudo, menos de 10\% de todos os casos de anemia foram atribuídos a infecção por Ascaris lumbricoides, infecção malárica ou desnutrição (STOLTZFUS et al., 1997).

Outras infecções, crônicas ou recorrentes, podem interferir com a ingestão ou utilização do ferro. Estas infecções incluem a malária e a doença diarréica crônica (GILLESPIE, 1998). Estudos realizados na Amazônia Ocidental Brasileira nos últimos 10 anos sugerem a malária e a deficiência de ferro alimentar como as principais causas subjacentes à maior parte dos casos de anemia, de elevada prevalência em várias faixas etárias (CARDOSO et al., 1992; CARDOSO et al., 1994). A malária ocasiona a ruptura dos eritrócitos parasitados, lise autoimune dos eritrócitos parasitados e normais, hiperfunção reticuloendotelial, comprometimento da eritropoiese, podendo a infecção malárica agravar uma deficiência de ferro préexistente (CARDOSO et al., 1994). A ocorrência de diarréia na infância, mesmo em situações moderadas, relaciona-se à menor taxa de absorção de ferro, com conseqüente redução na concentração de hemoglobina (REEVES, 1984). LEVY et al (2005), em estudo 
prospectivo com menores Beduínos de 18 meses, também observaram aumento no risco de anemia com aumento de infecções diarréicas e respiratórias. No estado de Pernambuco foi verificada associação negativa significante entre episódios de diarréia recentes e níveis de hemoglobina entre crianças aos 12 meses de idade (LIMA et al., 2004) e entre menores de cinco anos (OSÓRIO et al., 2004). A diarréia pode ocasionar perda sanguínea intestinal, e ocorrência recente desta infecção tem sido sugerida como um marcador de diarréia crônica (BERESFORD, 1971). No entanto, a relação causal entre estado nutricional de ferro e susceptibilidade a infecções permanece controversa (WALTER et al, 1997).

As práticas de aleitamento materno e consumo alimentar tem sido identificados como os principais fatores de risco para deficiência de ferro na infância (LEVY-COSTA \& MONTEIRO, 2004; SOH et al, 2004; WHO, 2001; SIEGEl et al, 2006). O leite materno contém ferro com biodisponibilidade excepcionalmente alta. Ainda assim, durante os primeiros meses de vida, o leite materno não provê quantidade de ferro suficiente para atingir as demandas de eritropoiese rápida, ocorrendo mobilização das reservas orgânicas do bebê para atingir suas necessidades, sendo necessária introdução de alimentos que atendam as demandas deste mineral a partir do sexto mês de vida. A transição da amamentação exclusiva para os alimentos da família representa um período onde as crianças estão muito vulneráveis, sendo necessários alimentos complementares apropriados com alta densidade energética e de nutrientes de alta biodisponibilidade (DAVIDSSON, 2003). Além disso, a curta duração da amamentação exclusiva, com oferta precoce de alimentos pobres em ferro, aumenta o risco de deficiência de ferro nas crianças. A introdução precoce do leite de vaca, por exemplo, foi apontada como fator de risco para a deficiência de ferro, pois, além de seu baixo conteúdo em ferro, pode causar sangramento gastrointestinal (CDC, 1998). Além disso, a 
qualidade e biodisponibilidade baixas do ferro da dieta infântil contribuem para a vulnerabilidade à deficiência de ferro nesta fase. Dietas com baixo conteúdo de ferro heme e constituintes facilitadores da absorção de ferro não-heme (carne e vitamina C) ou com altos teores de inibidores da absorção do ferro heme (fibras, fitatos, taninos) podem ocasionar a depleção de ferro no organismo (BHARGAVA et al., 2001). Em estudo de coorte com crianças da Dinamarca, acompanhadas do nascimento aos 12 meses de idade, observou-se que, entre os 6 e 9 meses de idade, o consumo de pão e leite de vaca foi inversamente associado aos valores de ferritina sérica ( $\mathrm{p}=0,001$ e $\mathrm{p}=0,07$, respectivamente), enquanto que o consumo de carnes $(p=0,07)$ e peixes $(p=0,08)$ apresentou correlação positiva com este parâmetro em modelo de regressão linear múltiplo (MICHAELSON et al., 1995).

\subsection{ESTRATÉGIAS DE PREVENÇÃO E CONTROLE DA ANEMIA FERROPRIVA NA INFÂNCIA}

Em 1999, o Brasil firmou compromisso social de redução da anemia por carência de ferro na infância, estabelecido pela Política Nacional de Alimentação e Nutrição do Brasil (MINISTÉRIO DA SAÚDE, 2000). Experiências em países industrializados evidenciam que o controle da deficiência de ferro na infância resultou da ação conjugada de desenvolvimento econômico e implantação de políticas públicas específicas. Desta forma, as estratégias públicas se pautaram na conjunção das ações de fortificação de alimentos com ferro, suplementação medicamentosa com ferro e a diversificação dietética por meio de medidas de saúde pública, tais como trabalhos de educação alimentar e nutricional (RAMAKRISHNAN \& YIP, 2002). A 
Organização Mundial de Saúde (WHO, 2001) aponta para a necessidade de promover a interação dos diversos setores e organizações da sociedade na tentativa de prevenir e controlar a anemia por deficiência de ferro.

Uma das ações para controle e prevenção da deficiência de ferro na infância se baseia em suplementar, de forma medicamentosa e obrigatória, grupos considerados em risco para deficiência de ferro, tais como crianças nascidas com baixo peso, gestantes e crianças de 6-12 meses de regiões onde a prevalência de anemia ferropriva seja superior a 40\% (WHO, 2001). No Brasil, para alcançar recomendações da OMS, a portaria de 16/05/2005 da Coordenação Geral da Política de Alimentação e Nutrição (Ministério da Saúde) instituiu o Programa Nacional de Suplementação Universal de Ferro, a ser implementado nos municípios habilitados nas condições de gestão do Sistema Único de Saúde (SUS), com os seguintes grupos-alvo: crianças de 6 a 18 meses, gestantes a partir da $20^{\mathrm{a}}$ semana de gravidez e mulheres até o terceiro mês pós-parto. Atualmente, este programa encontra-se em fase de implantação (MINISTÉRIO DA SAÚDE, 2005). A suplementação medicamentosa, muitas vezes pautada na administração de sulfato ferroso diariamente, tem tido baixa aderência pela população, devido tanto a fatores individuais (como efeitos gastrointestinais e sinais e sintomas indesejáveis ou mero esquecimento) como também por fatores programáticos (falha no abastecimento de suplementos e falta de orientação adequada para uso do suplemento) (WHO, 2001). Na tentativa de contornar a baixa adesão ao regime de suplementação diária de ferro, MONTEIRO et al (2001), em estudo de intervenção realizado na cidade de São Paulo, verificaram efeito preventivo significativo de redução de anemia entre menores de 5 anos que receberam suplementação profilática semanal com sulfato ferroso. A orientação da forma de administração do suplemento foi realizada pela equipe técnica da pesquisa durante 
cerca de 5 minutos. Após 5 a 8 meses de seguimento, a prevalência de anemia foi significantemente menor no grupo intervenção, quando comparado ao grupo que não recebeu a suplementação $(9,1 \%$ vs $21,6 \% ; \mathrm{p}<0,05)$. A estratégia de incluir a distribuição de sulfato ferroso em dose semanal para menores de cinco anos juntamente com demais ações dos Agentes do Programa de Saúde da Família (PSF) poderia representar uma alternativa de intervenção no estado nutricional de ferro infantil. No entanto, esta possibilidade deve ser avaliada em outras regiões do país.

Além da suplementação com ferro para grupos de risco, a OMS recomenda a conjugação de ações de enriquecimento de alimentos com ferro comumente utilizados na alimentação nos primeiros anos de vida (WHO, 2001). No Brasil, uma resolução de 2002 (RDC número 344, dezembro de 2002) tornou obrigatória a fortificação das farinhas de trigo e milho com ferro e ácido fólico (para cada $100 \mathrm{~g}$ das farinhas, 4,2 mg de ferro e $150 \mathrm{mcg}$ de ácido fólico) (MINISTÉRIO DA SAÚDE, 2002). No entanto, não localizamos, até o momento, estudos brasileiros publicados sobre impacto desta ação de fortificação.

Paralelamente, a OMS (WHO, 2001) recomenda atividades de educação alimentar e nutricional como medida de controle e prevenção da anemia ferropriva. Esta estratégia se pauta em políticas de divulgação de condutas desejáveis, que incluem:

* Estímulo do aleitamento materno exclusivo até o sexto mês, com introdução de alimentos de alta biodisponibilidade de ferro a partir de então, e mantendo o aleitamento materno até o segundo ano de vida da criança;

* Aumento da ingestão de alimentos ou constituintes alimentares que melhorem a absorção do ferro não-heme alimentar (tais como proteína animal, ácido cítrico e ascórbico provenientes de frutas e vegetais); 
- Divulgação de técnicas de cocção para redução das perdas de conteúdo de vitamina $\mathrm{C}$ dos alimentos;

* Redução da ingestão de componentes inibidores da absorção de ferro (fitatos, polifenóis e cálcio);

* Divulgação e estímulo de técnicas de cocção de germinação e fermentação, que produzem ácidos orgânicos, propiciadores da redução de ácido fítico dos alimentos;

* Aporte adequado de outros nutrientes relacionados ao metabolismo de ferro no organismo (vitamina A, folato, riboflavina e vitamina $\left.\mathrm{B}_{12}\right)$. 


\section{JUSTIFICATIVA}

A região norte brasileira apresenta cenário onde é notável a carência de investigações no campo da saúde coletiva, especialmente sobre a complexidade das condições de vida de habitantes da Amazônia e sua influência na produção e modulação do perfil endêmico-epidêmico, que atualmente depende menos da relação com a natureza e mais das condições urbanas de vida na região (GARNELO E ROCHA, 2006).

Há escassez de estudos de base populacional acerca das condições de saúde infantil na região norte brasileira. No Estado do Acre, municipios com pequenas populações apresentam forte característica rural e sobrevivem com grandes dificuldades financeiras devido à longa crise da sua economia extrativista. São grandes as deficiências educacionais, habitacionais, de acesso ao saneamento básico e de assistência à saúde. Os serviços públicos de assistência à saúde sempre foram gerenciados pelo Estado do Acre, que iniciou recentemente o processo de municipalização da saúde. No entanto, há inúmeras dificuldades a serem superadas, especialmente a ausência de infra-estrutura básica, de recursos humanos qualificados e de capacidade de resolução dos problemas de saúde da população. O relatório “Saúde Brasil 2004” (UNICEF, 2005) estima que a taxa de mortalidade infantil no estado do Acre, em 2001, era de 34,3/1000 nascidos vivos, substancialmente superior à média nacional $(27,7 / 1000$ nascidos vivos). Em 2000, somente 34\% da população acreana tinha acesso à rede geral de abastecimento de água, $52 \%$ à coleta de lixo e $28,7 \%$ à rede geral de instalação sanitária e fossa séptica; todos estes indicadores encontram-se abaixo das médias nacionais. O índice de desenvolvimento infantil (IDI) dos municipios do Acre é o segundo pior do país. 
Em 1994, a Universidade Federal do Acre (UFAC), em colaboração com a Secretaria Municipal da Saúde de Rio Branco e o Fundo das Nações Unidas para a Infância (UNICEF, 1994), realizou diagnóstico de saúde materno-infantil restrito aos habitantes da cidade de Rio Branco, mas permanece desconhecida a situação dos demais municipios do estado. O presente estudo representa um dos poucos estudos de base populacional realizados em áreas urbanas da região da Amazônia Ocidental Brasileira e que inclui, de forma pioneira, avaliação mais completa dos indicadores do estado nutricional de ferro na infância (com informações sobre reservas orgânicas de ferro).

O planejamento adequado de programas de nutrição infantil na região norte brasileira depende da disponibilidade de dados recentes, provenientes de inquéritos de base populacional, e que incluam informações sobre outras deficiências nutricionais prevalentes na infância, como da anemia ferropriva. A Figura 3 apresenta a localização dos municipios estudados no presente trabalho, Assis Brasil e Acrelândia, no Estado do Acre. 
Figura 3. Localização dos municipios estudados, Acre, Brasil.

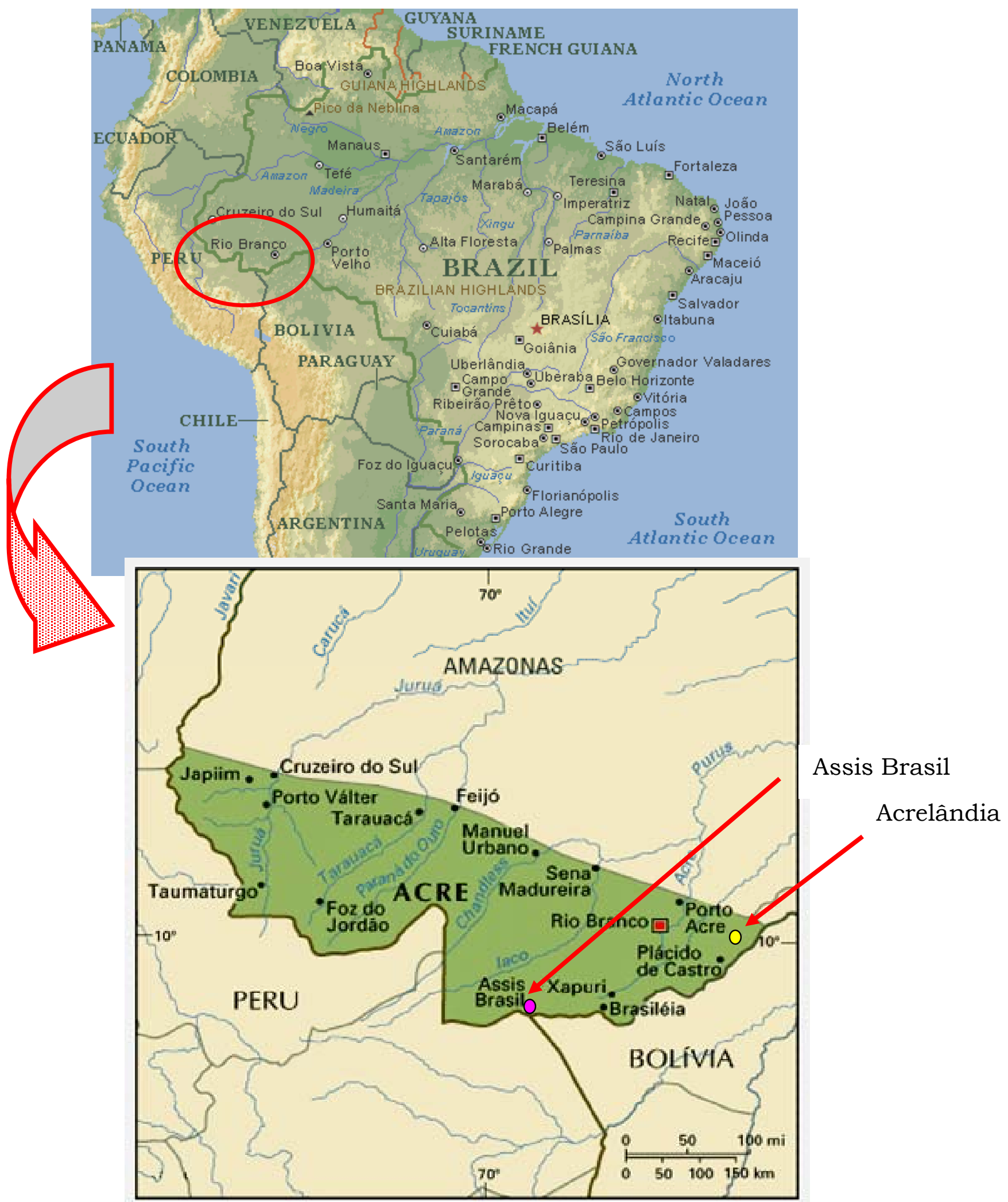




\section{OBJETIVOS}

Este trabalho apresenta 3 objetivos relacionados ao inquérito sobre condições de saúde e nutrição dos menores de 5 anos dos municípios de Assis Brasil e Acrelândia, Estado do Acre, Brasil, que são:

3.1. Caracterizar as condições de saúde e nutrição das crianças de 0 a 60 meses (Artigo 1);

3.2. Investigar a prevalência e os fatores associados ao risco de anemia ferropriva entre os menores de 5 anos (Artigo 2);

2.3. Descrever as práticas alimentares em amostra de crianças menores de 24 meses (Artigo 3). 


\section{ARTIGOS}

* Artigo 1: Muniz PT, Castro TG, Araújo TS, Nunes NB, Silvanunes M, Hoffmann EHE, Ferreira MU, Cardoso MA. Saúde e nutrição infantil na Amazônia Ocidental Brasileira: inquéritos de base populacional em dois municipios acreanos. Cadernos de Saúde Pública 2006, (aceito para publicação).

Artigo 2: Castro TG, Muniz PT, Silva-Nunes M, Conde WL, Ferreira MU, Cardoso MA. Prevalência e fatores associados ao risco de anemia ferropriva entre pré-escolares da Amazônia brasileira. A ser submetido à publicação na Revista Panamericana de Salud Pública/ Pan American Journal.of Public Health.

Artigo 3: Castro TG, Baraldi LG, Muniz PT, Cardoso MA. Dietary practices and nutritional status of 0-24-month-old children from Brazilian Amazon. A ser submetido à publicação no Public Health Nutrition. 


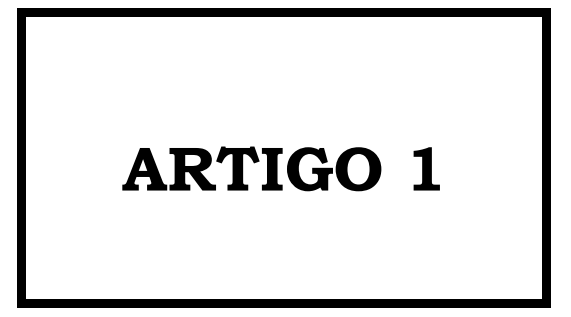




\section{SAÚDE E NUTRIÇÃO INFANTIL NA AMAZÔNIA OCIDENTAL BRASILEIRA: INQUÉRITOS DE BASE POPULACIONAL EM DOIS MUNICÍPIOS ACREANOS}

Child health and nutrition in Western Brazilian Amazon: population-based surveys in two towns in Acre State

Pascoal Torres Muniz ${ }^{1}$, Teresa Gontijo de Castro ${ }^{2}$, Tiago Santos de Araújo $^{1}$, Nara Barros Nunes ${ }^{1}$, Mônica da Silva-Nunes ${ }^{3}$, Erika Hellena Esther Hoffmann³, Marcelo Urbano Ferreira ${ }^{3}$, Marly Augusto Cardoso $^{2}$

${ }^{1}$ Departamento de Ciências da Saúde, Universidade Federal do Acre. BR 364 km4, 69915-900, Rio Branco (AC), Brasil.

2Departamento de Nutrição, Faculdade de Saúde Pública, Universidade de São Paulo. Av. Dr. Arnaldo 715, 01246-904, São Paulo (SP), Brasil.

32Departamento de Parasitologia, Instituto de Ciências Biomédicas da Universidade de São Paulo. Av. Prof. Lineu Prestes 1374, 05508-900, São Paulo (SP), Brazil.

Correspondência para/ Correspondence to:

Marly Augusto Cardoso

Departamento de Nutrição, Faculdade de Saúde Pública, Universidade de São Paulo. Av. Dr. Arnaldo, 715 - 01246-904

Fone/Fax: (011) 3066-7705 - E-mail: marlyac@usp.br 


\section{Saúde e nutrição infantil na Amazônia ocidental brasileira: Inquéritos de base populacional em dois municipios acreanos}

\section{Resumo}

As prevalências de desnutrição, parasitoses intestinais, anemia e deficiência de ferro foram avaliadas, através de inquéritos transversais de base populacional, em crianças de 0 a 60 meses de idade residentes na área urbana de Assis Brasil ( $\mathrm{n}=200) \mathrm{e}$ Acrelândia ( $\mathrm{n}=477)$, Acre, Brasil. Os indices antropométricos peso/estatura $(\mathrm{P} / \mathrm{E})$, peso/idade $(\mathrm{P} / \mathrm{I})$ e estatura/idade $(\mathrm{E} / \mathrm{I})$ foram calculados como escores $z$, com base na população de referência do National Center for Health Statistics (NCHS) de 1977. Diagnosticaram-se déficits nutricionais $(\leq 2$ desvios-padrão da mediana do NCHS), segundo os índices P/E, P/I e E/I, em 3,7\%, $8,7 \%$ e $7,5 \%$ das crianças examinadas, respectivamente. Diagnosticou-se obesidade segundo índice P/E ( $\geq 2$ desvios-padrão da mediana do NCHS) em 2,8\% das crianças. Encontraram-se parasitas intestinais em $32,5 \%$ das 554 amostras examinadas. Giardia duodenalis foi o parasita mais prevalente $(20,4 \%)$, sendo raras as infecções por helmintos. Com base nos níveis de hemoglobina sangüínea e niveis plasmáticos de ferritina e receptor solúvel de transferrina, diagnosticaram-se anemia e deficiência de ferro em $30,6 \%$ e $43,5 \%$ das crianças, respectivamente. Somente 47,6\% das crianças com deficiência de ferro tinham anemia, indicando que a medida isolada de hemoglobina sangüínea subestima a magnitude da deficiência de ferro nesta população. Além disso, 31,9\% das crianças anêmicas não tinham evidências bioquímicas de deficiência de ferro, sugerindo a ocorrência de outros determinantes, nutricionais, infecciosos ou hematológicos, de anemia. Nos dois municípios, a 
anemia e a desnutrição, mas não as parasitoses intestinais, foram significantemente mais prevalentes entre as crianças provenientes de famílias dos estratos sócio-econômicos mais baixos.

Palavras-chave: Saúde infantil; Antropometria; Estado nutricional; Anemia por deficiência de ferro; Amazônia.brasileira 
Abstract

Here we present prevalence rates for malnutrition, intestinal parasitic infections, anemia, and iron deficiency in urban Amazonian underfive children that have been derived from population-based crosssectional surveys performed in Assis Brasil $(n=200)$ and Acrelandia ( $\mathrm{n}=477)$, Acre, Brazil. Available data comprised: (a) weight and height measurements, standardized as $z$-scores using the 1977 National Center for Health Statistics (NCHS) reference population, (b) diagnosis of current intestinal parasitic infection, (c) blood hemoglobin levels, and (d) plasma levels of ferritin and soluble transferrin receptor. The overall prevalence rates of low weight-forheight, low weight-for-age and low height-for-age were respectively $3.7 \%, 8.7 \%$ and $7.5 \%$, with similar figures in both towns; $2.8 \%$ of the children were classified as obese (high weight-for-height), with no significant difference according to sex. Intestinal parasites were detected in $32.5 \%$ children. Giardia duodenalis was found in $20.4 \%$ of the 554 stool samples examined; helminths were uncommon. Anemia and iron deficiency were diagnosed in $30.6 \%$ and $43.5 \%$ of the children, respectively. Evidence of anemia was found in only $47.6 \%$ of the children with depleted iron stores, indicating that hemoglobin measurements alone would severely underestimate the magnitude of iron deficiency in this population. Moreover, $31.9 \%$ of anemic children had no biochemical evidence of iron deficiency, suggesting that other nutritional, infectious or hematologic conditions are major contributors to anemia. In both towns, anemia and malnutrition, but not parasitic infections, were significantly more prevalent among children in the lowest socioeconomic strata.

Key-words: Child health; Anthropometry; Nutritional status; Iron deficiency anemia; Brazilian Amazon. 


\section{Introdução}

As crianças menores de cinco anos de idade são grupos de grande vulnerabilidade aos agravos de saúde, constituindo alvo prioritário de programas de atenção básica à saúde. As condições de saúde e nutrição infantil estão diretamente relacionadas a vários fatores passiveis de prevenção ou modificação, como o consumo alimentar e a exposição a diversas infecções ${ }^{1}$. Nos países em desenvolvimento, cerca de $36 \%$ das crianças menores de cinco anos apresentavam baixo peso para idade e 43\% apresentavam déficit de altura até o início da década de $1990^{2}$, mas há evidências de que essas prevalências vêm diminuindo recentemente em diversas regiões do mundo ${ }^{3}$. A prevalência de anemia ferropriva na população infantil de alguns países em desenvolvimento pode chegar a 50\%, mas há poucos inquéritos de base populacional disponiveis para comparação ${ }^{4}$.

Como em outros países em desenvolvimento ${ }^{3}$, observou-se melhora significativa de indicadores de saúde na população infantil brasileira ao longo das últimas décadas, com redução da mortalidade e desnutrição infantil em nível nacional ${ }^{5}$. No entanto, como essas melhorias foram menos intensas nas Regiões Norte e Nordeste, exacerbaram-se as desigualdades pré-existentes entre essas regiões e o Centro-Sul do Brasil"5,6. Os dados disponiveis mais recentes sobre a prevalência de desnutrição infantil nos municípios brasileiros são provenientes da Pesquisa Nacional sobre Demografia e Saúde (PNDS) de 1996. Das 212 crianças menores de cinco anos de idade examinadas na Região Norte, 16,2\% tinham déficit estatural e 7,7\% tinham déficit ponderal7. Essa situação contrasta com aquela observada nas regiões Sul e Sudeste do país, onde as prevalências de déficit estatural e ponderal situam-se em torno de 3-6\%.7

O planejamento adequado de programas de nutrição infantil na região norte do Brasil depende da disponibilidade de dados recentes, 
provenientes de inquéritos de base populacional, que incluam não somente informações sobre déficits de crescimento como também sobre outras deficiências nutricionais. Por exemplo, as estimativas da prevalência de anemia ferropriva na população infantil brasileira são escassas, resultando do emprego de métodos laboratoriais inadequados para estimar reservas de ferro ${ }^{8}$. Não há dados publicados, provenientes de inquéritos de base populacional, sobre a prevalência de anemia ferropriva em populações infantis amazônicas.

Descreve-se aqui um amplo diagnóstico das condições de saúde e nutrição da população infantil de dois municípios amazônicos típicos, Acrelândia e Assis Brasil, que diferem entre si quanto ao modelo básico de desenvolvimento econômico adotado em anos recentes, mas que compartilham indicadores sócio-econômicos substancialmente abaixo da média nacional. $O$ município de Acrelândia originou-se de núcleos do Projeto de Assentamento Dirigido Pedro Peixoto, o maior plano de assentamento agrícola do estado do Acre, implementado pelo Instituto Nacional de Colonização e Reforma Agrária (INCRA) em meados da década de 1970. É um municipio de fronteira, cuja população adulta consiste predominantemente de migrantes das regiões Sudeste e Sul do país. Por outro lado, Assis Brasil é um município criado há 30 anos, habitado majoritariamente por famílias originárias da região, envolvidas em atividades econômicas extrativistas, como a extração de borracha e a coleta de castanha. Parte de sua área localiza-se na Reserva Extrativista Chico Mendes, a maior do estado.

\section{Metodologia}

\section{Áreas de estudo}

O município de Acrelândia, criado em 1993, ocupa área de $1607,5 \mathrm{~km}^{2}$ situada entre os rios Abunã e Iquiri (também conhecido como Ituxi), no Vale do Rio Acre; faz fronteira com a Bolivia e os 
estados do Amazonas e Rondônia. Nesta área, descrita detalhadamente em publicação anterior ${ }^{9}$, a Universidade de São Paulo (USP) e a Universidade Federal do Acre (UFAC) vêm realizando diversos inquéritos colaborativos sobre as condições de vida e saúde de populações urbanas e rurais. Acrelândia situa-se a $112 \mathrm{~km}$ a leste de Rio Branco, capital do estado do Acre, e tem população de 8.697 habitantes, segundo estimativa da Fundação IBGE para 200310, dos quais $43 \%$ na área urbana. O índice de desenvolvimento humano (IDH) foi estimado em 2000 em 0,680, com uma taxa de mortalidade infantil de 70,75 por 1000 nascidos vivos. A taxa de analfabetos funcionais é de 50,9\% e de analfabetismo é de 26,7\%11,12. A principal atividade econômica é a agricultura comercial.

Assis Brasil, município criado em 1976, tem população de 3.667 habitantes (estimativa da Fundação IBGE para 2003) ${ }^{9}$, dos quais $62 \%$ na área urbana. Ocupa área de $2.884,2 \mathrm{~km}^{2}$ situada na fronteira com a Bolivia, o Peru e os municípios acreanos de Brasiléia e Sena Madureira, a $344 \mathrm{~km}$ a sudoeste de Rio Branco. O IDH foi estimado em 2000, para a população geral do município, em 0,670, com uma taxa de mortalidade infantil de 67,4 por 1000 nascidos vivos. A taxa de analfabetos funcionais é de 51,3\% e de analfabetismo é de $29,0 \%{ }^{11,12}$. As principais atividades econômicas são a pecuária e exploração da madeira, com produção agrícola insignificante.

\section{População de estudo, coleta de dados e aspectos éticos}

Realizou-se estudo transversal de toda a população com idade inferior a cinco anos residente na área urbana de Acrelândia e Assis Brasil. A coleta dos dados (entrevistas, exames antropométricos e coleta de amostras para exames laboratoriais) foi realizada entre $14 \mathrm{e}$ 31 de janeiro de 2003, na estação chuvosa da Amazônia Ocidental. Foram visitados todos os 491 domicílios (334 em Acrelândia e 157 em 
Assis Brasil) em que moravam 724 crianças menores de cinco anos de idade, segundo os registros do Programa de Saúde da Família atualizados em dezembro de 2002. O trabalho de campo foi realizado com a participação de agentes comunitários de saúde, estudantes do curso de enfermagem da Universidade Federal do Acre e profissionais de saúde de nivel superior, com treinamento e supervisão local da equipe de pesquisadores do projeto. Durante as visitas domiciliares, os entrevistadores identificaram-se, explicaram os objetivos e beneficios da pesquisa e solicitaram a assinatura de termo de consentimento livre e esclarecido aos pais ou responsáveis pela criança, assegurando-lhes o sigilo das informações obtidas e a apresentação dos resultados individuais de exames laboratoriais. O estudo foi analisado e aprovado pela Comissão de Ética em Pesquisa com Seres Humanos da Faculdade de Saúde Pública da USP (protocolo de pesquisa $n^{\circ} 810$ ).

Caracterização das condições sócio-econômicas e morbidade pregressa

- Durante o trabalho de campo, dois supervisores distribuíram aos entrevistadores os questionários estruturados, a serem aplicados aos pais ou responsáveis pelas crianças em entrevistas domiciliares, para a obtenção de dados sobre variáveis sócio-econômicas e ambientais. As variáveis analisadas foram: (a) demográficas (sexo e idade da criança); (b) sócio-econômicas (presença no domicílio de eletrodomésticos e bens de consumo, escolaridade paterna, presença do pai na casa, trabalho materno, número de moradores no domicilio) e ambientais (presença de rede pública de esgoto e água, destino do lixo); (c) reprodutivas (idade materna, idade gestacional e peso ao nascer); (d) nutricionais (informações sobre aleitamento materno total e exclusivo e alimentos de desmame); (e) morbidade pregressa 
(presença de diarréia, tosse ou febre nos 15 dias anteriores à visita domiciliar, episódios de malária nos últimos 12 meses, internações da criança e chiado no peito nos últimos 12 meses).

\section{Avaliação antropométrica}

- As medições de peso e estatura foram realizadas por um único observador (TGC), utilizando-se valor médio de duas medições na análise dos dados. Para avaliação do peso de crianças com dois anos ou mais foi utilizada balança portátil digital eletrônica (Plenna, EUA), com capacidade de $150 \mathrm{~kg}$ e precisão de 100g. Para crianças menores de 2 anos, utilizou-se balança pediátrica digital, com capacidade de $16 \mathrm{~kg}$ e precisão de $10 \mathrm{~g}$ (Soehnle, Alemanha). Para as crianças com dois anos ou mais a estatura foi medida em estadiômetro com precisão de 0,1 cm, fixado em parede de superficie plana, sem rodapé e em ângulo de $90^{\circ} \mathrm{C}$ com o chão.

As crianças foram colocadas descalças na posição vertical no meio do estadiômetro, com a cabeça, ombros, nádegas e calcanhares encostados à parede. Para a medição de comprimento em crianças menores de 2 anos utilizou-se antropômetro infantil, com precisão de 0,1 cm. Para esta medição foram necessários 2 observadores (PTM e TGC), colocando-se a criança em posição supina no antropômetro apoiado em uma mesa. A cabeça da criança foi colocada em posição vertical e em contato com a base superior do equipamento, com as pernas estendidas. Os índices peso/idade $(\mathrm{P} / \mathrm{I})$, peso/estatura $(\mathrm{P} / \mathrm{E}) \mathrm{e}$ estatura/idade (E/I) foram calculados como escores $z$, com auxílio do software Epi-Info versão 6.01, com base na população de referência do National Center for Health Statistics (NCHS) de $1977^{13}$. Consideraram-se desnutridas as crianças com indices de peso/idade, estatura/idade e peso/estatura iguais ou inferiores ao valor de -2 escore z. Consideraram-se obesas as crianças com indice P/E igual 
ou superior a +2 escore $z$. Os pais de crianças com desvios nutricionais foram orientados a encaminhá-las à unidade local do Programa de Saúde da Família.

\section{Diagnóstico de parasitoses intestinais}

- Uma amostra fecal foi solicitada a todos os participantes da pesquisa, no momento da entrevista domiciliar, para posterior análise. Com esta finalidade, foram fornecidos recipientes coletores tipo Coprotest $\AA$, contendo solução preservativa (formalina a 10\%). As amostras fecais foram examinadas como descrito por Hoffman et al. ${ }^{14}$, em laboratório instalado nos próprios municipios de estudo. O método de diagnóstico parasitológico empregado é adequado para a detecção de ovos e cistos da maioria dos parasitas intestinais humanos, com exceção de cistos de Cryptosporidium parvum, Cryptosporidium hominis e Cyclospora cayetanensis, ovos de Enterobius vermicularis e larvas de Strongyloides stercoralis. O tempo decorrido entre a coleta e o processamento de cada amostra não ultrapassou duas semanas. Os indivíduos com infecção parasitária intestinal receberam tratamento medicamentoso gratuito ${ }^{15}$, prescrito pela equipe médica do projeto.

\section{Diagnóstico de anemia e deficiência de ferro}

- Amostras de sangue venoso, colhidas após jejum de 10-12 horas, foram utilizadas para a determinação de hemoglobina sangüínea em hemoglobinômetro portátil Hemocue (Ängelhom, Suécia). Definiu-se anemia nos casos em que os valores obtidos foram inferiores ao valor de corte de $11,0 \mathrm{~g} / 100 \mathrm{ml}$ de sangue, estabelecido pela Organização Mundial da Saúde (OMS) ${ }^{16}$. A avaliação de reservas orgânicas de ferro foi realizada em duas etapas. Inicialmente, determinaram-se os níveis plasmáticos de ferritina, 
sendo considerados diagnósticos de deficiência de ferro valores inferiores a $12 \mu \mathrm{g} /$ litro $^{16}$. Entre as crianças com niveis plasmáticos de ferritina acima do valor de corte estipulado, empregou-se um segundo teste: a determinação dos níveis plasmáticos de receptor solúvel de transferrina. Esta estratégia objetivou diagnosticar deficiência de ferro entre as crianças com processos inflamatórios ou infecciosos, que tendem a elevar os niveis de ferritina sem alterar os níveis de receptor solúvel de transferrina ${ }^{16}$. Ambas as dosagens foram realizadas através de imunoensaio enzimático (ELISA), com reagentes disponiveis comercialmente (Ramco Laboratories, Stafford, EUA). Como não há consenso quanto ao valor de corte para diagnóstico de deficiência de ferro com base nos niveis plasmáticos de receptor solúvel de transferrina ${ }^{16}$, empregou-se aquele sugerido pelo fabricante do kit utilizado $(8,3 \mathrm{mg} /$ litro). As crianças com anemia diagnosticada durante o estudo receberam tratamento gratuito com sulfato ferroso $(2 \mathrm{mg}$ de ferro por $\mathrm{kg}$ de peso para crianças com idade inferior a dois anos e $4 \mathrm{mg}$ de ferro por $\mathrm{kg}$ de peso para as demais faixas etárias), prescrito pela equipe médica do projeto de pesquisa.

\section{$\underline{\text { Processamento e análise dos dados }}$}

- As informações coletadas foram digitadas e analisadas no pacote estatístico SPSS PC+ (12.0). Foram calculadas as distribuições das freqüências relativas e absolutas, mediana, média e desviospadrão das variáveis. Empregaram-se na análise estatística os testes t de Student, para amostras independentes, e do qui-quadrado, para a comparação de médias e proporções, respectivamente. Foram considerados estatisticamente significantes valores de $\mathrm{P}$ inferiores a 0,05 .

Para avaliação do nível sócio-econômico das famílias, calculou-se um indice de riqueza com base na presença de bens de consumo e 
utilidades domésticas no domicílio ${ }^{17}$. A variável renda familiar não foi utilizada na presente análise por se tratar de dado de dificil obtenção, que espelha de modo impreciso a situação sócio-econômica das famílias. ${ }^{17} \mathrm{O}$ indice de riqueza foi obtido a partir da análise de componentes principais com auxílio do programa de computador XLSTAT versão 7.5.2 (Addinsoft, Nova Iorque, EUA). Do primeiro componente principal, que explicou $32,7 \%$ da variabilidade entre as famílias, derivaram-se pesos (entre parênteses) para cada item de consumo presente no domicílio: televisão $(0,264)$, aparelho de som $(0,280)$, vídeo $(0,135)$, fogão $(0,200)$, geladeira $(0,311)$, rádio $(0,203)$, telefone $(0,278)$, liquidificador $(0,345)$, bicicleta $(0,217)$, ferro elétrico $(0,307)$, carro $(0,161)$, sofá $(0,312)$, máquina de lavar roupa $(0,327)$ e antena parabólica $(0,295)$. Após a padronização dos pesos atribuídos aos itens de consumo avaliados, os maiores escores (positivos) foram associados à presença no domicílio de carro $(2,835)$, aparelho de videocassete $(2,865)$, telefone $(1,350)$, rádio $(1,242)$, antena parabólica $(1,161)$ e sofá $(1,039)$ e os menores escores (negativos) para a ausência de fogão $(-4,141)$, geladeira $(-1,876)$, televisão $(-1,833)$, bicicleta $(-1,446)$, liquidificador $(-1,303)$, máquina de lavar roupa ($1,292)$, aparelho de som $(-1,060)$ e ferro elétrico $(-1,275)$ no domicílio. Todos os escores foram somados, obtendo-se uma estimativa do índice de riqueza por domicílio, que foi então categorizado em quartis. As prevalências de distúrbios nutricionais foram analisadas segundo quartis do índice de riqueza.

\section{Resultados}

\section{Características demográficas, sócio-econômicas e ambientais}

Das 724 crianças identificadas no inquérito domiciliar, 720 $(99,4 \%)$ foram entrevistadas; somente quatro crianças deixaram de ser entrevistadas por falta de consentimento de seus pais ou 
responsáveis. No total, a população amostral compreendeu 677 indivíduos que completaram exame físico e clínico $(93,5 \%$ dos elegiveis). Em Assis Brasil, a idade média da população de estudo foi de 29,5 (desvio-padrão 16,9) meses, sendo 48,0\% das crianças do sexo masculino. Em Acrelândia, a idade média das crianças foi de 31,4 (desvio-padrão 16,9) meses, sendo 49,5\% das crianças do sexo masculino. A maioria das famílias de ambas as cidades não possui terra própria, observando-se em Assis Brasil uma proporção significantemente maior de proprietários de terra $(27,5 \%)$ do que em Acrelândia $(18,4 \%)(P=0,027)$.

A Tabela 1 descreve as características demográficas da população amostral e variáveis sócio-econômicas e ambientais dos domicílios segundo o município estudado. Apesar da menor escolaridade paterna observada em Acrelândia, em ambos os municipios a média de escolaridade foi baixa $(7,1$ anos em Assis Brasil e 6,2 anos de estudo em Acrelândia; teste $t$ de Student, $P<$ $0,05)$. Nos dois municípios, a maioria dos domicilios contava com a presença de vaso sanitário. No entanto, poucos domicílios eram ligados à rede pública de coleta de esgoto (3\% em Assis Brasil e 1,5\% em Acrelândia), sendo os dejetos geralmente lançados em fossas sépticas ou negras. Acrelândia apresentou menores proporções de domicílios com abastecimento público de água e esgoto. Na maioria dos domicílios, em ambos os municípios, dava-se destino adequado ao lixo (coleta, lixeira pública ou lixo enterrado ou queimado). 
Tabela 1. Distribuição de frequência de características demográficas, sócio-econômicas e ambientais segundo municipios estudados, Acre, 2003.

\section{Características sócio- econômicas}

\section{Assis Brasil}

(n = 200)

Sexo:

Masculino

Feminino

Faixa etáriaa:

0-5 m

6-11m

$12-23 m$

24-59m

Número de moradores por domicílio:

$$
\begin{aligned}
& \leq 3 \\
& 4-6 \\
& 7-10
\end{aligned}
$$

Escolaridade paterna:

Sem escolaridade

1-4 anos

5-8 anos

$>8$ anos

Água no domicílio:

Rede pública

Poço artesiano

Lixo:

Coleta publica

Esgoto:

Presença fossa séptica no domicílio

\section{Acrelândia}

( $n=477)$

N $\%$
$\mathbf{N}$

$\begin{array}{cccc}96 & 48,0 & 236 & 49,8 \\ 104 & 52,0 & 238 & 50,2\end{array}$

$\%$

$\begin{array}{cccc}20 & 10,0 & 53 & 11,2 \\ 42 & 21,0 & 85 & 17,9 \\ 43 & 21,5 & 101 & 21,3 \\ 95 & 47,5 & 235 & 49,6\end{array}$

a Em Acrelândia $n=474$ pois para 3 crianças não se obteve idade ou data de nascimento.

${ }^{*}$ Comparação entre os municipios pelo teste do qui-quadrado, $P<0,05$. 


\section{Caracteristicas reprodutivas, peso ao nascer e aleitamento materno}

Nos dois municipios estudados, a maioria das mães trabalhava em casa. Maior proporção de mães com trabalho fora de casa foi verificada em Assis Brasil (23,0\% vs 11,7\% Acrelândia; $P=0,023)$. Observou-se baixa freqüência de prematuridade referida entre as crianças estudadas: 2,5\% em Assis Brasil e 2,7\% em Acrelândia. A prevalência de baixo peso ao nascer (abaixo de 2500 g), segundo informação constante do cartão da criança, foi maior em Acrelândia $(9,6 \%)$ do que em Assis Brasil (4,5\%) $(P=0,025)$. As médias de idade materna (desvio-padrão) foram semelhantes nos dois municípios: 26,3 anos (desvio-padrão, 7,5) em Assis Brasil e 27,1 anos (desviopadrão, 8,9) em Acrelândia.

O percentual de crianças que iniciaram o aleitamento materno foi $94,1 \%(n=634)$ em toda a população estudada, sem diferença estatisticamente significante entre os municipios (92,0\% em Assis Brasil e 94,7\% em Acrelândia). No geral, o percentual de crianças em aleitamento materno exclusivo até os 6 meses (excluindo-se aquelas que nunca mamaram) foi de 30,0\%. O percentual de crianças amamentadas por 2 anos ou mais foi de $9 \%(n=43)$, observando-se mediana de aleitamento materno total de 180 dias.

\section{Estado nutricional}

As prevalências gerais de déficits nutricionais segundo os indices $\mathrm{P} / \mathrm{E}, \mathrm{P} / \mathrm{I}$ e $\mathrm{E} / \mathrm{I}$ foram de 3,7\%, 8,7\% e 7,5\%, respectivamente. A prevalência de déficits para $\mathrm{P} / \mathrm{E}$ e E/I aumentou significantemente com a idade, a partir de 12 meses (teste do qui-quadrado de tendência, $P<0,001)$. Não se observaram diferenças estatisticamente significantes entre as prevalências de desnutrição $\left(\chi^{2}=0,45, P=0,50\right.$; $\chi^{2}=0,07, P=0,79 ; \chi^{2}=0,28, P=0,59$, respectivamente para $\mathrm{P} / \mathrm{I}, \mathrm{P} / \mathrm{E}$ 
e E/I), e obesidade $\left(\chi^{2}=0,16, P=0,70\right)$ entre os municipios. A prevalência geral de obesidade, segundo o índice $\mathrm{P} / \mathrm{E}$, foi de 2,8\%, sem diferença estatisticamente significante segundo sexo. No entanto, a prevalência de obesidade tendeu a diminuir com a idade $\chi^{2}=6,05$, $P=0,014)$, observando-se maior prevalência de obesidade na faixa etária de 12 a 24 meses (7\%).

Mediram-se concentrações de hemoglobina sangüínea em 669 crianças $(92,4 \%$ das crianças elegiveis e 98,8\% das crianças entrevistadas e examinadas) e concentrações plasmáticas de ferritina em 628 crianças $(86,7 \%$ das crianças elegiveis e 92,8\% das crianças entrevistadas e examinadas). Os niveis plasmáticos de receptor de transferrina foram determinados nas 326 crianças que apresentaram valores plasmáticos normais ou elevados de ferritina. Com base nos níveis sangüineos de hemoglobina, 205 crianças $(30,6 \%)$ foram classificadas como anêmicas. Com base na análise combinada dos niveis plasmáticos de ferritina e de receptor de transferrina, 273 $(43,5 \%)$ crianças foram classificadas como deficientes em ferro. Combinando-se os resultados de dosagens de hemoglobina, ferritina e receptor solúvel de transferrina, 130 crianças $(20,9 \%)$ receberam o diagnóstico de anemia ferropriva. Não houve diferença estatisticamente significante nas prevalências de anemia, deficiência de ferro e anemia por deficiência de ferro segundo sexo ou município. No total, 68,1\% das crianças anêmicas tinham deficiência de ferro, atribuindo-se os demais casos de anemia a outras carências nutricionais ou a fatores etiológicos de natureza diversa. Somente $47,6 \%$ das crianças com deficiência de ferro apresentavam anemia, evidenciando a baixa sensibilidade da dosagem de hemoglobina para diagnóstico de deficiência de ferro em nível populacional. Observaram-se diferenças estatisticamente significantes nas prevalências de anemia, deficiência de ferro e anemia por deficiência de ferro de acordo com a idade; as maiores prevalências de anemia 
$(50,2 \%)$, de deficiência de ferro $(62,0 \%)$ e de anemia ferropriva $(38,9 \%)$ foram encontradas em crianças menores de 24 meses, quando comparadas com as demais faixas etárias (teste do quiquadrado, $P<0,0001)$.

A Tabela 2 apresenta a freqüência de déficits nutricionais em cada município. Não houve diferenças estatisticamente significante entre as prevalências de desnutrição e obesidade entre os municípios. No entanto, as prevalências de anemia e anemia ferropriva foram significantemente maiores em Assis Brasil.

Tabela 2. Distribuição de freqüência de déficits nutricionais pelos indices $\mathrm{P} / \mathrm{I}, \mathrm{E} / \mathrm{I}, \mathrm{P} / \mathrm{E}$, obesidade pelo índice $\mathrm{P} / \mathrm{E}$, deficiência de ferro e anemia ferropriva segundo municipios estudados. Acre, 2003.

\begin{tabular}{|c|c|c|c|c|}
\hline \multirow[t]{2}{*}{ Distúrbio nutricional } & \multicolumn{2}{|c|}{$\begin{array}{c}\text { Assis Brasil } \\
(\mathrm{n}=\mathbf{2 0 0})\end{array}$} & \multicolumn{2}{|c|}{$\begin{array}{l}\text { Acrelândia } \\
(n=477)\end{array}$} \\
\hline & $\mathbf{N}$ & $\%$ & $\mathbf{N}$ & $\%$ \\
\hline \multicolumn{5}{|l|}{ Desnutrição ${ }^{\mathrm{a}}$ : } \\
\hline $\mathrm{P} / \mathrm{I}$ & 15 & 7,5 & 44 & 9,3 \\
\hline $\mathrm{E} / \mathrm{I}$ & 13 & 6,5 & 37 & 7,8 \\
\hline $\mathrm{P} / \mathrm{E}$ & 8 & 4,0 & 17 & 3,6 \\
\hline Obesidade $^{b}$ & 4 & 2,0 & 15 & 3,2 \\
\hline Anemiac & 70 & 36,3 & 135 & $24,5^{*}$ \\
\hline Deficiência de ferrod & 85 & 45,2 & 188 & 42,7 \\
\hline $\begin{array}{l}\text { Anemia com deficiência } \\
\text { de ferro }\end{array}$ & 48 & 26,4 & 82 & $18,7^{*}$ \\
\hline \multicolumn{5}{|c|}{$\begin{array}{l}\text { ois desvios-padrão ou mais abaixo da mediana do padrão NCHS (1977); n= } 474 \text { em Acrelândia } \\
\text { ois desvios-padrão ou mais acima da mediana do padrão NCHS (1977); } \mathrm{n}=474 \text { em Acrelândia } \\
\text { Hemoglobina sangüinea inferior a } 11 \mathrm{~g} / \mathrm{dL} \text {. }\end{array}$} \\
\hline
\end{tabular}




\section{Morbidade referida e infeccões por parasitas intestinais}

Das 554 crianças que tiveram amostra fecal colhida e examinada $(76,5 \%$ das crianças elegiveis e $81,8 \%$ das crianças entrevistadas e examinadas), $180(32,5 \%)$ albergavam um ou mais protozoários ou helmintos intestinais detectáveis pelo método de exame parasitológico de fezes empregado neste estudo. Não foi observada diferença estatisticamente significante na prevalência de parasitas intestinais entre indivíduos do sexo masculino $(26,6 \%)$ e feminino $(27,5 \%)$ e entre as crianças dos municípios de Assis Brasil $(31,7 \%)$ e de Acrelândia $(32,4 \%)$.

As infecções mais comuns foram as causadas pelo protozoário parasita Giardia duodenalis (18,0\% em Assis Brasil [n = 29] e 27,7\% em Acrelândia [ $\mathrm{n}=109]$ ), pelo protozoário comensal Entamoeba coli (6,2\% em Assis Brasil [ $\mathrm{n}=10]$ e 5,1\% em Acrelândia [ $\mathrm{n}=20]$ ) e pelo helminto Ascaris lumbricoides (9,9\% em Assis Brasil [ $\mathrm{n}=16$ ], mas somente $0,2 \%$ em Acrelândia $[n=1])$. Observou-se poliparasitismo (infecção simultânea por duas ou mais espécies de parasitas ou comensais intestinais) em 6,8\% das crianças examinadas em Assis Brasil e em 4,1\% das examinadas em Acrelândia. Combinando-se os dados de ambos os municípios, observou-se que a prevalência de parasitoses intestinais aumentou, de modo significante, com a idade (teste do qui-quadrado de tendência, $P<0,00001$ ).

A Tabela 3 descreve a distribuição da prevalência de parasitoses intestinais e de eventos mórbidos referidos segundo os municípios estudados. Observou-se uma maior proporção de crianças com história de internação prévia em Acrelândia do que em Assis Brasil, mas não se encontraram diferenças estatisticamente significante ao se comparar, entre os municípios, a prevalência de outros eventos mórbidos referidos. Somente seis crianças $(1,2 \%)$ de 
Acrelândia e nenhuma de Assis Brasil tiveram algum episódio de malária diagnosticado nos 12 meses anteriores à pesquisa.

Tabela 3. Distribuição de freqüência de infecção por parasitas intestinais e morbidades referidas segundo municípios estudados. Acre, 2003.

\begin{tabular}{lcccc}
\hline Morbidades: & \multicolumn{3}{c}{ Assis Brasil (n = 200) } & \multicolumn{2}{c}{ Acrelândia (n= 477) } \\
& N & \% & N & \% \\
\hline Parasitose intestinal & 51 & 31,7 & 127 & 32,4 \\
$\begin{array}{l}\text { Ocorrência de diarréia } \\
\text { nos últimos 15 dias: }\end{array}$ & 69 & 34,5 & 129 & 27,2 \\
Internação alguma vez & 38 & 19,0 & 131 & $27,5^{*}$ \\
$\begin{array}{l}\text { Tosse ou febre nos } \\
\text { últimos 15 dias }\end{array}$ & 77 & 38,5 & 157 & 33,3 \\
$\begin{array}{l}\text { Chiado no peito nos } \\
\text { últimos 12 meses }\end{array}$ & 43 & 21,5 & 93 & 19,7 \\
\hline
\end{tabular}

*Teste do qui-quadrado, $\mathrm{p}<0,05$.

\section{Prevalência de desnutrição e anemia segundo indice de riqueza}

A Figura 1 mostra a associação entre o índice de riqueza e as prevalências gerais de desnutrição pelo índice $\mathrm{E} / \mathrm{I}$ e anemia na população infantil combinada de Assis Brasil e Acrelândia ( $\mathrm{n}=674$ ). Houve tendência estatisticamente significante de redução da prevalência de desnutrição e anemia com o aumento do índice de riqueza (teste do qui-quadrado de tendência, $P=0,006$ e $P=0,0005$, respectivamente). Esta associação não foi observada entre índice de riqueza e a prevalência de parasitoses intestinais. 


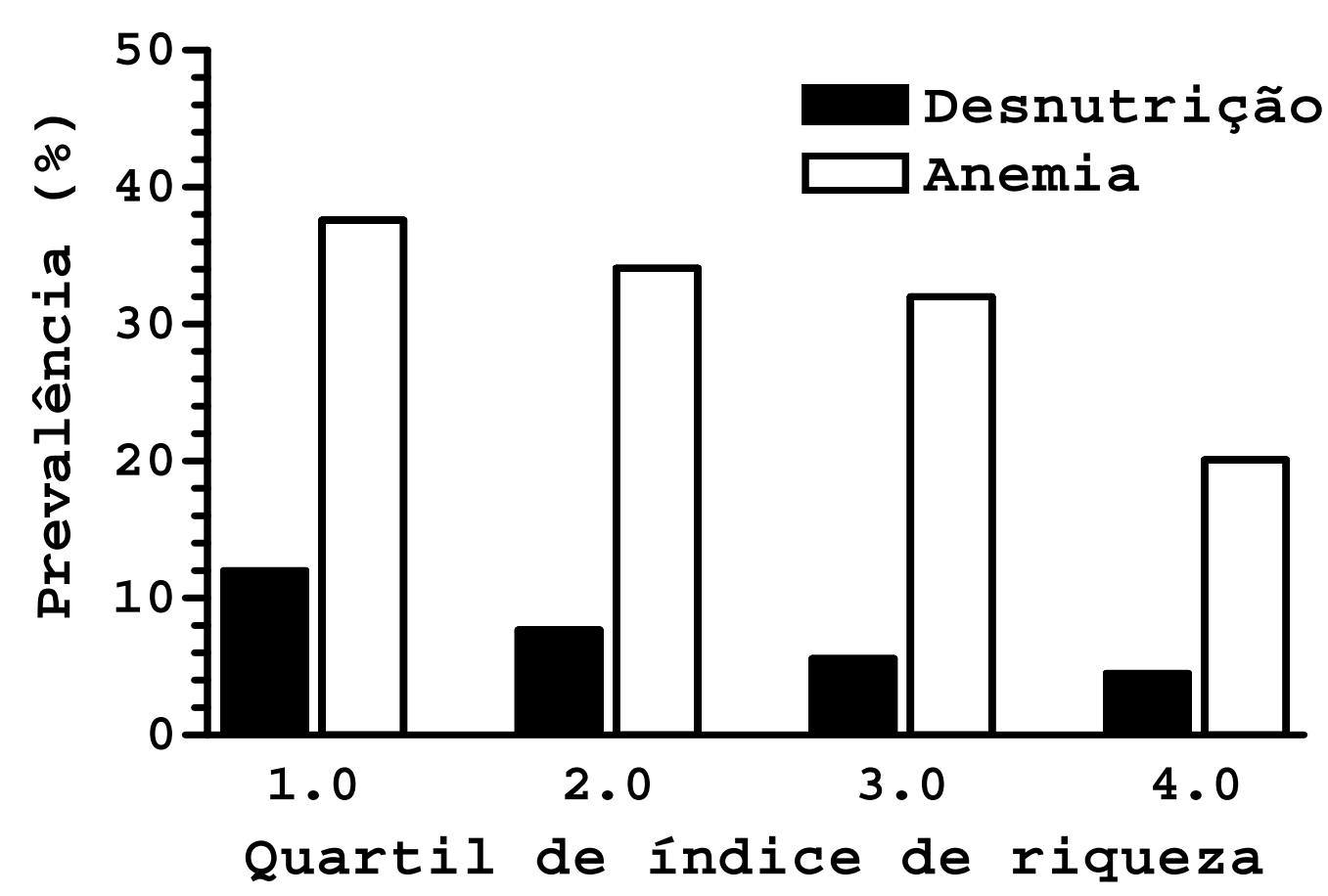

Figura 1. Prevalência de desnutrição pelo índice $E / I$ e anemia na população infantil de Assis Brasil e Acrelândia segundo quartis do indice de riqueza. Acre, $2003(\mathrm{n}=674)$. Tendência estatisticamente significante de redução da prevalência de desnutrição e anemia com o aumento do índice de riqueza: qui-quadrado de tendência, $p=0,006$ e $\mathrm{p}=0,0005$, respectivamente.

\section{Discussão}

Embora Acrelândia e Assis Brasil sejam exemplos de municípios amazônicos com atividades econômicas distintas, ambos apresentam indicadores de saúde infantis muito semelhantes. Entre as diversas estimativas obtidas neste estudo, encontraram-se diferenças significantes entre os municípios somente nas prevalências de anemia e de anemia ferropriva, mais freqüentes em Assis Brasil do que em Acrelândia (Tabela 2.1). Em ambos os municípios, a prevalência de déficit de crescimento (segundo o índice E/I) foi cerca de $50 \%$ inferior à observada entre 212 crianças da 
Região Norte examinadas durante a PNDS, em $1996(16,2 \%)^{7}$. A prevalência de baixo peso para a idade em ambos os municipios $(8,7 \%)$ foi semelhante à observada durante a PNDS $(7,7 \%)$, enquanto a prevalência de baixo peso para a estatura em Assis Brasil e Acrelândia $(3,7 \%)$ foi três vezes superior à estimada pela PNDS para a Região Norte $(1,2 \%) .{ }^{7}$ Surpreendentemente, a prevalência de baixo peso para a estatura entre as crianças da Região Norte examinadas pela PNDS foi a segunda mais baixa do país, pouco mais da metade da média nacional de 2,3\%.7 Como não há séries temporais disponíveis para análise, não se sabe se as discrepâncias entre as estimativas de nosso estudo e da PNDS se devem a heterogeneidades espaciais na Região Norte ou simplesmente refletem uma tendência de melhora preferencial de alguns indicadores de saúde e nutrição infantil ao longo da última década.

A escassez de estimativas de prevalência de anemia ferropriva em populações infantis brasileiras dificulta o estabelecimento de comparações. A maior parte dos estudos disponiveis refere-se a amostras de conveniência (usuários de serviços de saúde, por exemplo), submetidas exclusivamente a dosagens de hemoglobina sangüínea8, não fornecendo dados sobre as reservas orgânicas de ferro $^{18}$. Apresentam-se aqui as primeiras estimativas, derivadas de inquéritos de base populacional, da prevalência de anemia ferropriva entre crianças da Amazônia Brasileira. Destacam-se dois resultados particularmente relevantes para a prevenção e o controle da anemia nessa população: (a) somente $47,6 \%$ das crianças com deficiência de ferro tinham anemia, indicando que a medida isolada de hemoglobina sangüinea subestima a magnitude da deficiência de ferro nesta população em mais de $50 \%$ e (b) $31,9 \%$ das crianças anêmicas não tinham evidências bioquímicas de deficiência de ferro, sugerindo o papel de outros determinantes de anemia (nutricionais, bioquímicos ou infecciosos) nessa população. 
A proporção de crianças anêmicas em nossa amostra $(30,6 \%)$ foi semelhante à encontrada em pré-escolares do estado da Paraíba $(36,4 \%),{ }^{19}$ ainda que inferior à observada, na mesma faixa etária, em inquéritos recentes de base populacional no estado de Pernambuco $(40,9 \%)^{20}$ e nos municípios de São Paulo $(46,9 \%),{ }^{21}$, Criciúma $(54,0 \%)^{22}$ e Porto Alegre $(47,8 \%)^{23}$. Os dados disponiveis sugerem que as maiores prevalências de anemia na infância são encontradas nas áreas urbanas das regiões mais desenvolvidas do país. No entanto, alguns fatores restringem a validade dessas comparações: (a) várias estimativas derivam de estudos com amostras sangüíneas colhidas por punção digital, procedimento que pode levar à diluição da amostra e introduzir erro sistemático nas dosagens de hemoglobina ${ }^{24}$, e (b) o papel relativo de outras causas (nutricionais ou não) de anemia, além da deficiência de ferro, pode diferir segundo as regiões. De fato, a utilização isolada de hemoglobina sangüinea como teste de rastreamento de deficiência de ferro não é recomendada pela Organização Mundial da Saúde ${ }^{16}$. Sua baixa sensibilidade deve-se ao fato de serem necessárias grandes depleções das reservas de ferro corporal para afetar a concentração de hemoglobina. Sua baixa especificidade decorre da existência de outras causas de anemia com alta prevalência em certas populações, tais como outras deficiências nutricionais, infecções, deficiência de glicose-6-fosfato desidrogenase e diversas hemoglobinopatias ${ }^{18}$.

Entre os determinantes da deficiência de ferro em crianças, encontram-se a presença de anemia materna, o baixo peso ao nascer, a prematuridade ${ }^{25}$, as infestações parasitárias ${ }^{26}$, as infecções crônicas ou recorrentes, a curta duração do aleitamento materno e a introdução de dietas de desmame inadequadas ${ }^{27}$ e a baixa qualidade e a biodisponibilidade do ferro presente na dieta 28 . A deficiência de outros micronutrientes não avaliados neste estudo, como a vitamina B12, o ácido fólico e a vitamina A, representa outro importante 
determinante de anemia nutricional. Em estudo recente realizado em Pernambuco, com crianças de 6-60 meses de idade, a concentração sérica de vitamina A foi um dos fatores associados aos niveis de hemoglobina sangüínea ${ }^{20}$.

A baixa prevalência de helmintiases pode ser parcialmente explicada pelo uso profilático de medicamentos anti-helmínticos, amplamente distribuídos pelos agentes comunitários do Programa de Saúde da Família (PSF), em ambos os municípios. É pouco provável que o fato de ter sido examinada uma única amostra de fezes tenha produzido uma grande subestimação da prevalência das helmintíases de maior impacto clínico na região ${ }^{29}$. A ausência de associação significante entre a presença de helmintos e a ocorrência de anemia ou déficits de crescimento, em nossa população (dados nãoapresentados), não é surpreendente, diante da baixa prevalência de infecção por helmintos capazes de causar espoliação significativa de nutrientes, como Ascaris, Trichuris e ancilostomídeos. ${ }^{26}$ No entanto, as infecções por protozoários intestinais foram muito mais prevalentes em Acrelândia e Assis Brasil do que entre crianças menores de cinco anos do município de São Paulo estudadas entre 1995 e 1996,30 podendo contribuir para a elevada prevalência de doença diarréica recente referida por nossa população amostral (Tabela 3).

Observou-se em Acrelândia e Assis Brasil uma associação significante e negativa entre anemia e desnutrição (mas não parasitoses intestinais) e riqueza. Estudos prévios também observaram associação entre condições sócio-econômicas e estado nutricional de crianças de diversas regiões do Brasil, tanto em inquéritos transversais como em análises de séries temporais. Monteiro e colaboradores, por exemplo, verificaram menor redução da prevalência de desnutrição infantil no Brasil, no período de 1975 a 
1989, no estrato de menor renda per capita (25\% mais pobres) quando comparado ao maior estrato (25\% mais ricos) ${ }^{31}$. No município de São Paulo, observou-se aumento da prevalência de anemia em todos os estratos econômicos, entre crianças menores de cinco anos, no período entre 1984 a 1996; no entanto, essa evolução foi mais desfavorável entre as crianças provenientes de famílias mais pobres $^{21}$. Resultados semelhantes provêm de estudos realizados em Porto Alegre e Criciúma, entre crianças menores de três anos, com maior prevalência de anemia em crianças mais pobres ${ }^{22,23}$.

O acesso à água limpa e ao esgoto tratado é um dos principais determinantes do estado de saúde e nutrição infantil ${ }^{32}$. A evolução da desnutrição infantil no Brasil, entre 1975 e 1989, indica que as melhorias observadas estão associadas com o aumento da cobertura de serviços de saneamento, de saúde e de educação, bem como da oferta de programas de suplementação alimentar. No entanto, as regiões com maior prevalência de desnutrição infantil em 1975 (Norte e Nordeste) foram as que menos se beneficiaram desses serviços e programas, aumentando o hiato existente entre estas regiões e o restante do país ${ }^{31}$. Nos dois municípios acreanos estudados, a baixa cobertura de saneamento básico representa um sério obstáculo para a melhoria ulterior dos indicadores da saúde infantil.

A prevalência de baixo peso ao nascer no município de Acrelândia (9,6\%), em decorrência de prematuridade ou desnutrição intrauterina, encontra-se na faixa de variação encontrada em países da América Latina $(6,3-12,5 \%)^{33}$. É próxima às prevalências observadas no município de São Paulo em 1998 (8,9\%) ${ }^{34}$ e em Pelotas em $2005(10,4 \%)^{35}$. Em Assis Brasil, a prevalência de baixo peso ao nascer foi baixa $(4,5 \%)$, aproximando-se ao observado para países desenvolvidos ${ }^{33}$. 
A maioria das mães de Acrelândia e Assis Brasil iniciou o aleitamento materno, mas a mediana de duração de aleitamento materno total foi baixa (6 meses), sendo inferior ao relatado para a população brasileira geral $(7 \text { meses })^{36}$. No entanto, a prevalência de aleitamento materno exclusivo até os 6 meses (30\%) foi superior ao constatado por Longo e colaboradores ${ }^{37}$ entre crianças usuárias de serviços de saúde de doze capitais brasileiras (prevalência de aleitamento materno exclusivo até os quatro meses de $8 \%$ ). A duração do aleitamento materno e dieta complementar adequados constituem determinantes proximais importantes do adequado estado nutricional infantil, reduzindo o risco de desnutrição ${ }^{38}$ e de anemia ferropriva ${ }^{39}$.

Entre as metas estabelecidas para o Milênio para os países em desenvolvimento ${ }^{40}$, definidos em Sessão Especial da Assembléia Geral da Organização das Nações Unidas, está a redução em pelo menos um terço na prevalência de desnutrição entre crianças menores de cinco anos, com especial atenção às crianças menores de 2 anos de idade, até o ano de 201541. A Política Nacional de Alimentação e Nutrição do Brasil definiu também, como compromisso social, a redução da prevalência de anemia ferropriva ${ }^{42}$. No entanto, um relatório recente elaborado pela $\mathrm{UNICEF}^{43}$ mostra um panorama extremamente desfavorável para as crianças amazônicas: 40\% das crianças com até seis anos de idade vivem em famílias de baixa renda e $53 \%$ delas vivem em comunidades sem saneamento básico adequado, freqüentemente em moradias improvisadas. O relatório "Saúde Brasil 2004"44 estima que a taxa de mortalidade infantil no estado do Acre, em 2001, seja de 34,3/1000 nascidos vivos, substancialmente superiores à média nacional (27,7/1000 nascidos vivos). Em 2000, somente 34\% da população acreana tinham acesso à rede geral de abastecimento de água, 52\% à coleta de lixo e 28,7\% à rede geral de instalação sanitária e fossa séptica; todos estes indicadores encontram-se abaixo das médias nacionais. O índice de 
desenvolvimento infantil (IDI) dos municipios do Acre é o segundo pior do país ${ }^{45}$.

As desigualdades econômicas e sociais entre as regiões NorteNordeste e Centro-Sul do Brasil indicam a necessidade de implementação adequada de politicas públicas nacionais para minimizar seu impacto nos padrões de crescimento e desenvolvimento infantil. Diagnósticos de saúde derivados de estudos de base populacional, como o apresentado aqui, são fundamentais para o planejamento de intervenções destinadas a alterar essa realidade.

\section{Referências}

1. Victora CG, Barros FC, Kirkwood BR, Vaughan JP. Pneumonia, diarrhoea and growth in the first four years of life. A longitudinal study of 5,914 Brazilian infants. Am J Clin Nutr 1990; 52: 391-6.

2. de Onis M, Monteiro C, Akre J, Glugston G. The worldwide magnitude of protein-energy malnutrition: an overview from the WHO Global Database on Child Growth. Bull World Health Organ 1993; 71:703-12.

3. de Onis M, Frongillo EA, Blossner M. Is malnutrition declining? An analysis of changes in levels of child malnutrition since 1980. Bull World Health Organ 2000;78: 1222-33.

4. Food and Agriculture Organization/World Health Organization. International Conference on Nutrition: World Declaration and Plan of Action. FAO of the United Nations, Roma, Italy. Geneva: WHO, 1992.

5. Monteiro CA \& Benício MHD. Melhoria em indicadores de saúde associados à pobreza no Brasil dos anos 90: descrição, causas e impacto sobre desigualdades regionais. São Paulo: NUPENS/USP, 1997). 
6. Universidade Federal do Acre, Secretaria Municipal de Saúde de Rio Branco, Fundo das Nações Unidas para a infância (UNICEF). Diagnóstico das condições de saúde materno-infantil no município de Rio Branco, Acre. Rio Branco: UNICEF, 1994.

7. Ministério da Saúde. Pesquisa Nacional sobre Demografia e Saude. 2006.

http://dtr2004.saude.gov.br/nutrição/documentos/PesquisaNacDe mogrfiaSaude.pdf (acessado em 1-05-2006).

8. Vannucchi H, Freitas MLS, Szarfarc SC. Prevalência de anemias nutricionais no Brasil. Cad Nutr 1992; 4:7-26.

9. da Silva-Nunes M, Malafronte RS, Luz BA, Souza EA, Martins LC, Rodrigues SG, Chiang JO, Vasconcelos PFC, Muniz PT, Ferreira MU. The Acre Project: The epidemiology of malaria and arthropodborne virus infections in a rural Amazonian population. Cad Saúde Públ 2006; 22 (in press).

10. Fundação Instituto Brasileiro de Geografia e Estatística (IBGE). Resultados da amostra do censo demográfico 2000. http://www.ibge.gov.br (acessado em 01-05-2006).

11. Instituto Nacional de Estudos e Pesquisas Educacionais Anísio Teixeira. Mapa do Analfabetismo no Brasil . Brasília: Ministério da Educação, 2003. 44 p.

12. Ministério da Saúde. Atlas de saúde do Brasil. Brasília: Ministério da Saúde, 2004c. CD-ROM (Série G. Estatística e Informação em Saúde).

13. Organización Mundial de la Salud. Medicion del cambio del estado nutricional. Genebra, WHO, 1983.

14. Hoffman W, Pons JA, Janer JL. The sedimentation concentration method in schistosomiasis mansoni. Puerto Rico J Public Health Trop Med 1934; 9: 283-91.

15. Chieffi PP, Gryschek RCB, Amato-Neto V. Parasitoses intestinais. Diagnóstico e tratamento. São Paulo: Lemos editorial, 2002. 
16. World Health Organization (WHO). Iron Deficiency Anaemia. Assessment, Prevention and Control. Geneva: WHO, 2001.

17. Filmer D, Pritchett LH. Estimating wealth effects without expenditure data-or tear: an application to educational enrolments in states of India. Demography 2001; 38:115-32.

18. Cook J. Diagnosis and management of iron-deficiency anaemia. Best Practice Res Clin Haematol 2005; 18: 319-332.

19. Oliveira RS, Diniz AS, Benigna MJC, Silva SMM, Lola MM, Gonçalves MC et al. magnitude, distribuição espacial e tendência da anemia em pré-escolares da Paraíba. Rev Saúde Pública 2002: 36: $1-11$.

20. Osório MM, Lira PIC, Ashworth A. Factors associated with $\mathrm{Hb}$ concentration in children aged 6-59 months in the State of Pernambuco, Brazil. Br J Nutr 2004; 91:307-14.

21. Monteiro CA, Szarfac SC, Mondini L. Tendência secular da anemia na infância na cidade de São Paulo (1984-1996). Rev Saúde Pública 2000; 34:62-72.

22. Neuman NA, Tanaka OY, Szarfac SC, Guimarães PRV, Victora CG. Prevalência e fatores de risco para anemia no sul do Brasil. Rev Saúde Pública 2000; 34: 56-63.

23. Silva LSM, Giugliani ERJ, Aerts DRGC. Prevalência e determinantes de anemia em crianças de Porto Alegre, RS, Brasil. Rev Saúde Pública 2001; 35: 66-73.

24. Sari M, Pee S, Martini E, Herman S, Sugiatmi, Bloem MW, Yip R. Estimating the prevalence of anaemia: a comparison of three methods. Bull World Health Organ 2001; 79: 506-11.

25. Rasmussen KM. Is there a causal relationship between iron deficiency or iron-deficiency anemia and weight at birth, length of gestation and perinatal mortality? J Nutr 2001; 131: 590S-603S.

26. Stephenson, LS. Impact of helminth infections on human nutrition. New York: Taylor and Francis, 1987. 
27. Davidsson L. Approaches to improve iron bioavailability form complementary foods. J Nutr 2003; 133:1560S-2.

28. Bhargava A, Bouis HE, Scrimshaw NS. Dietary intakes and socioeconomic factors are associated with the hemoglobin concentration of Bangladeshi women. J Nutr 2001; 131: 758-64.

29. Gyorkos TW, McLean JD, Law CG. Absence of significant differences in intestinal parasite estimates after examination of either one or two stool specimens. Am J Epidemiol 1989; 130: 97680.

30. Ferreira MU, Ferreira CS, Monteiro CA. Tendência secular das parasitoses intestinais na infância na cidade de São Paulo (19841996). Rev Saúde Publica 2000; 34: 73-82.

31. Monteiro CA, Benicio MHDA, Iunes RF, Gouveia NC, Cardoso MAA. Evolução da desnutrição infantil. In: Monteiro CA (Org.). Velhos e novos males da saúde no Brasil. São Paulo, 2 ed, 2000. p.93-114.

32. Iunes RF. Mudanças no cenário econômico. In: Monteiro CA (Org.). Velhos e novos males da saúde no Brasil. São Paulo, 2 ed, 2000. p.33-60.

33. Kramer MS. The epidemiology of adverse pregnancy outcomes: an overview. J Nutr 2003; 133 (Suppl 2): 1592S-6S.

34. Monteiro CA, Benicio MHDA, Ortiz LP. Tendência secular do peso ao nascer na cidade de São Paulo (1976-1998). Rev Saúde Publica 2000; 34: 26-40.

35. Barros FC, Victora CG, Barros AJ, Santos IS, Albernaz G, Matijasevich A et al. The challenge of reducing neonatal mortality in middle-income countries: findings from three Brazilian birth cohorts in 1982, 1993 and 2004. Lancet 2005; 365: 847-54.

36. Venâncio \& Monteiro CA. Breast-feeding trends between 1970 to 1980 in Brazil. Rev Bras Epidemiol 1998; 1: 40-9. 
37. Longo GZ, Souza JMP, Souza SB, Szarfac SC. Crescimento de crianças até 6 meses de idade, segundo categorias de aleitamento materno. Rev Bras Saúde Matern Infant 2005; 5: 109-18.

38. Islam MA, Rahman MM, Mahalanabis D. Maternal and socioeconomic factors and the risk of severe malnutrition in a child: a case control study. Eur J Clin Nutr 1994; 48: 416-24.

39. Lima ACVM, Lira PIC, Romani SAM, Eickmann SH, Piscoya MD, Lima MC. Fatores determinantes dos niveis de hemoglobina em crianças aos 12 meses de vida na Zona da Mata Meridional de Pernambuco. Rev Bras Saúde Matern Infant 2004; 4:35-43.

40. United Nations. UN Millennium Development Goals (MDG). 2005. http://un.org./millenniumgoals/ (acessado em 15-04-2005).

41. Nações Unidas. Um mundo para as crianças. New York. 2002. http://unicef.org.br (acessado em 15-04-2005).

42. Ministério da Saúde. Política Nacional de Alimentação e Nutrição. Brasília: Ministério da Saúde, 2000. 48 p.

43. Fundo das Nações Unidas para a Infância. Ser criança na Amazônia: uma análise das condições de desenvolvimento infantil na Região Norte do Brasil. 2004. http://unicef.org/brazil/ser_crianca amazonia.pdf (acessado em 15/04/2005).

44. Ministério da Saúde. Saúde Brasil 2004: uma análise da situação de saúde. Brasília: Ministério da Saúde, 2004.

45. Fundo das Nações Unidas para a Infância. State of the world's children 2001. http://www.unicef.org/brazil/sib2001/index.html (acessado em 15/04/2005). 


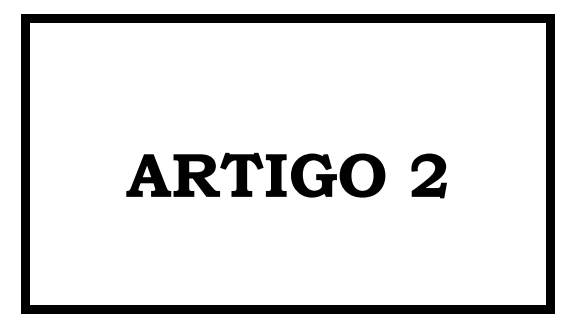


PREVALÊNCIA E FATORES ASSOCIADOS AO RISCO DE ANEMIA FERROPRIVA ENTRE PRÉ-ESCOLARES DA AMAZÔNIA BRASILEIRA

Prevalence and associated risk factors of iron deficiency anemia among preschool children from Brazilian Amazon

Teresa Gontijo de Castro $^{1}$; Pascoal Torres Muniz ${ }^{2}$; Mônica SilvaNunes $^{3}$; Wolney Lisboa Conde ${ }^{1}$; Marcelo Urbano Ferreira3; Marly Augusto Cardoso ${ }^{1}$

${ }^{1}$ Departamento de Nutrição, Faculdade de Saúde Pública, Universidade de São Paulo, Brasil.

2Departamento de Ciências da Saúde, Universidade Federal do Acre, Brasil.

32Departamento de Parasitologia, Instituto de Ciências Biomédicas, Universidade de São Paulo, Brasil.

Correspondência para/ Correspondence to:

Marly Augusto Cardoso

Departamento de Nutrição, Faculdade de Saúde Pública, Universidade de São Paulo. Av. Dr. Arnaldo, 715 - 01246-904

Fone/Fax: (011) 3066-7705 - E-mail: marlyac@usp.br 


\section{Prevalência e fatores associados ao risco de anemia ferropriva entre pré-escolares da Amazônia brasileira}

\section{Resumo}

Objetivo: Avaliar a prevalência de anemia, deficiência de ferro e anemia ferropriva e fatores associados ao risco de anemia ferropriva em menores de 5 anos da Amazônia Brasileira. Métodos: Estudo transversal de base populacional em Assis Brasil ( $n=200)$ e Acrelândia ( $n=477)$, Estado do Acre. Amostras de sangue venoso em jejum foram obtidas para dosagem de hemoglobina sanguinea, ferritina sérica e receptor solúvel de transferrina. Informações sobre condições socioeconômicas, demográficas, morbidades e aleitamento materno foram coletadas através de questionário estruturado. Os fatores associados ao risco de anemia ferropriva foram avaliados em modelo de regressão logística múltiplo, com auxílio do programa SPSS 12.0. Resultados: As prevalências gerais de anemia, deficiência de ferro e anemia ferropriva foram de $30,6 \%, 43,5 \%$ e $20,9 \%$, respectivamente. Ser menor de 24 meses [OR 13,72 (5,66-33,27)] e ocorrência de episódio recente de diarréia [OR 1,57 $(1,01-2,45)]$ foram fatores associados ao risco de anemia ferropriva e pertencer ao maior tercil do índice de riqueza [OR $0,48(0,28 ; 0,82)]$ foi fator associado à proteção. Conclusão: Destaca-se a importância dos programas de assistência ao pré-natal e de puericultura no planejamento de ações públicas para prevenção e controle da anemia ferropriva na infância em municipios acreanos.

Descritores: Anemia. Anemia ferropriva. Deficiência de ferro. Amazônia brasileira. Fatores de risco. Saúde infantil. 


\section{Abstract}

Objective: To assess the prevalence of anemia, iron deficiency and iron deficiency anemia and the associated factors with iron deficiency anemia in preschool children in Brazilian Amazonia. Methods: A population-based cross-sectional study carried out in the urban area of the towns of Assis Brasil $(n=200)$ and Acrelândia ( $n=477)$, in the State of Acre. A fasting venipuncture blood sample was collected from each child to determine haemoglobin, serum ferritin and soluble transferrin receptor concentrations. Questions about socioeconomic and demographic conditions, morbidities and breastfeeding were obtained through a structured questionnaire. The associated factors with iron deficiency anemia were evaluated using multiple logistic regression model, performed in the SPSS software version 12.0. Results: Anemia, iron deficiency and iron deficiency anemia were diagnosed in $30.6 \%, 43.5 \%$ and $20.9 \%$ of the children, respectively. Age under 24 months (Odds Ratio - OR = 13.7; 95\% Confidence Interval $-\mathrm{CI}=5.66-33.27$ ) and history of a recent diarrhea episode $(\mathrm{OR}=1.57 ; 95 \% \mathrm{CI}=1.01-2.45)$ were associated with a risk for iron deficiency anemia; however; the highest tertile of wealth index was a protector factor for iron deficiency anemia. Conclusion: We emphasize the importance of the pre-natal and puericulture programs in the planning of public actions of prevention and control of the iron deficiency anemia among children under-five in towns of Acre.

Descriptors: Anemia. Iron deficiency anemia. Iron deficiency. Brazilian Amazon. Risk factors. Childhood health. 


\section{Introdução}

A anemia foi definida pela Organização Mundial da Saúde (OMS) como o estado onde a concentração de hemoglobina está anormalmente baixa em conseqüência da carência de um ou mais nutrientes essenciais, qualquer que seja a origem desta carência ${ }^{1}$. A deficiência de ferro é apontada como a determinante causal principal da maioria dos casos, tornando-se a carência nutricional mais prevalente no mundo atual, atingindo tanto países desenvolvidos como os em desenvolvimento ${ }^{2}$.

Mais de 2 bilhões de pessoas no mundo são deficientes em ferro, com uma prevalência total estimada de $40 \%$ da população mundial $^{3}$. Dentre as populações de risco para a anemia ferropriva, as crianças em idade pré-escolar constituem um grupo altamente vulnerável à deficiência de ferro, o que suscita grande preocupação em saúde pública pelos prejuízos que acarreta no desenvolvimento destas crianças. Neste grupo, os sintomas da deficiência de ferro incluem: comprometimento do desenvolvimento mental, retardo de crescimento e desenvolvimento físico e aumento na freqüência de morbidades, dentre outros ${ }^{2}$.

Há diferenças discrepantes na prevalência mundial da anemia ferropriva: em países do oeste e leste europeu, a prevalência de anemia em pré-escolares é de 5\% e 10\%, respectivamente, sendo estimada em torno de 53\% em pré-escolares dos países em transição4 ${ }^{4}$ No Brasil, segundo estudos de prevalência realizados em São Paulo nas décadas de 1980 e 1990, houve aumento substancial (de 36\% para 47\%) da prevalência de anemia em crianças entre 6 meses e 5 anos de idade 5 .

No entanto, há escassez de inquéritos brasileiros de base populacional acerca da prevalência da anemia 6 . A maioria dos estudos disponiveis foi realizada em usuários de serviços de saúde ou de grupos restritos, que não compõem uma amostra representativa 
da população6,7. Além disto, os estudos de base populacionais disponiveis avaliaram a prevalência da anemia com base na medição única de hemoglobina sanguínea, não havendo, até o presente momento, levantamentos que incluam informações sobre a situação das reservas orgânicas de ferro em grupos de risco. Sabe-se que parâmetros hematológicos e bioquímicos podem ser utilizados isoladamente ou associados no diagnóstico do estado nutricional de ferro em indivíduos ou populações. No entanto, quando utilizados de forma isolada, nenhum deles é suficientemente sensivel ou específico ${ }^{8}$.

Há, portanto, poucos estudos de base populacional sobre fatores associados ao risco para anemia ferropriva na infância. A compreensão destes fatores em grupos-alvo constitui importante etapa para a orientação de estratégias de politicas públicas em saúde que visem combater a deficiência de ferro na infância. O presente trabalho analisou os fatores associados à anemia ferropriva em préescolares da Amazônia Brasileira.

\section{Materiais e Métodos}

Um inquérito transversal de base populacional foi realizado em todas as crianças menores de cinco anos residentes na área urbana dos municipios de Acrelândia e Assis Brasil, Estado do Acre. Neste estado, municípios com pequenas populações apresentam forte característica rural e sobrevivem com grandes dificuldades financeiras devido à longa crise da sua economia extrativista. O índice de desenvolvimento infantil (IDI) do estado do Acre é o segundo pior do país ${ }^{4}$, sendo as taxas de mortalidade infantil estimadas, em 2001, em Assis Brasil e Acrelândia, de 67,4/1000 nascidos vivos e 70,75/1000 nascidos vivos, respectivamente. Estes valores são substancialmente superiores à média nacional (27,7/1000 nascidos vivos) ${ }^{9}$. 
A coleta dos dados (entrevistas, exames antropométricos e coleta de amostras para exames laboratoriais) foi realizada em janeiro de 2003, na estação chuvosa da Amazônia Ocidental. Foram visitados todos os 491 domicílios (334 em Acrelândia e 157 em Assis Brasil) em que moravam 724 crianças menores de cinco anos de idade, segundo os registros do Programa de Saúde da Família atualizados em dezembro de 2002. O trabalho de campo foi realizado com a participação de agentes comunitários de saúde, estudantes do curso de Enfermagem da Universidade Federal do Acre e profissionais de saúde de nível superior, com treinamento e supervisão local da equipe de pesquisadores do projeto. Durante as visitas domiciliares, os entrevistadores identificaram-se, explicaram os objetivos e beneficios da pesquisa e solicitaram a assinatura de termo de consentimento livre e esclarecido aos pais ou responsáveis pela criança, assegurando-lhes o sigilo das informações obtidas e a apresentação dos resultados individuais de exames laboratoriais. O estudo foi analisado e aprovado pela Comissão de Ética em Pesquisa com Seres Humanos da Faculdade de Saúde Pública da USP (protocolo de pesquisa no 810 ).

Para avaliação antropométrica, as crianças com dois anos ou mais foram pesadas utilizando-se balança portátil digital eletrônica (Plenna, EUA), com capacidade de $150 \mathrm{~kg}$ e precisão de 100 g. Neste grupo, a estatura foi medida em estadiômetro com precisão de 0,1 $\mathrm{cm}$. Em menores de 2 anos, o peso foi medido em balança pediátrica digital, com capacidade de $16 \mathrm{~kg}$ e precisão de $10 \mathrm{~g}$ (Soehnle, Alemanha) e o comprimento com auxílio de antropômetro infantil, com precisão de $0,1 \mathrm{~cm}$. As mensurações de peso e estatura/comprimento seguiram técnicas recomendadas pela $\mathrm{WHO}^{10}$. Os indices peso/idade $(\mathrm{P} / \mathrm{I})$, peso/estatura $(\mathrm{P} / \mathrm{E})$ e estatura/idade (E/I) foram calculados como escores $z$, com auxílio do software Epi- 
Info versão 6.01 , com base na população de referência do National Center for Health Statistics (NCHS) de $1977^{11}$.

- Amostra fecal foi solicitada a todos os participantes para avaliação parasitológica que foi realizada com base na metodologia descrita por Hoffman et $\mathrm{al}^{12}$. Os individuos com infecção parasitária intestinal receberam tratamento medicamentoso gratuito, prescrito pela equipe médica do projeto.

Amostras de sangue venoso, colhidas após jejum de 10-12 horas, foram utilizadas para a determinação de hemoglobina sangüinea $(\mathrm{Hb})$, ferritina plasmática e niveis plasmáticos de receptor solúvel de transferrina. A concentração de hemoglobina foi medida por meio de hemoglobinômetro portátil Hemocue (Ängelhom, Suécia), sendo a avaliação das reservas orgânicas de ferro (níveis plasmáticos de ferritina e de receptor solúvel de transferrina) realizada através de imunoensaio enzimático (ELISA), com reagentes disponiveis comercialmente (Ramco Laboratories, Stafford, EUA). Esta avaliação foi realizada em duas etapas: no primeiro momento determinaram-se os niveis plasmáticos de ferritina e, com base nestes resultados, os niveis plasmáticos de receptor solúvel de transferrina foram dosados entre as crianças com valores de ferritina acima do valor de corte estipulado para deficiência de ferro $(\geq 12 \mu \mathrm{g} / \text { litro })^{2}$. Esta estratégia objetivou diagnosticar a deficiência de ferro entre as crianças com processos inflamatórios ou infecciosos, que tendem a elevar os niveis de ferritina sem alterar os niveis de receptor solúvel de transferrina ${ }^{2}$. Foram consideradas anêmicas as crianças com concentrações de hemoglobina inferiores a $11 \mathrm{~g} / \mathrm{dL}$ e deficientes em ferro aquelas com valores plasmáticos de ferritina inferiores a $12 \mu \mathrm{g} /$ litro $^{2}$. Como não há consenso quanto ao valor de corte para diagnóstico de deficiência de ferro com base nos níveis plasmáticos de receptor solúvel de transferrina $^{2}$, empregou-se aquele sugerido pelo fabricante do kit utilizado $(8,3 \mathrm{mg} /$ litro). A anemia ferropriva foi definida com base na 
análise combinada dos 3 indicadores: concentração de hemoglobina inferior a $11 \mathrm{~g} / \mathrm{dL}$, ferritina plasmática inferior a $12 \mu \mathrm{g} /$ litro e receptor solúvel de transferrina $>8.3 \mathrm{mg} / \mathrm{L}$. As crianças diagnosticadas anêmicas durante o estudo receberam tratamento gratuito com sulfato ferroso, prescrito pela equipe médica do projeto.

- Informações sobre a situação demográfica, socioeconômica, ambiental, de aleitamento materno e morbidades pregressas foram obtidas por meio de questionário estruturado, aplicado diretamente aos pais ou responsáveis pelas crianças em entrevistas domiciliares. Para avaliação do nível sócio-econômico das famílias, calculou-se um índice de riqueza com base na presença de bens de consumo e utilidades domésticas no domicílio ${ }^{13}$ por meio de análise de componentes principais (programa XLSTAT, 7.5.2 -Addinsoft, Nova Iorque, EUA). Esta variável foi utilizada como uma proxy de renda familiar, que não foi utilizada na presente análise por se tratar de dado de difícil obtenção, espelhando de modo impreciso a situação sócio-econômica das famílias. Do primeiro componente principal, que explicou 32,7\% da variabilidade entre as famílias, derivaram-se pesos para cada item de consumo presente no domicílio e, após a padronização dos pesos atribuídos aos itens, os maiores escores (positivos) foram associados à presença e os menores escores (negativos) à ausência do item no domicílio. Todos os escores foram somados, obtendo-se uma estimativa do indice de riqueza por domicílio, categorizados e analisados em tercis neste estudo.

As informações coletadas foram digitadas e analisadas no pacote estatístico SPSS PC+ (12.0). Para análise descritiva dos resultados, distribuições das freqüências relativas e absolutas, média e desviospadrão das variáveis foram calculadas. A associação entre a anemia ferropriva e seus possiveis determinantes foi estudada inicialmente por análise bivariada, e, após, por meio de regressão logística 
múltipla. Na seleção inicial das variáveis utilizou-se valor de $\mathrm{P}<0,20$, em ordem decrescente de significância estatística, ou variáveis classicamente descritas como associadas ao desfecho de interesse. A seleção de variáveis para análise em modelo de regressão logística múltiplo não seguiu procedimento hierarquizado em niveis devido pequeno número de variáveis associadas ao desfecho de interesse e devido à pequena variabilidade das variáveis dos níveis distais e intermediários de determinação da anemia ferropriva nesta população. Os resultados foram expressos pela razão de produtos cruzados (Odds Ratio, OR) e respectivos intervalos de confiança (IC). No modelo final, foram considerados fatores de associação as variáveis com $\mathrm{P}<0,05$ e de ajuste aquelas com $\mathrm{P}<0,10$. Foram avaliados os determinantes da concentração de hemoglobina sangüínea e de ferritina plasmática (após transformação logarítmica) em modelos de regressão linear múltiplos. Nas análises mencionadas foram excluidas as crianças menores de 6 meses, com base nos critérios diagnósticos para anemia preconizados pela OMS ${ }^{2}$.

\section{Resultados}

\section{Caracterização da população de estudo}

No total, somente quatro crianças deixaram de ser entrevistadas por falta de consentimento de seus pais ou responsáveis $(0,6 \%)$. A população de estudo foi constituída por 677 crianças que completaram exame físico e clínico (93,5\% dos elegiveis).

As características de saúde, socioeconômicas e ambientais da população de estudo são apresentadas na Tabela 1. A idade média das crianças foi de 30,9 meses (desvio-padrão 16,9), sendo 49,0\% pertencentes ao sexo masculino. Quanto às condições de nascimento, observou-se baixa prevalência de crianças prematuras e com baixo peso ao nascer. O aleitamento materno foi iniciado para a maioria das crianças $(94,1 \%)$, mas a prevalência de aleitamento materno 
exclusivo até o sexto mês foi de apenas 30\%, com baixa mediana de duração do aleitamento materno total (180 dias). A média de anos de escolaridade formal do pai foi de 5,9 anos (desvio-padrão 3,8 anos); a maioria das mães trabalhava em casa e pequena proporção das famílias possuía terra própria. Quanto às características ambientais de moradia, grande parte das paredes e pisos dos domicílios era constituída de madeira, com grande aglomeração de pessoas por dormitórios ( $\geq 4$ pessoas/dormitório) na maioria das casas $(71,8 \%$ ). A coleta pública do lixo era realizada na maioria dos domicílios, mas era inexistente rede pública de coleta de esgoto, observando-se presença de esgoto a céu aberto em $22,3 \%$ dos domicílios.

As prevalências gerais de déficits nutricionais segundo os indices $\mathrm{P} / \mathrm{E}, \mathrm{P} / \mathrm{I}$ e $\mathrm{E} / \mathrm{I}$ foram de 3,7\%, 8,7\% e 7,5\%, respectivamente. Dentre as 554 crianças que tiveram amostra fecal colhida e examinada, 180 (32,5\%) albergavam um ou mais protozoários ou helmintos intestinais. Os parasitas mais comuns foram a Giardia duodenalis, Entamoeba coli e Ascaris lumbricoides. Foi observada baixa prevalência de geohelmintos $(3,7 \%)$.

Entre as crianças menores de 6 meses, 35 (68,6\%) estavam amamentando ao seio e apenas 16 (31,4\%) estavam em aleitamento materno exclusivo. O valor médio de hemoglobina observado entre as crianças desta faixa etária foi de 10,9 g/dL (desvio padrão 1,4) enquanto a mediana para ferritina plasmática foi de $31 \mu \mathrm{g} /$ litro. 
Tabela 1. Características de saúde, socioeconômicas e ambientais da população de estudo, Acre, Brasil.

\begin{tabular}{lc}
\hline Variáveis & \\
\hline Idade em meses (média e desvio-padrão) & $30,9(16,9)$ \\
Sexo feminino (\%) & 51,0 \\
Crianças nascidas prematuras (\%) & 2,8 \\
Crianças nascidas com peso < 2500 g (\%) & 7,0 \\
Crianças que iniciaram aleitamento materno (\%) & 94,1 \\
Crianças em aleitamento materno exclusivo por 6 meses (\%) & 30,0 \\
Mediana duração aleitamento materno total (dias) & 180 \\
Escolaridade do pai em anos (média e desvio-padrão) & $5,9(3,8)$ \\
Mães com trabalho fora de casa (\%) & 31,1 \\
Família proprietária de terra (\%) & 21,4 \\
Parede constituída de madeira (\%) & 78,8 \\
Piso constituído de madeira (\%) & 66,4 \\
4 ou mais pessoas / dormitório no domicílio (\%) & 71,8 \\
Presença de esgoto a céu aberto no domicílio (\%) & 22,3 \\
Coleta pública do lixo (\%) & 80,0 \\
\hline N= 677 & \\
\hline
\end{tabular}

\section{Prevalência de anemia, deficiência de ferro e anemia ferropriva}

As concentrações de hemoglobina sangüinea foram medidas em 669 crianças $(92,4 \%$ das crianças elegiveis e 98,8\% das crianças entrevistadas e examinadas) e concentrações plasmáticas de ferritina em 628 crianças $(86,7 \%$ das crianças elegiveis e $92,8 \%$ das crianças entrevistadas e examinadas). Os níveis plasmáticos de receptor de transferrina foram determinados nas 326 crianças que apresentaram 
valores plasmáticos normais ou elevados de ferritina. Entre as crianças maiores de 6 meses, com base nos niveis sangüíneos de hemoglobina, 180 crianças $(29,2 \%)$ foram classificadas como anêmicas. $\mathrm{Na}$ análise combinada dos niveis plasmáticos de ferritina e de receptor de transferrina, 268 (44,9\%) crianças foram classificadas como deficientes em ferro. A análise conjunta dos valores de hemoglobina, ferritina e receptor solúvel de transferrina, apontou 127 crianças $(21,5 \%)$ com diagnóstico de anemia ferropriva. Entre as crianças anêmicas, 68,1\% tinham deficiência de ferro, atribuindo-se os demais casos de anemia a outras carências nutricionais ou a fatores etiológicos de natureza diversa não avaliados no presente estudo. Somente $47,6 \%$ das crianças com deficiência de ferro apresentavam anemia. A Figura 1 ilustra a distribuição das prevalências de anemia, deficiência de ferro e anemia ferropriva entre as crianças maiores de 6 meses, nas diferentes faixas etárias. Maiores prevalências de anemia, anemia ferropriva e deficiência de ferro foram observadas entre crianças de 6-24 meses (teste do quiquadrado, $P<0,05)$.

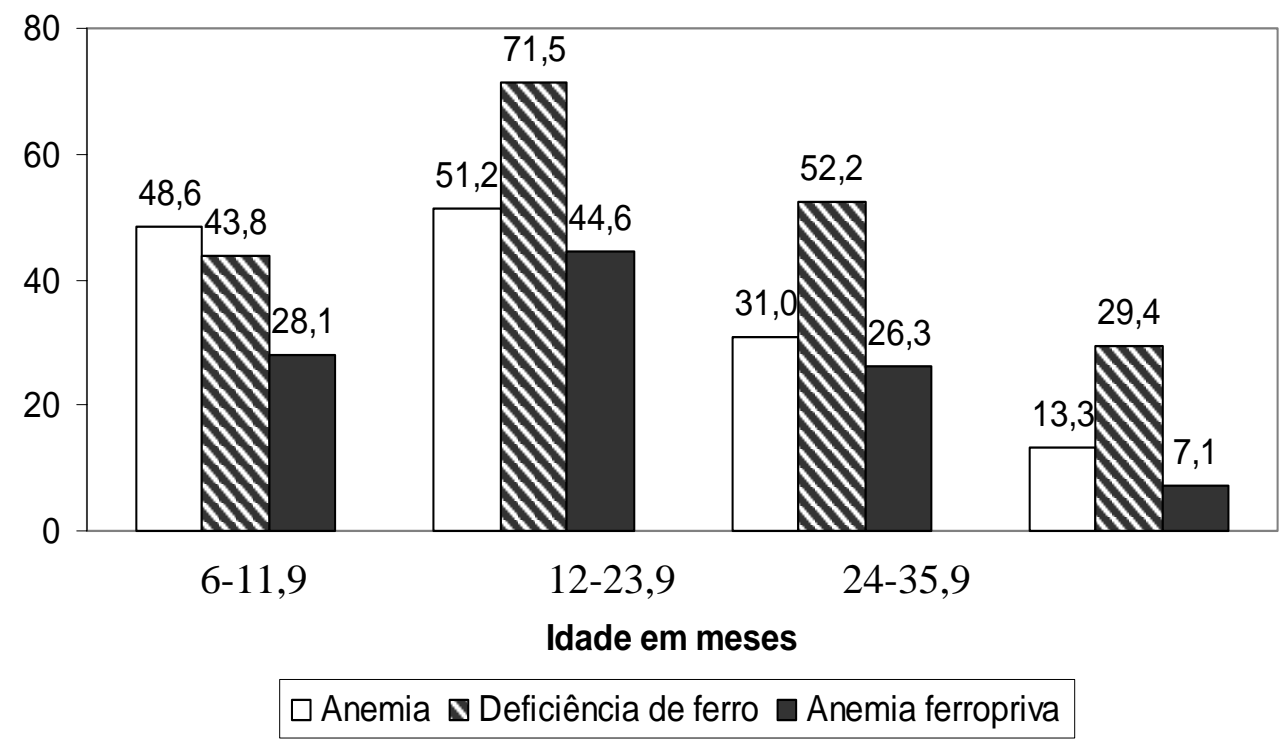

Figura 1. Prevalência de anemia, deficiência de ferro e anemia ferropriva em crianças de 6-60 meses, Acre, Brasil. 


\section{Fatores associados à anemia ferropriva}

As prevalências de anemia ferropriva entre as categorias das variáveis independentes são apresentados na Tabela 2 . Na análise bivariada as seguintes variáveis associaram-se a anemia ferropriva: idade, idade gestacional, peso ao nascer, índice estatura/idade, ocorrência de diarréia nos últimos 15 dias, coriza nos últimos 15 dias, chiado no peito nos últimos 12 meses, presença de geohelmintos, duração do aleitamento materno total, possuir casa própria, aglomeração de pessoas/dormitório, índice de riqueza e realização de tratamento da água de beber.

Tabela 2. Prevalência de anemia ferropriva entre crianças de 6-60 meses nas categorias das variáveis independentes e resultado da análise univariada, Acre, Brasil.

\begin{tabular}{|c|c|c|c|}
\hline Variáveis & $\mathbf{n}$ & $\begin{array}{c}\text { Anemia } \\
\text { Ferropriva } \\
(\%)\end{array}$ & OR (IC 95\%) \\
\hline \multicolumn{4}{|c|}{ Idade (meses) } \\
\hline$\geq 48$ & 131 & 5,3 & 1 \\
\hline$\geq 24 \mathrm{e}<48$ & 274 & 17,5 & $3,76(1,65 ; 8,55)$ \\
\hline$>6 \mathrm{e}<24$ & 185 & 38,9 & $11,27(4,98 ; 25,51)$ \\
\hline \multicolumn{4}{|l|}{ Sexo } \\
\hline Masculino & 290 & 23,8 & 1 \\
\hline Feminino & 300 & 19,3 & $0,77(0,52 ; 1,14)$ \\
\hline \multicolumn{4}{|c|}{ Possui casa própria? } \\
\hline $\mathrm{Sim}$ & 462 & 19,5 & 1 \\
\hline Não & 124 & 29,8 & $1,76(1,12 ; 2.75)$ \\
\hline \multicolumn{4}{|c|}{ Índice de riqueza em tercis } \\
\hline 1 & 191 & 28,8 & 1 \\
\hline 2 & 197 & 19,8 & 0,61 (0.38; 0.98) \\
\hline 3 & 197 & 16,2 & $0,48(0.29 ; 0.78)$ \\
\hline \multicolumn{4}{|c|}{$\begin{array}{l}\text { A criança tem irmãos menores } \\
\text { de } 5 \text { anos? }\end{array}$} \\
\hline Não & 267 & 19,5 & 1 \\
\hline $\operatorname{Sim}$ & 318 & 23,6 & $1,28(0,86 ; 1,90)$ \\
\hline \multicolumn{4}{|c|}{ Aglomeração pessoas/dormitório } \\
\hline$\leq 4.5$ & 287 & 19,2 & 1 \\
\hline$>4.5$ & 294 & 24,5 & $1,37(0,92 ; 2,03)$ \\
\hline
\end{tabular}




\begin{tabular}{|c|c|c|c|}
\hline \multicolumn{4}{|l|}{ Destino do lixo } \\
\hline Coletado & 480 & 21,4 & 1 \\
\hline Queimado ou enterrado & 61 & 22,9 & $1,09(0,58 ; 2,06)$ \\
\hline Joga área aberta/rio & 43 & 23,2 & $1,11(0,53 ; 2,32)$ \\
\hline \multicolumn{4}{|c|}{ Tratamento da água de beber? } \\
\hline $\operatorname{Sim}$ & 416 & 19,2 & 1 \\
\hline Não & 170 & 27,6 & $1,60(1,06 ; 2,43)$ \\
\hline \multicolumn{4}{|l|}{ Idade qestacional } \\
\hline A termo & 543 & 20,8 & 1 \\
\hline Prematuro & 15 & 46,7 & $3,33(1,18 ; 9,38)$ \\
\hline \multicolumn{4}{|l|}{ Peso ao nascer $(\mathrm{kg})$} \\
\hline$<2,5$ & 42 & 33,3 & 1 \\
\hline 2,5 a 3,0 & 81 & 24,7 & $0,66(0,29 ; 1,48)$ \\
\hline$>3,0$ & 422 & 19,9 & $0,50(0,25 ; 0,99)$ \\
\hline \multicolumn{4}{|c|}{ Altura-idade em Z-score(quartis) } \\
\hline 1 & 151 & 26,5 & 1 \\
\hline 2 & 148 & 21,6 & $0,77(0,45 ; 1,30)$ \\
\hline 3 & 146 & 21,9 & $0,78(0,46 ; 1,33)$ \\
\hline 4 & 136 & 16,2 & $0,54(0,30 ; 0,96)$ \\
\hline \multicolumn{4}{|l|}{$\begin{array}{l}\text { Resultado do exame } \\
\text { parasitológico }\end{array}$} \\
\hline Negativo & 320 & 20,9 & 1 \\
\hline Positivo & 167 & 19,2 & $0,89(0,56 ; 1,43)$ \\
\hline \multicolumn{4}{|c|}{ Presença de geohelmintos? } \\
\hline Não & 466 & 19,7 & 1 \\
\hline Sim & 20 & 35,0 & $2,19(0,85 ; 5,64)$ \\
\hline \multicolumn{4}{|c|}{$\begin{array}{l}\text { A criança teve diarréia nos } \\
\text { últimos } 15 \text { dias? }\end{array}$} \\
\hline Não & 414 & 18,1 & 1 \\
\hline Sim & 173 & 30,0 & $1,94(1,29 ; 2,93)$ \\
\hline \multicolumn{4}{|c|}{$\begin{array}{l}\text { A criança teve coriza nos } \\
\text { últimos } 15 \text { dias? }\end{array}$} \\
\hline Não & 303 & 17,8 & 1 \\
\hline $\operatorname{Sim}$ & 281 & 26,0 & $1,62(1,09 ; 2,41)$ \\
\hline \multicolumn{4}{|c|}{$\begin{array}{l}\text { A criança teve pneumonia nos } \\
\text { últimos } 12 \text { meses? }\end{array}$} \\
\hline Não & 490 & 20,8 & 1 \\
\hline $\operatorname{Sim}$ & 87 & 26,4 & $1,37(0,81 ; 2,31)$ \\
\hline \multicolumn{4}{|c|}{$\begin{array}{l}\text { A criança teve chiado no peito } \\
\text { nos últimos } 12 \text { meses? }\end{array}$} \\
\hline Não & 472 & 18,6 & 1 \\
\hline Sim & 114 & 34,2 & $2,27(1,44 ; 3,56)$ \\
\hline \multicolumn{4}{|c|}{$\begin{array}{l}\text { Duração aleitamento materno } \\
\text { (dias) }\end{array}$} \\
\hline$>120$ & 306 & 17,0 & 1 \\
\hline $30-120$ & 113 & 27,4 & $1,85(1,11 ; 3,07)$ \\
\hline$<30$ ou nunca mamou & 20 & 20.0 & $1,22(0,39 ; 3,80)$ \\
\hline
\end{tabular}


A Tabela 3 apresenta os fatores associados à anemia ferropriva na população de estudo, após ajuste para as variáveis de confusão. Maior risco de anemia ferropriva foi observado entre crianças menores de 2 anos, com relato de diarréia nos últimos 15 dias e pertencentes ao primeiro tercil de distribuição do índice de riqueza.

Tabela 3. Fatores associados à anemia ferropriva entre crianças de 660 meses, Acre, Brasil.

\begin{tabular}{lcc}
\hline Variáveis & OR $_{\text {ajustada }}$ (IC 95\%) & p \\
\hline Idade criança (meses) & 1 & \\
$\geq 48$ & $4,38(1,81 ; 10,62)$ & 0,001 \\
$\geq 24$ e $<48$ & $13,72(5,66 ; 33,27)$ & 0,000 \\
$>6$ e $<24$ & 1 & \\
Indice de riqueza em tercis & & \\
1 & $0,64(0,38 ; 1,07)$ & 0,086 \\
2 & $0,48(0,28 ; 0,82)$ & 0,007
\end{tabular}

\section{Diarréia nos últimos 15 dias?}

Não

$\frac{\operatorname{Sim}}{\mathrm{N}=590 . \text { Modelo ajustado para sexo e valores do indice estatura/idade. }}$

Em modelos lineares múltiplos, idade (em meses) e valores do indice estatura/idade (em escore $z$ ), explicaram 19,6\% da variabilidade da concentração de hemoglobina sangüinea, após ajuste para sexo. Para a concentração de ferritina plasmática, idade (em meses) foi positivamente associada $(\mathrm{P}=0,000)$ (dados não apresentados).

\section{Discussão}

No presente estudo, a prevalência geral de anemia entre as crianças de 6-60 meses do Acre foi de 30,6\%, o que caracteriza esta deficiência como um problema de saúde pública na região ${ }^{2}$. No entanto, entre as crianças anêmicas, 31,9\% não tinham evidências 
bioquímicas de deficiência de ferro, o que sugere outros determinantes da anemia. Nossa observação corrobora a premissa da OMS de não se utilizar isoladamente o indicador de concentração de hemoglobina sangüínea como teste de rastreamento para deficiência de ferro ${ }^{2}$.

A prevalência de anemia encontrada entre os menores de cinco anos nos municípios acreanos estudados assemelha-se aos resultados de outro inquérito brasileiro entre pré-escolares do estado da Paraíba $(36,4 \%)^{14}$. Porém, foi inferior às prevalências observadas, na mesma faixa etária, em inquéritos de base populacional no estado de Pernambuco $(40,9 \%)^{15}$ e nos municípios de São Paulo $(46,9 \%)^{5}$. No entanto, alguns fatores restringem a validade dessas comparações. Um deles é que os estudos citados são derivados de levantamentos com amostras sangüíneas colhidas por punção digital, procedimento que pode levar à diluição da amostra e introduzir erro sistemático nas dosagens de hemoglobina ${ }^{16}$.

Em relação à deficiência de ferro, não há estudos brasileiros de base populacional que permitam a comparação das prevalências observadas em nosso estudo. Na América Latina, estudos realizados na Argentina apontam que a deficiência de ferro é um problema de saúde pública entre os menores de 24 meses ${ }^{17,18}$. Estudo mais recente, no Chaco, neste mesmo país, apontou que a deficiência de

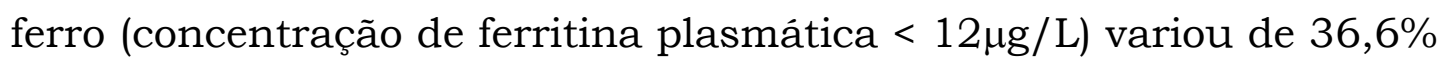
entre crianças de 6-8 meses a 72,9\% entre aqueles de 18 a 24 meses $^{18}$. Na África, inquérito transversal de base populacional, realizado com 1573 menores de cinco anos em área urbana e em 3 comunidades rurais da Costa do Marfim ${ }^{19}$, apontou maiores prevalências de deficiência de ferro (63\%) e de anemia ferropriva (39\%) quando comparadas aos nossos resultados nos pré-escolares acreanos. Maiores prevalências de deficiência de ferro (67,8\%) e 
anemia $(59,7 \%)$ foram também observadas entre crianças de 6-60 meses de área rural da Tanzânia, utilizando-se os indicadores de hemoglobina e protoporfirina eritrocitária livre 20.

Semelhantemente ao que se observa para a anemia $5,15,21$ e deficiência de ferro ${ }^{20}$, a anemia ferropriva apresenta maior prevalência entre 6-24 meses, e posterior redução com o aumento da idade. O efeito independente da idade sobre os indicadores hematológicos de ferro entre crianças mais jovens decorre da maior necessidade fisiológica do mineral devida à maior taxa de crescimento nesta fase da vida.

Neste estudo, a ocorrência de diarréia nos últimos 15 dias foi significantemente associada ao risco para anemia ferropriva. A diarréia pode ocasionar perda sanguínea intestinal e a ocorrência recente desta infecção tem sido sugerida como um marcador de episódios mais freqüentes e persistentes ${ }^{22}$. Levy et $\mathrm{al}^{23}$, em estudo prospectivo com menores Beduínos de 18 meses, observaram aumento no risco de anemia com aumento de infecções diarréicas e respiratórias. Beresford et $\mathrm{al}^{22}$ aponta que infecções diarréicas e respiratórias, mesmo em situações moderadas, comprometem a absorção de ferro, com conseqüente redução dos níveis dos indicadores hematológicos deste mineral. No entanto, a relação causal entre estado nutricional de ferro e susceptibilidade a infecções permanece controversa pela escassez de evidências provenientes de estudos longitudinais. Esta relação pode ser confundida também por variáveis ambientais e socioeconômicas por serem fatores de risco tanto para a anemia ferropriva quanto para infecções ${ }^{24}$.

Em nosso estudo, as crianças pertencentes ao terceiro tercil do indice de riqueza, quando comparadas às crianças do primeiro tercil, tiveram 52\% menor chance de ter anemia ferropriva. No entanto, a prevalência de anemia ferropriva foi alta em todos os estratos do 
indice de riqueza, o que foi também observado em outros estudos brasileiros sobre anemia $5,21,25$. No município de São Paulo, entre menores de cinco anos, observou-se aumento da prevalência de anemia em todos os estratos econômicos entre 1984 a 1996, sendo essa evolução mais desfavorável entre as crianças provenientes de familias mais pobres ${ }^{5}$. Resultados semelhantes foram observados em estudos realizados em Porto Alegre e Criciúma, entre menores de três anos, e em estudo realizado em Pernambuco com menores de 5 anos, onde houve maior prevalência de anemia entre crianças mais pobres $^{21,25,26}$.

Apesar de não dispormos de informações sobre o consumo alimentar para todas as crianças envolvidas no presente estudo, é provável que as características de padrão alimentar com alta ingestão de carboidratos e mingaus à base de leite de vaca observado entre os menores de 2 anos em nossa população de estudo ${ }^{27}$ contribua para a baixa biodisponibilidade de ferro das dietas, inclusive das crianças mais velhas. Dois estudos brasileiros de base populacional realizados com crianças menores de 60 meses, na cidade de São Paulo e no estado de Pernambuco, apontaram maior prevalência de anemia entre crianças com maior proporção de calorias provenientes do leite de vaca, quando comparadas com crianças de menor consumo calórico deste alimento 28,26 Estudos internacionais apontam também efeito deletério do alto consumo de leite de vaca nos primeiros anos de vida, que, além de representar substituinte de alimentos fontes de ferro biodisponivel29, tem efeito inibidor sobre a absorção do ferro presente nos demais alimentos ingeridos ${ }^{29}$.

A ausência de associação significante entre a presença de helmintos e prevalência de anemia ferropriva em nossa população não é surpreendente, diante da baixa prevalência de infecção por helmintos capazes de causar espoliação significativa de nutrientes. Tatala et $\mathrm{al}^{20}$, avaliando pré-escolares da Tanzânia, não encontraram 
associação significante entre infestação parasitária e risco de anemia e deficiência de ferro e observaram prevalência de geohelmintos $(3,8 \%)$ semelhante à verificada entre as crianças de nosso estudo. A baixa prevalência de helmintos em nossa população talvez possa ser explicada pelo uso rotineiro de medicamentos anti-helmínticos administrados pelos agentes de saúde do Programa de Saúde da Família. Mesmo assim, as infecções por protozoários intestinais foram mais prevalentes entre as crianças do Acre do que entre crianças menores de cinco anos do municipio de São Paulo30, o que pode ter contribuído para a elevada ocorrência de doença diarréica recente referida nesta população. A prevalência de diarréia nos últimos 15 dias (29,5\%) observada neste estudo foi substancialmente maior que a encontrada entre menores de 5 anos em São Paulo nas últimas 2 semanas anteriores àquele inquérito $(4,7 \%)^{31}$.

Uma das limitações de nosso estudo inclui o delineamento transversal, impossibilitando a identificação da relação temporal entre infecções e risco para anemia ferropriva.

Com base em nossos resultados, dentre as medidas aplicáveis em serviços públicos de saúde para redução da prevalência da anemia ferropriva entre os pré-escolares de municípios acreanos, reforça-se a importância de ações preventivas voltadas aos menores de 2 anos. A idade compreendida dos 6 aos 24 meses representa período crítico sobre o estado nutricional de ferro na infância, pois, aliado ao efeito independente da idade sobre as necessidades fisiológicas de ferro, soma-se o risco aumentado para a ocorrência de infecções (diarréicas e respiratórias) ${ }^{32,31}$ e para práticas inadequadas de aleitamento materno e alimentação complementar ${ }^{2}$. No presente estudo, apesar do maior risco para anemia ferropriva entre as crianças pertencentes ao menor tercil de indice de riqueza, altas prevalências de anemia ferropriva foram também observadas em 
crianças pertencentes aos maiores tercis. Porém, cabe mencionar a importância da equidade socioeconômica e de ambientes adequados de moradia e saneamento do meio sobre o quadro de saúde infantil, sendo estabelecidas relações entre poder aquisitivo das famílias e disponibilidade de alimentos, moradias precárias ou densamente ocupadas e enfermidades respiratórias, ou entre a inexistência de água tratada ou rede de esgoto e enfermidades parasitárias e de diarréia 33,34 .

Em conclusão, a anemia ferropriva na infância tem múltiplas causas, o que exige a conjunção de diversas estratégias para controle e prevenção. No Acre, a oferta e melhoria da qualidade dos serviços de assistência ao pré-natal e de puericultura devem estar integradas às ações rotineiras de suplementação medicamentosa com ferro a grupos-alvo (gestantes, crianças nascidas prematuras e de baixo peso) e de fortificação compulsória com ferro em alimentos amplamente utilizados na alimentação infantil.

\section{Agradecimentos}

A Francisca Souza Santiago pela participação no trabalho de campo. TGC recebeu bolsa de doutorado da Fundação de Amparo à Pesquisa do Estado de São Paulo (FAPESP- proc no 03/12491-7). Esta pesquisa recebeu apoio financeiro do CNPq (processos 50.2937/2003-3 e $551359 / 2001-3)$.

\section{Referências bibliográficas}

1. Organização Mundial de Saúde -OMS. Anemias Nutricionais. Genebra, 1968. 40 p. (OMS- Série de Informes Técnicos, 405).

2. World Health Organization (WHO). Iron Deficiency Anaemia. Assessment, Prevention and Control. Geneva: WHO, 2001. 
3. Gillespie S. Major issues in the control of iron deficiency. New York: The micronutrient initiative/ United Nations Children's Fund, 1998.104p.

4. Fundo das Nações Unidas para a Infância. State of the world's children 2001. http://www.unicef.org/brazil/sib2001/index.html (acessado em 15/04/2005).

5. Monteiro CA, Szarfac SC, Mondini L. Tendência secular da anemia na infância na cidade de São Paulo (1984-1996). Rev Saúde Pública 2000; 34:62-72.

6. Souza SB, Szarfac SC, Souza JMP. Anemia no primeiro ano de vida em relação ao aleitamento materno. Rev Saúde Pública 1997; 31:1520.

7. Vannucchi H, Freitas MLS, Szarfarc SC. Prevalência de anemias nutricionais no Brasil. Cad Nutr 1992; 4:7-26.

8. Paiva AA, Rondó PHC, Guerra-Shinohara EM. Parâmetros para avaliação do estado nutricional de ferro. Rev Saúde Pública 2000; 34:421-6.

9. Ministério da Saúde (2004). Saúde Brasil 2004: uma análise da situação de saúde. Brasília: Ministério da Saúde, 2004.

10. World Health Organization (WHO). Physical status: the use and interpretation of anthropometry. Geneva: WHO, 1995.

11. Organización Mundial de la Salud. Medicion del cambio del estado nutricional. Genebra, WHO, 1983.

12. Hoffman W, Pons JA, Janer JL. The sedimentation concentration method in schistosomiasis mansoni. Puerto Rico J Public Health Trop Med 1934; 9: 283-291.

13. Filmer D, Pritchett LH. Estimating wealth effects without expenditure data-or tear: an application to educational enrolments in states of India. Demography 2001; 38:115-132.

14. Oliveira RS, Diniz AS, Benigna MJC, Silva SMM, Lola MM, Gonçalves MC et al. magnitude, distribuição espacial e tendência da 
anemia em pré-escolares da Paraíba. Rev Saúde Pública 2002; 36: 111.

15. Osório MM, Lira PIC, Ashworth A. Factors associated with $\mathrm{Hb}$ concentration in children aged 6-59 months in the State of Pernambuco, Brazil. Br J Nutr 2004; 91:307-314.

16. Sari M, Pee S, Martini E, Herman S, Sugiatmi, Bloem MW, Yip R. Estimating the prevalence of anaemia: a comparison of three methods. Bull World Health Organ 2001; 79: 506-11.

17. Calvo EB, Gnazo N. Prevalence of iron deficiency in children aged 9-24 mo from a large urban area of Argentina. Am J Clin Nutr 1990; 52: $534-40$.

18. Morasso MC, Molero J, Vinocur P, Acosta L, Paccussi N, Raselli S, Falivene G, Viteri FE. Iron and vitamin A deficiences and prevalence of anemia in boys and girls between 6 to 2 months of acge in Chaco, Argentina. Arch Lationam Nutr 2003; 53 (1): 21-7.

19. Asobayire FS, Adou P, Davidsson L, Cook JD, Hurrel RF. Prevalence of iron deficiency with and without concurrent anemia in population groups with high prevalences of malaria and other infections: a study in Côte d'Ivoire. Am J Clin Nutr 2001; 74: 776-82. 20. Tatala S, Svanberg U, Mduma B. Low dietary iron availability is a major cause of anemia: a nutrition survey in the Lindi of Tanzania. Am J Clin Nutr 1998; 68: 171-8.

21. Neuman NA, Tanaka OY, Szarfac SC, Guimarães PRV, Victora CG. Prevalência e fatores de risco para anemia no sul do Brasil. Rev Saúde Pública 2000; 34: 56-63.

22. Beresford $\mathrm{CH}$, Neale RJ, Brooke OG. Iron absorption and pyrexia. Lancet 1971; i: 568-72.

23. Levy A, Fraser D, Shirley DR, Dagan R, Deckelbaum RJ, Coles C, Naggan L. Anemia as a risk factor for infectious diseases in infants and toddlers: results from a prospective study. Eur J Epidemiol 2005; 20: $277-84$. 
24. Walter T, Olivares M, Pizarro F, Munoz C. Iron, anemia, and infection. Nutr Rev 1997; 55 (4): 111-124.

25. Silva LSM, Giugliani ERJ, Aerts DRGC. Prevalência e determinantes de anemia em crianças de Porto Alegre, RS, Brasil. Rev Saúde Pública 2001; 35: 66-73.

26. Oliveira MAA, Osório MM, Raposo MCF. Concentração de hemoglobina e anemia em crianças no Estado de Pernambuco, Brasil: fatores sócio-econômicos e de consumo alimentar associados. Cad Saúde Pública 2006; 22 (10): 2169-78.

27. Castro TG, Baraldi L, Muniz PT, Cardoso MA. Dietary practices and nutritional status of 0-24 month-old children from Brazilian Amazon. In: Sixth International Conference on Dietary Assessment Methods: complementary advances in diet and physical activity assessment methodologies, 2006, Copenhagen- Dinamarca. Abstracts Book, 2006.

28. Levy-Costa RB, Monteiro CA. Consumo de leite de vaca e anemia na infância no Município de São Paulo. Rev Saúde Pública 2004; 38 (6):797-803.

29.Thane CW, Bates CJ, Prentice A. Risk factors for low iron intake and poor iron status in a national sample of British young people aged 4-18 years. Public Health Nutr 2003; 6 (5): 485-96.

30. Ferreira MU, Ferreira CS, Monteiro CA. Tendência secular das parasitoses intestinais na infância na cidade de São Paulo (19841996). Rev Saúde Publica 2000; 34: 73- 82.

31. Benicio MHDA, Monteiro CA. Tendência secular da doença diarréica na infância na cidade de São Paulo (1984-1996).Rev Saúde Publica 2000; 34 (6 supl): 83-90.

32. Benicio MHDA, Cardoso MRA, Gouveia NC, Monteiro CA. Tendência secular da doença respiratória na infância na cidade de São Paulo (1984-1996). Rev Saúde Publica 2000; 34 (6 sup1): 91-101. 
33. Monteiro CA, Freitas ICM. Evolução de condicionantes sócioeconômicas da saúde na infância na cidade de São paulo (19841996). Rev Saúde Publica 2000; 34 (6 supl): 8-12.

34. Monteiro CA, Nazário CL. Evolução de condicionantes ambientais da saúde na infância na cidade de São Paulo (1984-1996). Rev Saúde Publica 2000;

34

(6 supl): 13-8. 


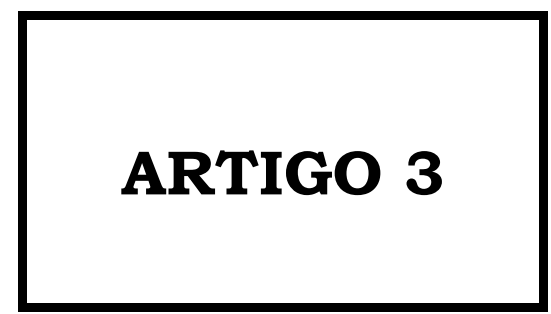




\section{DIETARY PRACTICES AND NUTRITIONAL STATUS OF 0-24- MONTH-OLD CHILDREN FROM BRAZILIAN AMAZONIA}

Teresa Gontijo de Castro*, Larissa Gastraldi Baraldi*, Pascoal Torres Muniz $^{* *}$, Marly Augusto Cardoso*

*Department of Nutrition, School of Public Health, University of São Paulo, Brazil.

${ }^{* *}$ Department of Health Sciences, Federal University of Acre, Brazil.

Correspondência para/ Correspondence to:

Marly Augusto Cardoso

Departamento de Nutrição, Faculdade de Saúde Pública, Universidade de São Paulo. Av. Dr. Arnaldo, 715 - 01246-904

Fone/Fax: (011) 3066-7705 - E-mail: marlyac@usp.br 


\title{
Dietary practices and nutritional status of 0-24-month- old children from Brazilian Amazon
}

\begin{abstract}
Objectives: To assess the nutritional status and dietary practices of 024-month-old children in Amazon area.

Design: Cross-sectional population-based study. The dietary intake of the infants and toddlers was obtained from diet history data, using a standardized equation sheet by the interviewer to assess the overall pattern of eating, coupled with $24 \mathrm{~h}$ recall. Weight and length were measured for anthropometric evaluation. Iron status was assessed using fasting venous blood samples: haemoglobin, serum ferritin and soluble transferrin receptor were measured.
\end{abstract}

Setting: The cities of Assis Brasil and Acrelândia, state of Acre, northwest Brazil.

Subjects: A total of 75 randomly selected 0-24-month-old children.

Results: Of these under-twos, 40.3\% were anaemic, 63.1\% were iron deficient, $28.1 \%$ have iron deficiency anaemia and $7.0 \%$ were stunted. Breastfeeding was initiated by $97.3 \%$ of mothers, following early feeding with complementary foods. Dietary pattern reflected a high intake of carbohydrate-rich foods and cow's milk, with irregular intakes of fruit, vegetables and meat. All infants and $92.3 \%$ of toddlers were at risk of inadequate iron intakes. Iron from animal foods contributed on average $0.5 \%$ and $14.3 \%$ of total dietary iron among infants and toddlers, respectively.

Conclusions: The poor nutritional status and the inadequate feeding practices in our study population reinforce the importance of exclusive breastfeeding during the first 6 months of life. Greater emphasis is required to improve bioavailability of dietary iron during complementary feeding practices. 


\section{Introduction}

At about six months of age, the supply of energy and some nutrients and micronutrients from breast milk can no longer meet the infants' needs and the complementary foods must be provided to achieve a well-balanced diet. The period from 6 to 24 months of age has been considered the greatest nutritional threat to children, when feeding practices are concerned, with repercussions in the growth and development, and consequently, in the risk of morbidity and mortality among young children ${ }^{1,2,3}$.

In developing countries is difficult to achieve an adequate intake of several nutrients from complementary feeding, which is based, commonly, in traditional and unfortified foods ${ }^{4}$. Previous studies have been suggested that complementary foods and food preparations are limited especially in micronutrients, such as iron, zinc and calcium ${ }^{5,1}$.

Iron deficiency (ID), the most common and widespread nutritional deficiency worldwide ${ }^{3}$, has been related to dietary inadequacies during the first two years of life. In addition to this critical period, when rapid changes occur from a predominantly milkbased diet to one based on solid foods, the increased risk for ID is related with higher iron requirements for growth, and it coincides with age when body iron stores are depleted ${ }^{6}$.

The assessment of feeding practices of children under 2 years old requires, among other items, data on breastfeeding patterns, dietary intakes and nutritional status indicators ${ }^{7}$. To date, the relationship among biochemical iron status, anthropometrical indicators and the dietary intakes of young children in Amazonia has not been previously investigated. The only other survey on risk factors for anaemia and ID in Amazonia published so far did not assess food intakes ${ }^{8}$. Here we present an exploratory study about food intake and nutritional status of a randomly selected sample of 0 - 
24-month-old children living in two towns from Brazilian Amazon area.

\section{Methods}

\section{Survey design and population}

In January 2003, a population-based cross-sectional study on child health and nutrition was carried out in the towns of Acrelândia and Assis Brasil, located respectively $350 \mathrm{~km}$ and $100 \mathrm{~km}$ from Rio Branco, in the state of Acre, northwest Brazil. Subsistence agriculture and cattle raising are the main local activities; coffee and banana are the predominant cash crops.

In these cities, all households with children less than 5 years of age were identified through a census performed by our field team, and they were invited to participate of the main study. Data collection from 491 households (334 in Acrelândia and 157 in Assis Brasil) was available (100\% of eligible households). Sampling strategies and results of the survey were reported elsewhere ${ }^{9}$.

The survey included a structured face-to-face interview, usually with the child's mother and it was applied by trained fieldworkers. Questionnaires were completed for 724 children, with questions about socioeconomic and demographic conditions, household environment, birth condition, breastfeeding initiation, and morbidity during childhood (diarrhoea). Diarrhoea occurrence was defined as the passage of frequent loose or liquid stools in the last 15 days prior the survey, according the reference of the child caregiver. Of the interviewed children, 677 who provided blood samples (94\% of those eligible) comprised the population analysed in the main study.

Among the 250 children under 2 years old $(36.9 \%$ of that in the main study), a sample of $30 \%$ was randomly selected with stratification by gender in each city to collect detailed information about breastfeeding and complementary feeding practices, 
represented by 75 participants. This study was approved by the ethical review board of the School of Public Health of the University of São Paulo, Brazil (research protocol no 810). Written informed consent was obtained from a primary caregiver for each child participating in the survey.

\section{Anthropometry}

Length and weight were measured by trained research assistants following standardized procedures and using calibrated equipment ${ }^{10}$. Recumbent length was measured on an infant measuring board (model 98-702, Carlstadt, NJ) and recorded to the nearest $0.1 \mathrm{~cm}$. Weights were taken on a digital pediatric scale (Soehnle, Germany) and recorded to the nearest $0.05 \mathrm{~kg}$. Each measurement was made in duplicate and the mean value calculated. Birth dates were recorded directly of the birth certificates or child health cards.

The Z-scores for height-for-age (HAZ), weight-for-age (WAZ), and weight-for-height (WHZ) were calculated using the DoMeas program in EPI-Info, version 6.0411. Anthropometric cut-offs were analysed according to the National Center for Health Statistics reference as prescribed by $\mathrm{NCHS} / \mathrm{WHO}^{12}$.

\section{Nutritional iron status}

A fasting venipuncture blood sample was collected from each child. Hemoglobin $(\mathrm{Hb})$ concentration was measured using a HemoCue photometer (HemoCue AB, Angelholm, Sweden). Serum samples were transported on dry ice to São Paulo, where concentrations of serum ferritin $(\mathrm{SF})$ and soluble transferrin receptor (sTfR) were measured using commercial enzyme immunoassay kits 
(Ramco Laboratories, Houston, USA). The normal range of sTfR levels determined by the manufacturer is $2.9-8.3 \mathrm{mg} / 1$.

Anemia, iron-deficiency anemia (IDA) and iron deficiency without anemia (ID) were defined on the basis of haemoglobin, serum ferritin and transferrin receptor values. Anemia was defined as $\mathrm{Hb}$ concentration below $110 \mathrm{~g} / \mathrm{dL}$. Iron-deficiency anemia was diagnosed when $\mathrm{Hb}$ concentration $<110 \mathrm{~g} / \mathrm{dL}, \mathrm{SF}<12 \mu \mathrm{g} / \mathrm{L}$ and $\mathrm{sTfR}>8.3 \mathrm{mg} / \mathrm{L}$. The definition for ID was identical, except that hemoglobin had to be $\geq 110 \mathrm{~g} / \mathrm{dL} 3,13$. Anemic children detected during the survey received adequate treatment with ferrous sulphate, prescript by the medical team involved in the project.

\section{Breastfeeding and complementary feeding practices}

Breastfeeding and complementary feeding practices were evaluated and carried out by trained nutritionists. The dietary intake of the infants and toddlers was obtained from diet history data, using a standardized equation sheet by the interviewer to assess the overall pattern of eating, coupled with 24 hours recall ${ }^{14}$. Weighed food records were taken on accurate scales. The intake of breast milk volume was estimated using the following formula: $\mathrm{Y}=489-0.63 \mathrm{X}+$ $13.45 Z$ (where $\mathrm{Y}$ is the predictor of breastfeeding intake in $\mathrm{mL}, \mathrm{X}$ is the age in months and $Z$ is the number of breast-feeding during the day) ${ }^{15}$.

Average recipes were previously established and compiled from weighed food records for to calculate the nutrient composition, which was derived from the database of the World Food Dietary Assessment System (WFood), version 2.0 (Office of Technology Licensing, University of California Berkeley). The nutrient composition database for Brazilian foods was created using databases for Mexican and Kenyan foods. For those Brazilian foods where comparable foods from the Mexican or Kenyan databases could not be identified, all nutrient 
values were taken from the standard food composition table of Brazil. This was limited to cooked beans (with broth), refined maize and wheat flours (non-enriched).

Using the software WFood, zinc bioavailability was calculated based on basal requirements ${ }^{16}$. The percentage bioavailability of zinc was calculated on a per meal basis and was primarily determined by the phytate:zinc molar ratio; ratios of $0-5,5-15$, and $>15$ were assigned zinc bioavailability factors of 55, 35 and $15 \%$, respectively. Percentage zinc bioavailability was then adjusted considering intake of animal protein as an enhancing factor (>16g/1000 Kcal, +5\%) and calcium as an inhibiting factor $(>500 \mathrm{mg} / 1000 \mathrm{kcal},-5 \%$; > $750 \mathrm{mg} / 1000 \mathrm{kcal},-10 \%)$. The bioavailability of haem iron was calculated using $\mathrm{FAO} / \mathrm{WHO}$ estimate of $25 \% 17$. For non-haem iron, bioavailability was determined for each meal as previously described ${ }^{1}$. Starting with a basal bioavailability of $5 \%$, bioavailability was increased by the meal content of meat/fish/poultry protein (>9g/100kcal, +5\%; >27g/1000kcal, $+10 \%$ ) and ascorbic acid (>35mg/1000kcal, +5\%; >105mg/1000kcal, +10\%), and decreased by tannin-containing teas and coffee $(250 \mathrm{~g}$ standard strength beverage, $20 \%$ of percentage bioavailability, to a maximum of $60 \%$ per meal).

Daily energy and nutrient intakes from complementary foods and breastmilk were compared with estimated needs determined in a recent review ${ }^{4,7}$. Values for the nutrient composition of breastmilk were derived from the nutrient composition of whole cow's milk.

Classification of breastfeeding categories was based on WHO criteria $^{18}$ : a) exclusive breast-feeding: only breast milk (including milk expressed or from wet-nurse). Does not allow the infant to receive anything else, only drops and syrups; b) predominant breast-feeding: breast milk (including milk expressed or from wet-nurse) as the predominant source of nourishment. Allows liquids, ritual fluids and 
drops or syrups; c) breast-feeding: breast milk. It allows any food or liquid including non-human milk.

\section{$\underline{\text { Statistical methods }}$}

Information on ownership of 13 household assets was used to derive a wealth index; a derived variable used as proxy of income in the domiciles. For realize this, principal component analysis, carried using the XLSTAT software, version 7.5.2 (Addinsoft, New York, USA), was used to define the weights of household assets ${ }^{19}$. The first principal component explained $32.7 \%$ of the variability and gave greatest weight to ownership of a blender (0.345), a washing machine (0.327) and a refrigerator (0.311). After standardisation of these weighted asset variables, the highest scores were associated with the ownership of a videotape player/recorder (2.865), a car (2.835) and a telephone (1.350). Lowest scores were given to households without a gas stove (-4.141), a refrigerator $(-1.876)$ and a television $(-1.833)$. The asset scores were summed to a wealth index for each household, which was divided into tertile for further analysis.

Variables were presented as proportions (\%) or means and standard deviation and were compared using chi-square test or t-test for independent samples, respectively. The children were grouped into three age categories: infants (0-6 and 6-12 months) and toddlers (12-24 months). Due to non-normal distributions, dietary variables were expressed as median values and interquartile ranges according to age groups. Statistical analyses were performed using the SPSS software version 12.0. All p-values were two tailed and $<0.05$ was the level of significance. 


\section{Results}

Among the 75 children enrolled in this study $50.7 \% \quad(n=38)$ were male. The mean ages (SD) were 12.5 (6.8) and 12.5 (7.4) months for boys and girls, respectively. Twenty-five children (33.3\%) were living in Assis Brasil and 50 (66.7\%) in Acrelândia. There were 18 (24\%) children under 6-month-old.

In relation to the socioeconomic and environmental characteristics, among the head of the family, 6.7\% never studied at school, $14.8 \%$ studied less than four years and $49.2 \%$ had between four and eight years of formal education. Most houses were made of wood; the agglomeration of people/bedroom $\geq 4$ in the domiciles was observed for $42(65.6 \%)$ of the children. In both towns there was not a sanitation system.

Overall, breastfeeding was initiated by $97.3 \%$ of mothers and 65 children (86.3\%) were currently breastfeeding. Among babies under 6 months, only 6 (33.3\%) were in exclusive breast-feeding. The frequencies of breast-feeding according to age group were: under 6 months old: 8.3\%; 6-12 months old: 44.4\%; 12-24 months old: $59.0 \%$. It was observed low prevalence $(4.2 \%)$ of low birth weight $<$ $2500 \mathrm{~g})$ and high prevalence of recent diarrhoea episode among children $(\mathrm{n}=27 ; 36 \%)$.

Table 1 presents the characteristics of the nutritional status of the children, according to age. Higher proportion of iron deficiency together with lower mean values for anthropometric indices (LAZ and WAZ) was observed among infants. Overall, $69.7 \%$ of the detected anaemia was due to iron deficiency. 
Table 1. Characteristics of the nutritional status of infants (6-12 month-old) and toddlers, Acre, Brazil.

\begin{tabular}{|c|c|c|c|}
\hline & $\begin{array}{c}\text { All } \\
\mathrm{N}=\mathbf{5 7}\end{array}$ & $\begin{array}{c}\text { 6-12 months } \\
N=18\end{array}$ & $\begin{array}{c}\text { 12-24 months } \\
\mathrm{N}=39\end{array}$ \\
\hline Anaemia N (\%) & $23(40.3)$ & $9(50.0)$ & 14 (35.9) \\
\hline Iron deficiency $\mathrm{N}(\%)$ & $36(63.1)$ & 7 (38.9) & 29 (74.3)* \\
\hline Iron deficiency anaemia N (\%) & $16(28.1)$ & $4(22.2)$ & $12(30.8)$ \\
\hline \multicolumn{4}{|l|}{ Length-for-age (LAZ): } \\
\hline Mean & -0.307 & 0.56 & $-0.71^{* *}$ \\
\hline Standard deviation -SD & 1.83 & 2.44 & 1.32 \\
\hline Percentage <2SD (stunting) & $4(7.0 \%)$ & 0 & $4(10.2 \%)$ \\
\hline \multicolumn{4}{|l|}{ Weight-for-age (WAZ) } \\
\hline Mean & -0.290 & 0.40 & $-0.61^{* *}$ \\
\hline SD & 1.34 & 1.55 & 1.12 \\
\hline$\%<2$ SD (underweight) & $5(8.8 \%)$ & $1(5.5 \%)$ & $4(10.2 \%)$ \\
\hline \multicolumn{4}{|l|}{ Weight-for-Length (WLZ) } \\
\hline Mean & -0.103 & 0.179 & -0.23 \\
\hline $\mathrm{SD}$ & 1.056 & 1.08 & 1.03 \\
\hline$\%<2 \mathrm{SD}$ (wasted) & 0 & 0 & 0 \\
\hline$\%>2 \mathrm{SD}$ (overweight) & $1(1.75 \%)$ & 0 & $11(2.56 \%)$ \\
\hline
\end{tabular}

Figure 1 illustrates the percent contribution of complementary food and breast milk (as \% of total energy intake) according to age groups. In both age groups the major food contributors to energy, excluding breast milk among infants, were cereals (specially nonenriched rice and maize flours), non-enriched cow's milk and sugar (from soda and artificial juices and added to porridges). Infant milk formula was used only for 1 child (premature). Low intakes of meat, beans, vegetables and fruits were observed. 


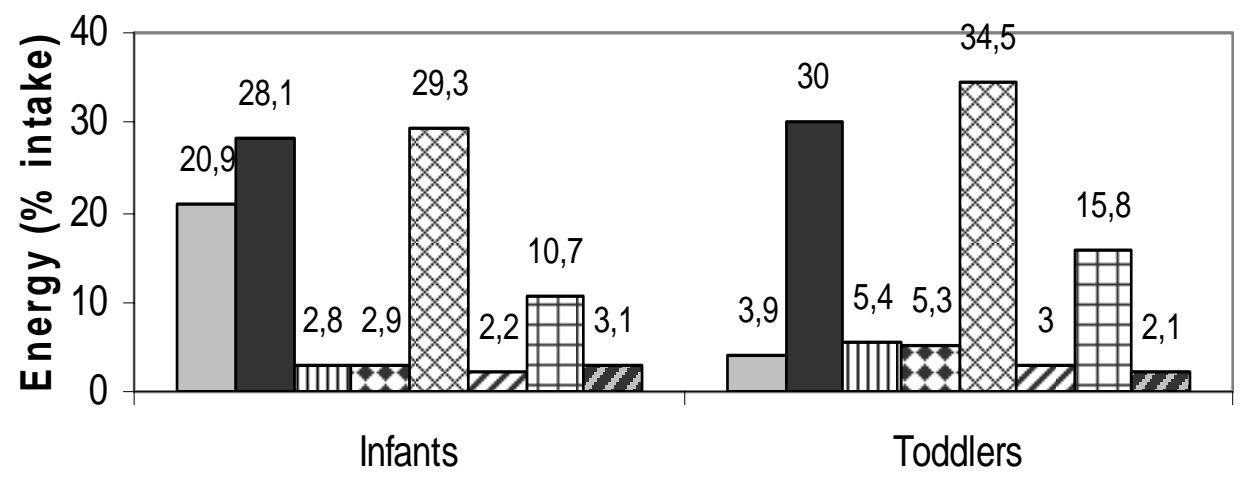

Food Groups

\begin{tabular}{|ll|}
\hline$\square$ Breast milk & $\square$ dairy and eggs \\
$\square$ Poultry, meat and fish & $\square$ Legumes (beans) \\
$\square$ Cereals & $\square$ Fruits, fruit juice and vegetables \\
$\square$ Sugar, candies and soda & $\square$ Other \\
\hline
\end{tabular}

Figure 1 Contribution of food groups and breast milk to total energy intake among infants and toddlers, Acre, Brazil $(\mathrm{N}=57)$.

The median intake of daily energy and nutrient, according to age groups, are shown in Table 2. Energy description included calories provided by breast milk. According to international recommendation ${ }^{4,7}$, the intake of protein, vitamin $\mathrm{B}_{6}$, calcium and tiamin among infants and toddlers were adequate. Total zinc consumption was adequate only among toddlers. However, the median intake of bioavailable zinc was adequate in both age groups. The intake levels of other nutrients were insufficient. The median intake of bioavailable iron was very low in all age groups. 
Table 2. Median (interquartile ranges: 25 th; 75 th) of energy and selected nutrient intakes according to age categories (over 6-monthold children), Acre, Brazil.

\begin{tabular}{lccc}
\hline & \multicolumn{3}{c}{ Age in months } \\
\cline { 2 - 4 } & All (n= 57) & $\mathbf{6 - 1 2}(\mathbf{n}=\mathbf{1 8})$ & $\mathbf{1 2 - 2 4}(\mathbf{n}=\mathbf{3 9})$ \\
\hline Energy (Kcal) & $952.0(739.0 ;$ & $840.5(547.0 ;$ & $1053.0(831.0 ;$ \\
& $1273.0)$ & $935.7)$ & $1574.0)$ \\
Protein (g) & $33.6(22.7 ; 42.7)$ & $30.8(18.7 ; 35.8)$ & $35.5(23.0 ; 50.0)$ \\
Animal protein (g) & $23.9(16.5 ; 34.3)$ & $21.3(15.4 ; 28.5)$ & $23.9(17.3 ; 35.6)$ \\
Protein from meat & $4.4(0.0 ; 10.5)$ & $0.1(0.0 ; 6.3)$ & $6.6(0.7 ; 13.0)$ \\
(g) & & & \\
Vitamin A (RE) & $316.0(235.0 ;$ & $316.0(232.7 ;$ & $320.0(234.0 ; 568.0)$ \\
& $507.5)$ & $481.5)$ & \\
Ascorbic acid (mg) & $20.0(13.5 ; 36.5)$ & $15.5(9.5 ; 39.0)$ & $21.0(14.0 ; 36.0)$ \\
Tiamin (mg) & $0.4(0.2 ; 0.5)$ & $0.31(0.22 ; 0.44)$ & $0.4(0.2 ; 0.6)$ \\
Riboflavin (mg) & $1.0(0.8 ; 1.4)$ & $1.08(0.83 ; 1.26)$ & $1.0(0.7 ; 1.5)$ \\
Niacin (m) & $2.9(1.6 ; 5.4)$ & $1.8(1.2 ; 3.3)$ & $3.7(2.2 ; 6.0)$ \\
Vitamin B6 (mg) & $0.6(0.4 ; 0.9)$ & $0.4(0.3 ; 0.6)$ & $0.6(0.4 ; 1.0)$ \\
Folate (mg) & $79.0(53.0 ; 106.5)$ & $60.0(48.0 ; 79.5)$ & $83.0(66.0 ; 131.0)$ \\
Vitamin B12 (mg) & $2.1(1.1 ; 3.8)$ & $2.0(0.8 ; 3.1)$ & $2.2(1.1 ; 3.8)$ \\
Calcium (mg) & $683.0(486.5 ;$ & $707.5(556.7 ;$ & $625.0(473.0 ; 895.0)$ \\
& $887.0)$ & $890.7)$ & \\
Iron (mg) & $2.4(1.5 ; 4.6)$ & $1.8(1.0 ; 2.3)$ & $2.8(2.0 ; 4.8)$ \\
Iron from animal & $0.3(0.0 ; 0.6)$ & $0.01(0.00 ; 0.4)$ & $0.4(0.09 ; 0.9)$ \\
foods (mg) & & & \\
Available iron (mg) & $0.2(0.1 ; 0.4)$ & $0.1(0.05 ; 0.30)$ & $0.3(0.2 ; 0.6)$ \\
Zinc (mg) & $4.3(3.0 ; 5.6)$ & $3.8(2.4 ; 4.4)$ & $4.7(3.0 ; 6.9)$ \\
Available zinc (mg) & $1.6(1.1 ; 2.4)$ & $1.5(1.1 ; 2.1)$ & $1.7(1.1 ; 2.8)$ \\
\hline
\end{tabular}

The percent of children with adequate nutrients intakes are shown in the Figure 2. Only the recommendation for animal protein was met by all children. Insufficient energy intake was observed for $55.4 \%$ of children. Very low percent of children met the recommended intake for iron $(5.4 \%$ of children), folate (19.6\%), niacin $(25.0 \%)$, tiamin (37.5\%), vitamin C (35.7\%) and vitamin A (37.5\%). All infants and $92.3 \%$ of toddlers were at risk of inadequate iron intakes. Iron from animal foods contributed on average $0.5 \%$ and $14.3 \%$ of total dietary iron among infants and toddlers, respectively. The recommendation intakes for calcium and zinc were met for $73.2 \%$ and $53.6 \%$ of children, respectively. Proportions of children with 
adequate intake of riboflavin and vitamin B were higher among children from families with higher tertiles of wealth index $(\chi 2$ for trend, $\mathrm{p}<0.05)$.

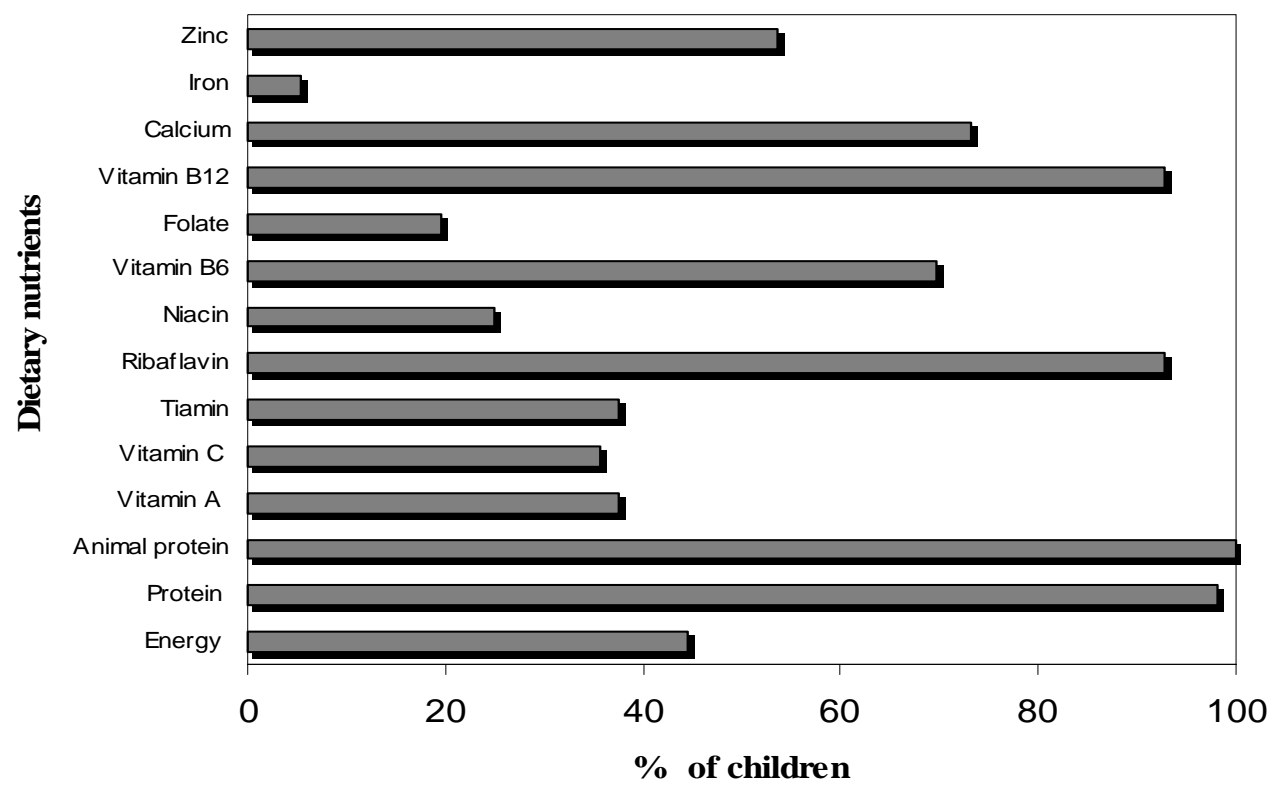

*According to the recommendation of Dewey and Brown (2003).

Figure 2 Percent of children (6-24-month-old) met the recommendation* of energy and nutrients intake, Acre, Brazil.

\section{Discussion}

The present study is the first population-based nutritional survey to assess biochemical iron status, anthropometric indicators and dietary practices in a randomly selected sample of 0-24-monthold children living in Amazon area. In Brazil, the Acre state has the second worst childhood development index, with a childhood mortality rate $(34.3 / 1000)$ higher than that observed for overall Brazilian children $(27.7 / 1000)^{20}$.

In this study, low percent of exclusive breastfeeding among infants less than 6 months was observed, with early introduction of 
complementary feeding characterized by diets with high content of carbohydrate and cow's milk and low frequencies of fruits, vegetables and meat. Weaning diets were limited in energy and some micronutrients, especially total iron and bioavailable iron, vitamin $\mathrm{C}$, folate and vitamin A. Although the overall prevalence of stunting was not as high as in many developing countries, it should not be neglected. The high prevalence of anaemia, iron deficiency and iron deficiency anaemia observed might be a consequence of the poor quality of diet.

Stunting prevalence $(7 \%)$ in our investigation was lower than percents observed in other studies in developing countries ${ }^{1,21,22}$. Faber $\&$ Benadé $^{21}$ found a prevalence of stunting of $15.3 \%$ among the under-twos in a rural South African community and Siegel et al ${ }^{22}$ found a prevalence of stunting of 30.8\% among children 4-17-monthold living in south central Nepal. In infants from rural Malawi areas a prevalence of $30 \%$ of stunting was observed and this rate increased according to age, for $36 \%$ and $46 \%$ at $12-18$ months and 18- 24 months, respectively ${ }^{1}$. Previous study carried out in Latin America 23 found that the association between feeding practices and stunting was generally weaker and less consistent among children during the first year of life, increasing gradually with age. The magnitude of this association was greater among 30-36-month-old children. The additional factor that may explain the greater effect of feeding practices on HAZ index among older children is the clustering of positive practices and behaviours, where the cumulative effect of improved practices may become apparent only after a certain age, possibly starting during the second year and is likely to increase over time ${ }^{23}$.

In this study, the haematological indicators showed a high prevalence of anaemia, iron deficiency and iron deficiency anaemia among the children. Overall, $30.3 \%$ of the anaemic children did not 
show evidence of iron deficiency. Other nutrient deficiencies might be involved based in a possible effect of the low intakes of folate, vitamin $\mathrm{B}_{12}$ and vitamin $\mathrm{A}$. Unfortunately, we did not assess other biochemical indicators that could elucidate the origin of the remained anaemia, such as serum retinol. Percent of anaemia found among the under-twos from Acre was similar to that one reported by $\mathrm{WHO}^{3}$ for children from developing countries (39\%). Higher prevalences of anaemia and iron deficiency were also found among the under-twos from a rural community of South Africa: 65.2\% and 43.2\%, respectively ${ }^{21}$. However, in our study the prevalence of anaemia and iron deficiency was higher than that observed in infants from developed areas. In a longitudinal study with children during the first two years in Dunedian (New Zealand) iron deficiency was observed in $7 \%$ of children at 9, 12 and 18 months, and it was absent at 24 months of age ${ }^{24}$. Different results were found in our study, with a significant increase in the iron deficiency percent in toddlers when compared with infants.

The breastfeeding indicators in our study population showed that exclusive breast-feeding was interrupted prior the sixth month of life, with early introduction of complementary foods. Kalanda et al 25 found lower prevalence of exclusive breastfeeding (which included children receiving supplemented water) in a cohort of infants living in a poor rural Malawian community $(13 \%$ at 4 months, $6.3 \%$ at 5 months and $1.5 \%$ at 6 months). The nutritional value and protective immune properties of breast milk as well as the psychosocial benefits to the infants are widely recognized, and the World Health Organization $^{3}$ issued the exclusive breastfeeding until 6 months, with the introduction of additional food to meet the child's nutrient needs after this age. However, early introduction of complementary food is still a common practice in many developing country settings and the inclusion of non-breast-milk foods and beverages in the children's 
diet less than 6-month-old increases the risk of nutrient imbalances/deficiencies and infectious diseases ${ }^{26}$. Longitudinal study realized with Vietnamese children concluded that over the whole age range from 1 mo to 4 years, $z$-scores for all anthropometric indices (weight-for-age, height-for-age and weight-for-height) of the children that received complementary food were significantly lower than those of children who were exclusively breast-fed for at least 3 months. In this same study, morbidity from diarrhoea and acute respiratory infections was significantly lower for the $\geq 3$ months exclusively breast-fed group, compared with group with less time exclusively breast-fed 27 . Similar results were found by Victora et $\mathrm{al}^{26}$ in a population-based case-control study carried out in two urban areas in Brazil, reporting that the type of milk in an infant's diet was an important risk factor for deaths from diarrhoeal and respiratory infections. Children completely weaned, compared with those who were breast-fed with no milk supplements, had 14.2 and 3.6 times the risk of death from diarrhoea and respiratory infections, respectively.

In relation to morbidity, we found a high prevalence of recent diarrhoea $(36 \%)$ in our study children. The common occurrence of recent diarrhoea might be a consequence of combined effects of the reduced time of exclusive breastfeeding, early introduction of complementary foods with unhygienic utensils and foods, and the inappropriate environmental insertion of the children 7 (domiciles with high agglomeration of people/bedroom and lack of sanitation system).

Analyses of food groups intake showed a high content of carbohydrate and porridges made of cow's milk and no-enriched flours and low quantity of meat, vegetables and fruits. Faber \& Benadé $^{21}$ and Hotz \& Gibson ${ }^{1}$ found similar food pattern among infants and toddlers from a rural South African community and rural area in Malawi, respectively. In these studies complementary diets 
were characterized by high content of energy provided by carbohydrate and low frequencies of fruits, vegetables, meat, iron, vitamin A, and vitamin C. In our study, cow's milk intake represented $28.1 \%$ and $30.0 \%$ of the total energy consumed by infants and toddlers, respectively. Several studies have shown the deleterious effect in the iron nutritional status with the introduction of cow's milk in the diet of the under-twos ${ }^{6,28}$. Soh et $\mathrm{al}^{6}$ found that among children 6-24-month-old New-Zealanders receiving cow's milk > 500 $\mathrm{mL} /$ dia there was a decrease of $25 \%$ in the ferritin values. A Brazilian study showed a significant and positive association between cow's milk intake and anaemia risk among children under 5 years old and a possible inhibitor effect of cow's milk on the absorption of the iron from other foods ${ }^{28}$.

The low contents of iron, iron bioavailable and vitamin $\mathrm{C}$ observed in the complementary feeding adopted by our study children were also observed in other studies from developing countries, where feeding practices based on cereals and legumes influence negatively the iron bioavailability from plant-based complementary foods, with relatively high amounts of phytic acid and negligible amounts of ascorbic acid ${ }^{29}$. The low intakes of iron and bioavailable iron can be cause of the high rates of iron deficiency observed in our study (48\%). A cross-sectional study ${ }^{6}$ investigated the food sources and dietary factors associated with serum ferritin levels in 6-24 month-old children and that the intakes of total iron (from diet and supplemented) and vitamin $\mathrm{C}$ were positively associated with serum ferritin levels, after controlling for possible confounders. Differently from other studies realized in other developing countries ${ }^{1,5,21}$, in our study the median intake of calcium and zinc among toddlers were adequate. There is a lack of conclusive evidence that suboptimal calcium intake leads to a clinical or subclinical deficiency state or contributes to linear growth faltering ${ }^{1}$. The most convincing evidence 
for the role of a specific nutrient deficiency in causing linear growth faltering among young children is $z \mathrm{zinc}^{30}$.

The choice of instruments used to collect information about feeding practices, needs to consider two performance criteria: validity and reliability. An additional complexity of measuring infant's dietary patterns is that feeding practices tend to vary widely within short periods of time. For instance, the 24-hour recall method, the most used time period for collecting dietary information, may be less prone to memory errors than longer periods. On the other hand, it is likely to be less representative of usual practices or intakes ${ }^{31}$. In our study, to minimise the memory bias and the day-by-day variability, we conjugated to the 24- hour recall the weight registration of foods and receipts and a diet history data, instead of asking the caregiver "what did the child eat yesterday", the question was "What usually the child eat?"

Promotion of adequate complementary feeding has received insufficient attention as a public health intervention. Given the important consequences of early childhood malnutrition for health and development, there is an urgent need to act ${ }^{32}$. However, complementary feeding practices encompass a number of interrelated behaviors that need to be addressed simultaneously. Child feeding practices are also age-specific within narrow age ranges, which add to the complexity of developing recommendations and measuring responses ${ }^{31}$.

The present study represents the first step for the elaboration of programs that intend to improve the quality of diet among children under-twos in Acre. Our results highlight that it is necessary to conduct nutritional education and intervention programs that emphasize the quality of diet addressing micronutrient deficiencies, and focusing on complementary diets with high bioavailable iron. Additionally, the recommendation for exclusive breastfeeding in the 
first 6 months should be reinforced together with other actions, including improvement of iron and zinc dietary bioavailability.

In conclusion, the low duration of exclusive breastfeeding and the insufficient energy and poor quality of the complementary foods, especially their content in iron, folate, vitamin $\mathrm{C}$ and vitamin A can be an important causal factor to the high prevalence of anaemia and iron deficiency found in our study children. In addition to inappropriate weaning practices, repeated infections (presented here by the high frequency of recent diarrhoea episodes) could contribute to long-term consequences in height-for-age index ${ }^{33}$, reflecting the growth retardation in the future.

\section{Acknowledgements}

Our sincere appreciation to the Conselho Nacional de Desenvolvimento Científico e Tecnológico-CNPq (proc $\mathrm{n}^{\circ}$ 50.2937/2003-3 e 551359/2001-3) and Fundação de Amparo à Pesquisa no Estado de São Paulo - FAPESP (proc no 03/12491-7). We thank Francisca Souza Santiago for her technical support and the mothers and guardians who participated in the study.

\section{References}

1. Hotz C, Gibson RS. Complementary feeding practices and dietary intakes from complementary foods among weanlings in rural Malawi. European Journal of Clinical Nutrition 2001; 55: 841-9.

2. Victora CG, Kirwood BR, Ashworth A, Black RG, Rogers S, Sazawal $\mathrm{S}$, Campbell H, Gove S. Potential interventions for the prevention of childhood pneumonia in developing countries: improving nutrition. American Journal of Clinical Nutrition 1999; 70:309-320.

3. World Health Organization (2001): Iron deficiency anaemia. Assessment, prevention and control. A guide for programme managers. WHO/NHD/0.13. Geneva: WHO. 
4. World Health Organization (1998): Complementary feeding of young children in developing countries: a review of current scientific knowledge. Geneva, WHO.

5. Gibson RS, Ferguson EL, Lehrfeld J. Complementary foods for infant feeding in developing countries: their nutrient adequacy and improvement. European Journal of Clinical Nutrition 1998; 52: 76470.

6. Soh P, Ferguson EL, McKenzie JE, Skeaff S, Parnell W, Gibson RS. Dietary intakes of 6-24-month-old urban South Island New Zealand children in relation to biochemical iron status. Public Health Nutrition 2002; 5 (2):339-356.

7. Dewey KG, Brown KH. Update on technical issues concerning complementary feeding of young children in developing countries and implications for intervention programs. Food Nutrition Bullettin 2003; 24: 5-28.

8. Cardoso MA, Ferreira MU, Camargo LMA, Szarfarc SC. Anaemia, iron deficiency and malaria in a rural community in Brazilian Amazon. European Journal of Clinical Nutrition 1994; 48: 326-32.

9. Muniz PT, Castro TG, Araujo T, Nunes NB, Silva-Nunes M, Hoffmann EH, Ferreira MU, Cardoso MA. Saúde e nutrição infantil na Amazônia Ocidental Brasileira: inquéritos de base populacional em dois municipios acreanos. Cadernos de Saúde Pública 2006 (no prelo).

10. Lohman TG, Roche AF, Martorell R (eds) (1988): Anthropometric standardization reference manual. Champaigne, IL: Human Kinects Books.

11. Dean AG, Dean AJ, Coulombier D, Burton AH, Brendel KA, Smith DC, Dicker RC, Sullivan KM, Fagan RF (1994). Epi Info, Version 6: a word processing database, and statistics program for epidemiology on microcomputers. Atlanta, GA: Centers for Disease Control and Prevention. 
12. Organización Mundial de la Salud. Medicion del cambio del estado nutricional. Genebra, WHO, 1983.

13. DeMayer EM, Dallman P, Gurney JM, Hallberg L, Sood SK, Srikantia SG (1989). Preventing and controlling iron deficiency anaemia through primary health care. Geneva: World Health Organization.

14. Wharf SG, Fox TE, Fairweather-Tait SJ, Cook JD. Factors affecting iron stores in infants 4-18 months of age. European Journal of Clinical Nutrition 1997; 51:504-9.

15. Drewett RF, Woolridge MW, Jackson DA, Imong SM, Mangklabruks A, Wongsawasdii L, et al. Relationships between nursing patterns, supplementary food intake and breast-milk intake in a rural Thai population. Early Human Development 1989; 20:1323.

16. FAO/WHO/IAEA (1996): Trace elements in human nutrition and health. Geneva: WHO.

17. FAO/WHO (1988): Requirements of vitamin $A$, iron, folate and vitamin B-12: Report of a joint FAO/WHO expert consultation. FAO Food Nutr Ser no 23. Rome: FAO.

18. World Health Organization (1991): Indicators for assessing breast feeding practices. Géneve, (WHO/CDD/SER/91.14).

19. Filmer D, Pritchett LH. Estimating wealth effects without expenditure data-or tear: an application to educational enrolments in states of India. Demography 2001; 38:115-132.

20. Fundo das Nações Unidas para a Infância. State of the world's children 2001. http://www.unicef.org/brazil/sib2001/index.html (acessado em 15/04/2005).

21. Faber M, Benadé AJS. Nutritional status and dietary practices of 4-24-month-old children from a rural South African community. Public Health Nutrition 1999; 2 (2): 179-185. 
22. Siegel EH, Stoltzfus RJ, Khatry SK, LeClerq SC, Katz J, Tielsch JM. Epidemiology pf anemia among 4-to 17-month-old children living in south central Nepal. European Journal of Clinical Nutrition 2006; 60: 228-35.

23.Ruel MT, Menon P. Creating a child feeding index using the demographic and health surveys: an example from Latin America. FCND Discussion Paper from International Food Policy Research Institute 2002; 130: 1- 45.

24.Heath ALM, Tuttle CR, Simons MSL, Cleghorn CL, Parnell WR. Longitudinal study of diet and iron deficiency anaemia in infants during the first two years of life. Asia Pacific Journal of Clinical Nutrition 2002; 11 (4): 251-157.

25. Kalanda BF, Verhoeff FH, Brabin BJ. Breast and complementary feeding practices in relation to morbidity and growth in Malawian infants. European Journal of Clinical Nutrition 2005; 1-7.

26. Victora CG, Vaughan JP, Lombardi C, Fuchs SMC, Gigante LP, Smith PG, Nobre LC, Teixeira AMB, Moreira LB, Barros FC. Evidence for protection by breast-feeding against infant deaths from infectious diseases in Brazil. The Lancet 1987; 8:319-321.

27. Hop LT, Gross R, Giay T, Sastroamidjojo S, Schultnik W, Lang NT. Premature complementary feeding is associated with poorer growth of Vietnamese children. Journal of Nutrition 2000; 130: 26832690.

28. Levy-Costa RB, Monteiro CA. Consumo de leite de vaca e anemia na infância no Município de São Paulo. Revista de Saúde Pública 2004; 38 (6): 797-803.

29. Davidsson L. Approaches to improve iron bioavailability from complementary foods. The Journal of Nutrition 2003; 133: 1560-1562.

30. Brown KH, Peerson JM, Allen LH. Effect of zinc supplementation on children's growth: a meta-analysis of intervention trials. Bibl Nutrition Diet 1998; 54: 76-83. 
31.Ruel MT, Brown KH, Caulfield LE. Moving forward with complementary feeding: indicators and research priorities. FCND Discussion Paper from International Food Policy Research Institute 2003; 146: 1- 75 .

32. Daelmans B, Martines J, Saadech R. Conclusions of the Global Consultation on Complementary Feeding. Food and Nutrition Bulletin 2003; 24(1): 126-129.

33. Lutter CK, Mora JO, Habicht JP, Rasmussen KM, Robson DG, Sellers SG, Super CM, Herrera MG. Nutritional supplementation: effects on stunting because of diarrhoea. American Journal of Clinical Nutrition 1989; 50:1-8. 


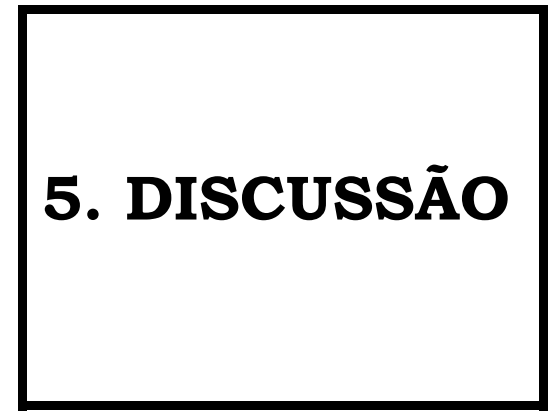


Os resultados de inquérito epidemiológico acerca das condições de saúde e nutrição infantis no Acre foram apresentados na forma de 3 artigos, submetidos ou a serem submetidos à publicação em periódicos científicos. Apesar de Acrelândia e Assis Brasil apresentarem indicadores de saúde infantis abaixo da média nacional, estes municipios apresentam diferenças em relação às principais atividades econômicas e na constituição de sua população (Acrelândia formada de grande contingente de migrantes provenientes da região sul brasileira e Assis Brasil formada majoritariamente pela população nativa do Estado do Acre).

No entanto, de maneira geral, em ambos os municipios, as famílias eram pobres e com baixo nível de escolaridade paterna (Artigo 1). Em relação à situação de inserção ambiental das crianças, observou-se escassez de rede de coleta de esgoto e tratamento de água (Artigo 1). Observaram-se baixas prevalências de desnutrição para os índices $\mathrm{P} / \mathrm{I}, \mathrm{P} / \mathrm{E}$ e E/I, não diferindo significativamente das prevalências observadas em outras regiões do país (Artigo 1). Semelhante também ao observado em território nacional, as prevalências de deficiência de ferro, anemia e anemia ferropriva entre os menores de 5 anos do Acre foram elevadas (Artigos 1 e 2). À informação sobre o estado nutricional de ferro na infância no Acre nossos resultados agregam a observação de que cerca de 1/3 da prevalência de anemia detectada nesta população foram decorrentes de outras razões que não a deficiência de ferro, sugerindo outras causas da mesma (Artigos 1 e 2). Dentre os determinantes da anemia ferropriva entre as crianças de 6 a 60 meses, nosso estudo apontou maior risco desta entre os mais jovens (menores de 24 meses), mais pobres (pertencentes ao primeiro tercil do indice de riqueza) e que haviam apresentado episódio recente de infecção diarréica (Artigo 2). Com relação às morbidades comuns na infância, observou-se baixa prevalência de parasitoses intestinais, mas alta ocorrência de outros 
indicadores de infecções, representados pela ocorrência recente de diarréia e de episódios respiratórios (como chiado no peito e tosse) (Artigo 1). Apesar de não dispormos de informações de consumo alimentar para todas as crianças do presente estudo, dados provenientes de amostra entre os menores de 2 anos sugerem baixa prevalência de aleitamento materno exclusivo até o sexto mês de idade, com introdução precoce de alimentos com baixo teor de ferro total e de ferro biodisponivel. De maneira geral, observamos um padrão de alimentação complementar caracterizado por dietas com alto conteúdo em carboidratos (espessantes e açúcar utilizados na confecção de mingaus, predominantemente), alto consumo de leite de vaca e baixo consumo de frutas, vegetais e carnes (Artigo 3).

Uma das limitações de nosso estudo relaciona-se ao delineamento do tipo transversal. Estudos transversais de base populacional são particularmente úteis ao diagnóstico de saúde infantil, porém não permitem avaliar a seqüência temporal entre exposições e desfechos de interesse. Ainda assim, considerando-se que este inquérito foi o primeiro estudo de base populacional com avaliação bioquímica de indicadores de reservas orgânicas de ferro, espera-se que os resultados organizados nos artigos desta tese (Artigos 1, 2 e 3) possam contribuir para o planejamento de programas de saúde e nutrição infantil na região norte brasileira, auxiliando a definição de políticas públicas nacionais que visem minimizar as desigualdades socioeconômicas entre esta região e as demais do país, com impacto a longo prazo nos padrões de crescimento e desenvolvimento infantil.

Dentre as medidas aplicáveis nos serviços públicos de saúde para redução da prevalência da anemia ferropriva entre pré-escolares do Acre, destaca-se a importância de ações preventivas voltadas aos menores de 2 anos de idade. A faixa etária de 6 a 24 meses representa período crítico sobre o estado nutricional de ferro, pois, 
aliado ao efeito independente da idade sobre as necessidades fisiológicas de ferro, somam-se o risco aumentado para a ocorrência de infecções (diarréicas e respiratórias) (BENÍCIO et al, 2000; BENÍCIO e MONTEIRO, 2000) e práticas inadequadas de aleitamento materno e alimentação complementar (WHO, 2001). Apesar do maior risco de anemia ferropriva entre as crianças pertencentes ao menor tercil de índice de riqueza em nossa população, não se justifica ação de prevenção diferenciada para este segmento, uma vez que a prevalência de anemia ferropriva foi também alta nos tercis de riqueza maiores. Desta forma, torna-se crucial a disponibilidade e melhoria da qualidade dos serviços de pré-natal e puericultura, seja nos postos de saúde ou nos atendimentos domiciliares realizados pelos Agentes do Programa de Saúde da Família

No Acre, os serviços públicos de assistência à saúde sempre foram gerenciados pelo Estado, que iniciou recentemente o processo de municipalização da saúde e implantação do Programa de Saúde da Família. No entanto, há inúmeras dificuldades a serem superadas, especialmente a ausência de infra-estrutura básica e de recursos humanos qualificados. Segundo dados do MINISTÉRIO DA SAÚDE (2003), em 2002, o Acre era o único estado brasileiro que não havia iniciado o processo de implantação da estratégia da "Atenção Integrada às Doenças Prevalentes na Infância (AIDPI)" dentro do contexto do Programa de Saúde da Familia (PSF). Esta estratégia foi incorporada como política de saúde fundamental para países da América Latina pela Organização Panamericana de Saúde (OPAS) a partir de 1996, com intenção de redução da mortalidade infantil nos países em desenvolvimento, devendo o AIDPI ser prioritariamente implantado nos municípios com maiores taxas de mortalidade infantil. Este enfoque visa apresentar um novo paradigma de modelo assistencial, de forma ampla e integrada, onde foram adotadas normas de promoção, prevenção e tratamento dos problemas infantis 
mais freqüentes, tais como aqueles relacionados ao aleitamento materno, promoção da alimentação saudável, crescimento e desenvolvimento, imunização e controle dos agravos à saúde como a desnutrição, doenças diarréicas, infecções respiratórias agudas e malária (MINISTÉRIO DA SAÚDE, 2003).

A anemia ferropriva na infância tem múltiplas causas, o que exige a conjunção de estratégias diversas para seu combate. Desta forma, às condutas de assistência à saúde a gestantes e crianças menores de cinco anos, devem ser integradas: ações de suplementação medicamentosa rotineira de ferro nos serviços, fortificação compulsória com ferro de alimentos amplamente utilizados na alimentação infantil e programas de educação alimentar para melhor adequação do ferro total e biodisponível (WHO, 2001).

É também claramente importante o papel da equidade socioeconômica e de ambientes adequados de moradia e saneamento do meio sobre o quadro de saúde na infância, sendo estabelecidas relações entre poder aquisitivo das famílias e disponibilidade de alimentos, moradias precárias ou densamente ocupadas e enfermidades respiratórias, ou entre a inexistência de água tratada e rede de esgoto e a ocorrência de enfermidades parasitárias e de diarréia (MONTEIRO e FREITAS, 2000; MONTEIRO e NAZÁRIO, 2000). Nos municípios aqui estudados observou-se baixo nível socioeconômico das famílias e ausência de rede de saneamento básico. Portanto, cabe aos gestores de saúde a consideração conjunta destes fatores no planejamento de melhorias nas condições locais da saúde infantil. 


\section{REFERÊNCIAS BIBLIOGRÁFICAS}

Assis AMO, Gaudenzi EM, Gomes G, Ribeiro RC, Szarfac SC, Souza SB. Niveis de hemoglobina, aleitamento materno e regime alimentar no primeiro ano de vida. Rev Saúde Pública. 2004; 38:543-51. Beresford $\mathrm{CH}$, Neale RJ, Brooke OG. Iron absorption and pyrexia. Lancet. 1971 ; i: 568-72.

Benicio MHDA, Monteiro CA. Tendência secular da doença diarréica na infância na cidade de São Paulo (1984-1996).Rev Saúde Publica. 2000; 34: 83-90.

Benicio MHDA, Cardoso MRA, Gouveia NC, Monteiro CA. Tendência secular da doença respiratória na infância na cidade de São Paulo (1984-1996).Rev Saúde Publica. 2000; 34: 91-101.

Bhargava A, Bouis HE, Scrimshaw NS. Dietary intakes and socioeconomic factors are associated with the hemoglobin concentration of Bangadeshi women. J Nutr. 2001; 131: 758-64.

Bloem MW. Interdependence of vitamin A and iron: an important association for programmes of anaemia control. Proc Nutr Soc. 1995; 54: 501-87.

Cardoso MA, Ferreira MU, Camargo LMA, Szarfarc SC. (1992). Anemia em população de área endêmica de malária, Rondônia (Brasil). Rev Saúde Pública. 1992; 26: 161-6.

Cardoso MA, Ferreira MU, Camargo LMA, Szarfarc SC. Anaemia, iron deficiency and malaria in a rural community in Brazilian Amazon. Eur J Clin Nutr. 1994; 48: 326-32.

Center Disease Control. Recommendations to prevent and control iron deficiency in the United States. MMWR. 1998; 47:1-31.

Cessie S1, Verhoeff FH, Mengistie G, Kazembe P, Broadhead R, Brabin BJ. Changes in hemoglobin level in infants in Malawi: effect of low- 
birth weight and fetal anaemia. Arch Dis Child Fetal Neonatal Ed. 2002;86:182-7.

Chang S, O`Brien KO, Nathanson MS, Mancini J, Witter FR. Hemoglobin concentrations influence birth outcomes in pregnant African-American adolescents. J Nutr. 2003; 133: 2348-55.

Colomer J, Colomer C, Gutierrez D, Jubert A, Nolasco A, Donat J, et al. Anaemia during pregnancy as a risk factor for infant iron deficiency: report form the Valencia Infant Anaemia Cohort (VIAC) study. Paediatr Perinat Epidemiol. 1990; 4:196-204.

Davidsson L. Approaches to improve iron bioavailability from complementary foods. J Nutr. 2003; 133: 1560S-62S.

Filho MB \& Rissin A. A transição nutricional no Brasil: tendências regionais e temporais. Cad Saúde Pública. 2003; 19: S181-S191.

Fundo das Nações Unidas para a Infância UNICEF/ Association of Paediatricians in the Federation of Bosnia and Herzegovina. Intervention programme for prevention of nutritive anaemia among children aged 0-6 in the Federation of Bosnia and Herzegovina: Final report: 1999-2000, 2000. 20p.

Fundo das Nações Unidas para a Infância. Ser criança na Amazônia: uma análise das condições de desenvolvimento infantil na Região $\begin{array}{llll}\text { Norte do Brasil. } & 2004 .\end{array}$ http://unicef.org/brazil/ser_crianca_amazonia.pdf (acessado em $15 / 04 / 2005)$.

Garnelo, L \& Rocha RS. Cenário atual e perspectivas de pesquisa em saúde coletiva na Amazônia. Cad Saúde Publica 2006; 22: 1126-7.

Gillespie S, Kevany J, Mason J. Controlling iron deficiency. Geneva: United Nations/Administrative

Committee

on Coordinations/Subcommittee on Nutrition, 1991.

Gillespie S. Major issues in the control of iron deficiency. New York: The micronutrient initiative/ United Nations Children's Fund, 1998.104p. 
Gupta R e Ramji S. Effect of delayed cord clamping on iron stores in infants born to anemic mothers: a randomized controlled trial. Indian Pediatr. 2002; 39:130-5.

Guyatt HL, Brooker S, Kihamia CM, Hall A, Bundy DAP. Evaluation of efficacy of school-based anthelmintic treatments against anaemia in chidren in the United Republic of Tanzania. Bull. WHO. 2001; 79:695-703.

Holand CV. Negected infections- Trichiuriasis and Stronyloidiasis. In: Stephenson, L.S. Impact of helminth infections on human nutrition. New York: Taylor and Francis, 1987.

Levy A, Fraser D, Shirley DR, Dagan R, Deckelbaum RJ, Coles C et al. Anemia as a risk factor for infectious diseases in infants and toddlers: results from a prospective study. Eur J Epidemiol. 2005; 20: $277-84$.

Levy-Costa RB, Monteiro CA. Consumo de leite de vaca e anemia na infância no Município de São Paulo. Rev Saúde Pública. 2004; 38: 797-803.

Lima ACVMS, Lira PIC, Romani SAM, Eickmann SH, Piscoya MD, Lima MC. Fatores determinantes dos niveis de hemoglobina em crianças aos 12 meses de vida na Zona da Mata Meridional de Pernambuco. Rev Bras Saúde Matern Infant. 2004; 4: 35-43.

Michaelson KF, Milman N, Samuelson G. A longitudinal study of iron status in healthy Danish infants: effects of early iron status, growth velocity and dietary factors. Acta Paediatr. 1995, 84:1035-44.

Ministério da Saúde (1998). Assistência pré-natal: normas e manuais técnicos. Brasília: Ministério da Saúde, 1998.

Ministério da Saúde (2000). Política Nacional de Alimentação e Nutrição. Brasília: Ministério da Saúde, 2000. 48 p.

Ministério da Saúde. Resolução n³44, de 13 de dezembro de 2002: Regulamento técnico para fortificaçãodas farinhas de trigo e das 
farinhas de milho com ferro e ácido fólico. Ministério da Saúde. Brasília, 13 dez 2002.

Ministério da Saúde (2002). Dez passos para uma alimentação saudável - Guia alimentar para crianças menores de 2 anos. Brasília: Ministério da Saúde, 2002. 45p.

Ministério da Saúde (2003). AIDPI - Atenção integrada às doenças prevalentes na infância. Brasília: Ministério da Saúde, 2003.

Ministério da Saúde. Portaria n730, de 13 de maio de 2005: institui o programa nacional de suplementação de ferro para prevenir a anemia ferropriva e dá outras providências. Ministério da Saúde. Brasília, 16 mai 2005.

Monteiro CA, Freitas ICM. Evolução de condicionantes sócioeconômicas da saúde na infância na cidade de São Paulo (19841996). Rev Saúde Publica. 2000; 34: 8-12.

Monteiro CA, Nazário CL. Evolução de condicionantes ambientais da saúde na infância na cidade de São Paulo (1984-1996). Rev Saúde Publica. 2000; 34: 13-8.

Monteiro CA, Benício MHD. Melhoria em indicadores de saúde associados à pobreza no Brasil dos anos 90: descrição, causas e impacto sobre desigualdades regionais. São Paulo: NUPENS/USP, 1997. $35 \mathrm{p}$.

Monteiro CA, Szarfac SC, Mondini L. Tendência secular da anemia na infância na cidade de São Paulo (1984-1996). Rev Saúde Pública. 2000; 34:62-72.

Monteiro CA, Szarfac SC, Brunken GS, Gross R, Conde WL. Longterm preventive mass prescription of weekly doses of iron sulfate may be highly effective to reduce endemic child anemia. Food Nutr Bull. $2001 ; 22: 53-61$.

Neuman NA, Tanaka OY, Szarfac SC, Guimarães PRV, Victora CG. Prevalência e fatores de risco para anemia no sul do Brasil. Rev Saúde Pública. 2000; 34: 56-63. 
Oliveira RS, Diniz AS, Benigna MJC, Silva SMM, Lola MM, Gonçalves MC et al. Magnitude, distribuição espacial e tendência da anemia em pré-escolares da Paraíba. Rev Saúde Pública. 2002; 36: 1-11.

Onis M et al Methodology for estimating regional and global trends of child malnutrition. Int J Epidemiol. 2004; 3:1260-70.

Onís M, Monteiro CA, Akré J, Clugston G. The worldwide magnitude of protein-energy malnutrition: an overview from the WHO Global Database on Child Growth. Bull. WHO. 1993; 71:703-12.

Organização Mundial de Saúde -OMS. Anemias Nutricionais. Genebra, 1968. 40 p. (OMS- Série de Informes Técnicos, 405).

Oski FA. Iron deficiency in infancy and childhood. $\mathrm{N}$ Engl $\mathrm{J}$ Med. 1993; 329:190-3.

Osório MM, Lira PIC, Ashworth A. Factors associated with $\mathrm{Hb}$ concentration in children aged 6-59 months in the State of Pernambuco, Brazil. Br J Nutr. 2004; 91:307-14.

Paiva AA, Rondó PHC, Guerra-Shinohara EM. Parâmetros para avaliação do estado nutricional de ferro. Rev Saúde Pública. 2000; 34:421-6.

Pee S, Bloem MW, Sari M, Kiess L, Yip R, Kosen S. The high prevalence of low hemoglobin concentration among Indonesian infants aged3-5 months is related to maternal anemia. J Nutr. 2002; 132: $2215-21$.

Ramakrishnan U, Yip R. Experiences and challenges in industrialized countries: control of iron deficiency in industrialized countries. $J$ Nutr. 2002; 132: 820S-4S.

Ramussen KM. Is there a causal relationship between iron deficiency or iron-deficiency anemia and weight at birth, length of gestation and perinatal mortality? J Nutr. 2001; 131: 590S-603S.

Reeves JD, Yip R, Kiley VA, Dallman PR. Iron deficiency in infants: the influence of mild antecedent infection. J Pediatr. 1984; 105:8749. 
Siegel EH, Stoltzfus RJ, Khatry SK, LeClerq SC, Katz J, Tielsch JM. Epidemiology pf anemia among 4-to 17-month-old children living in south central Nepal. Eur J Clin Nutr. 2006; 60: 228-35.

Silva LSM, Giugliani ERJ, Aerts DRGC. Prevalência e determinantes de anemia em crianças de Porto Alegre, RS, Brasil. Rev Saúde Pública. 2001; 35: 66-73.

Soh P, Ferguson EL, McKenzie JE, Skeaff S, Parnell W, Gibson RS. Dietary intakes of 6-24-month-old urban South Island New Zealand children in relation to biochemical iron status. Public Health Nutr. 2002; 5:339-56.

Souza SB, Szarfac SC, Souza JMP. Anemia no primeiro ano de vida em relação ao aleitamento materno. Rev Saúde Pública. 1997; 31: 1520.

Stoltzfus RJ, Chwya HM, Tielsch JM, Albonico M, Savioli L. Epidemiology of iron deficiency anemia in Zanzibari schoolchildren: the importance of hookworms. Am J Clin Nutr. 1997; 65:153-9.

Universidade Federal do Acre, Secretaria Municipal de Saúde de Rio Branco, Fundo das Nações Unidas para a Infância (UNICEF). Diagnóstico das condições de saúde materno-infantil no município de Rio Branco, Acre. Rio Branco: UNICEF, 1994.

Vannucchi H, Freitas MLS, Szarfarc SC. A prevalência de anemias nutricionais no Brasil. Cad Nutr. 1992; 4: 7-26.

Victora CG, Smith PG, Vaughan JP, Nobre LC, Lombardi C, teixeira AMB, Fuchs SMC, Moreira LB, Gigante LP, Barros FC. Evidence for a strong protective effect of breast-feeding against infant deaths due to infectious diseases in Brazil. Lancet. 1987; 2: 319-22.

Victora CG, Barros FC, Kirkwood BR, Vaughan JP. Pneumonia, diarrhoea and growth in the first four years of life. A longitudinal study of 5,914 Brazilian infants. Am J Clin Nutr. 1990; 52: 391-6.

Walter T, Olivares M, Pizarro F, Munoz C. Iron, anemia, and infection. Nutr Rev. 1997; 55: 111-24. 
World Health Organization. Iron deficiency anaemia: assesment, prevention and control - a guide for programme managers. Geneva: WHO, 2001.

Zlotkin S. The role of nutrition in the prevention of iron deficiency anemia in infants, children and adolescents. CMAJ. 2003; 168: 5865. 
ANEXO 1

TERMO DE CONSENTIMENTO E PARECER DO CEP/FSP/USP 


\section{TERMO DE CONSENTIMENTO LIVRE E ESCLARECIDO}

PROJETO DE PESQUISA : CONDIÇÕES DE SAÚDE E NUTRIÇÃO DE CRIANÇAS DA AMAZÔNIA OCIDENTAL BRASILEIRA .

Durante a leitura do documento abaixo, fui informado que posso interromper para fazer qualquer pergunta, com o objetivo de tirar dúvidas e o meu melhor esclarecimento.

$\mathrm{Eu}$, , com anos de idade fui procurado(a) por um membro da equipe de pesquisa coordenada pelo professor Dr. Pascoal Torres Muniz, quando fui informado(a) sobre o objetivo da pesquisa com o título acima citado. O objetivo principal dessa pesquisa é avaliar o estado de saúde e nutrição de crianças menores de 5 anos. Foi explicado que as crianças anêmicas e/ou com parasitas intestinais receberão tratamento sob orientação médica da equipe de pesquisa.

O Dr. Pascoal, ou membro da sua equipe, também leu este documento e esclareceu os seus termos, bem como deixou claro que se desejar tenho o direito de saber o resultado desta pesquisa. Segundo as informações prestadas, a pesquisa consta de levantamento de dados raciais e de saúde dos meus filhos menores de 5 anos de idade. Ficou claro que caso não aceite participar desta pesquisa , não terei qualquer prejuízo.

$\mathrm{Na}$ apresentação do pesquisador foi dito também que todas as informações a serem prestadas sobre a minha pessoa e de família serão mantidas em sigilo e não poderei ser, identificada como participante da pesquisa. 
e concordo em participar como voluntário(a) deste estudo . COMO TENHO DIFICULDADE PARA LER (SIM( ) NÃO（），Ｏ ESCRITO ACIMA, ATESTO TAMBÉM QUE O DR. PASCOAL (OU MEMBRO DA SUA EUIPE) LEU PAUSADAMENTE ESSE DOCUMENTO E ESCLARECEU AS MINHAS DÚVIDAS, E COMO TEM A MINHA CONCORDÂNCIA PARA PARTICIPAR DO ESTUDO, COLOQUEI ABAIXO A MINHA ASSINATURA ( OU IMPRESSÃO DIGITAL).

Rio Branco- Acre de de 2002 .

Pesquisado

Nome:

Assinatura

IMPRESSÃO DATILOSCÓPICA ( quando se aplicar)

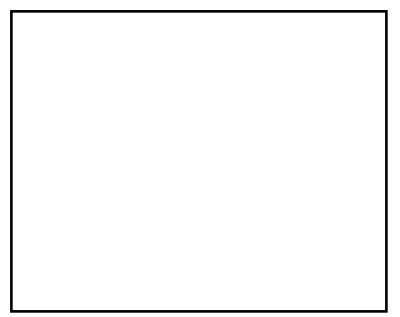

Testemunhas :

1. Nome:

Assinatura:

2. Nome :

Assinatura:

Pascoal Torres Muniz Ou Membro da Equipe

Documento em duas (2) vias, uma para ser entregue a pessoa ( ou responsável) que vai participar da pesquisa. 


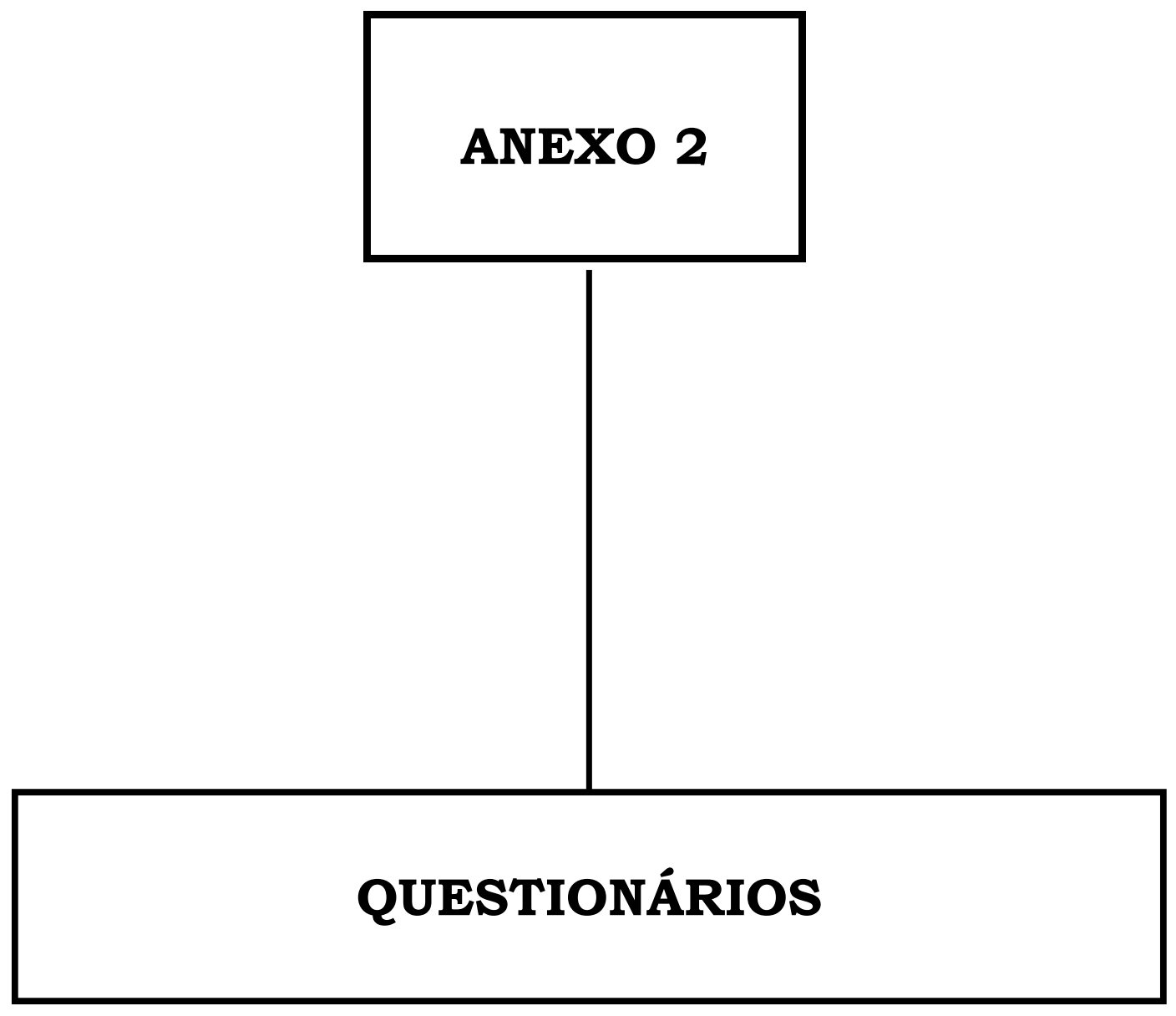


Condições de Saúde e Nutrição de Crianças da Amazônia Ocidental Brasileira

\section{SÓCIO ECONÔMICO-FAMILIARI MÃE OU RESPONSÁVEL PELAS CRIANÇAS}

Identificação do Domíclio início (hs) : / término:

Município (1- Assis Brasil 2-Acrelândia)

Número domicílio:

Nome informante:

Endereço completo:

Ponto de referência:

Telefone:

Entrevistador:

Data: ____ I2001 (1 $1^{\text {a }}$ visita $)$ resultado da entrevista: (código)

Data: /2001 (2 $2^{\mathrm{a}}$ visita) resultado da entrevista: (código)

Data: /2001 (3 $3^{\mathrm{a}}$ visita) resultado da entrevista:

Códigos

01 - entrevista completa

02 - entrevista incompleta

03 - moradores ausentes

04 - adiada

05 - recusa total

06 - domicílio desocupado

77 - outra

Revisado pelo entrevistador? ( ) sim ( )não 


\section{CONDICCÕES SÓCIO - ECONÔMICAS E AMBIENTAIS}

Caso não seja possível identificar a resposta, pergunte.

01-Quais são as pessoas que moram na casa?

pai/chefe família

(1) $\operatorname{sim}$ (0)não

mãe/responsável

(1) $\operatorname{sim}$ (0)não

irmãos menores que a criança :

(00)nenhum

outros irmãos:

(00)nenhum

outras pessoas;

(00)nenhum

01a.paiche

01b.maere

01c.irme

01d.outir

01e.outpes

02- Tipo de domicílio (observar)

01 - casa

02 - apartamento

02. tipodo

03 - barraco

04 - quarto/cômodo

- outros:

03- Presença de esgoto a céu aberto? (observar)

03. esgot

$01-\operatorname{sim}$

02 - não

04- Material predominante da cobertura (telhado/observar)

01 - telha cerâmica

02 - telha internit

03 - laje de concreto

$04-$ zinco

05 - madeira aparelhada

06 - madeira aproveitada

07 - plástico/palha

- - - outros:

05- Material predominante na parede:(observar)

01 - tijolo/bloco c/ revestimento

02 - tijolo/bloco s/ revestimento

03 - madeira aparelhada

04 - madeira aproveitada

05 - taipa com revestimento

06 - taipa sem revestimento

07 - lata / papelão / palha

08 - adobe

- - outros: 
06- Material predominante do piso:(observar)

01 - terra batida

06. piso

02 - cimento/tijolo

03 - madeira

04- cerâmica/mosaico

05 - carpete

- outro:

07- Este domicílio é:

01 - próprio (pago)

02 - próprio (pagando)

03 - alugado

04 - cedido

05 - ocupação de terra (assentados)

06- acampamento (invasão de terra)

- outro:

08- Quantos cômodos tem este domicílio? (não incluir o banheiro)

08. comod número cômodos:

09- Quantos são dormitórios?

09 .comdor

10- Possui vaso sanitário?

01 - sim, individual s/ descarga

02 - sim, individual c/ descarga

10. vaso

03 - sim, coletivo $\mathrm{c} /$ descarga

04 - sim,coletivo s/ descarga

05 - não possui

11- De onde vem a água usada em sua casa? (predominantemente)

01 - água de rede geral de distribuição canalizada para dentro de casa

02 - água de rede geral de distribuição canalizada para fora de casa

03 - água de torneira pública/chafariz

04 - poço/nascente não canalizada

05 - poço/nascente canalizada

06 - caminhão - pipa

07 - rio/barreira/açude

- - outro:

12- Quantas torneiras existem dentro de sua casa ? (excluir chuveiro)

01 - nenhuma

02 - uma

03 - duas

04 - três

05 - quatro ou mais

13- Com que freqüência falta água em sua casa?

13. freqa

01 - nunca

03 - freqüentemente

02 - raramente

88 - não se aplica

11. água

12. torn 
14- Qual o tratamento da água utilizada para beber?

01 - fervida

02 - filtrada

03 - mineral

04 - filtrada e fervida

05 - clorada em casa

06 - não é tratada

15- O que você faz com o lixo desta casa?

01 - coloca na porta para coleta

02 - coloca em lixeira pública

03 - enterra ou queima

04 - joga fora em área aberta

05 - joga em córrego/rio

- - outros:

16- Para onde vai o esgoto de sua casa?

01 - rede de esgoto

02 - fossa séptica não ligada a rede de esgoto

03 - fossa séptica ligada a rede de esgoto

04 - fossa rudimentar

05 - vala a céu aberto

06 - rio/riacho

- - outros:

17- Existe energia elétrica em sua casa?

$01-\operatorname{sim} 02$ - não

17. ener

18- Quais dos bens abaixo existem em seu domicílio?
01 - televisão a cores
(01)sim
(01) sim
(02)não
02 - televisão preto e branco
(01) sim
(02)não
03 - aparelho de som
(01) sim
(02)não
04 - vídeo cassete
(01)sim
(02)não
05 - fogão à gás
(01)sim
(02)não
06 - geladeira
(02)não
07 - rádio
(01)sim
(02)não
08 - telefone
(01)sim
(02)não
09 - liquidificador
(01)sim
(02)não
10 - bicicleta
(01) sim
(02)não
11 - ferro elétrico
(01)sim
(02)não
12 - carro
(01)sim
(02)não
13 - jogo de sala estofado
(01)sim
(02)não
14 - máquina de lavar roupa
(01)sim
(02)não
15 - antena parabólica
(01)sim
(02)não

15. lixoc

16. oesgo

19- A família é proprietária de terra, sítio, fazenda ou roça? (se não/não sabe passe p/ 21)

$01-\operatorname{sim}$

02 - não

99 - não sabe

18.1. Televc

18.2. televp

18.3. apas

18.4. videoc

18.5. fogs

18.6. gela

18.7. radi

18.8. tele

18.9. iqui

18.10.bici

18.11. ferre

18.12. car

18.13. oges

18.14. malav

18.15. antpar

19. terra

20- Se sim, qual o tamanho da terra? 


\begin{tabular}{|c|c|c|}
\hline \multicolumn{3}{|c|}{ (anotar o tamanho da terra na medida referida) } \\
\hline 999.99 - não sabe & 888.88 & \\
\hline \multicolumn{3}{|c|}{ 21- A família produz alimentos para consumo próprio? quais? } \\
\hline 01 - verduras e hortaliças & (01)sim & (02)não \\
\hline 02 - leite e derivados & (01)sim & (02)não \\
\hline 03 - carnes e ovos & (01)sim & (02)não \\
\hline 04 - leguminosa (feijão, andu) & (01)sim & 02)não \\
\hline 05 - cereais (arroz,milho) & (01)sim & $(02) n$ \\
\hline
\end{tabular}

22- Alguém na família (ou domicílio) tem plano de saúde?

(01) sim

(02)não

23- Se sim, quantos têm?

24- Nesta família alguém participa de algum destes grupos? (ler)

01 - associação de moradores

(01)sim

(01) sim

(01)sim

03 - grupo de jovens

04 - grupo de igreja

(01) sim

(01) sim

(01sim

(02)não

(02)não

(02)não

(02)não

(02)não

77- outros

(02)não

25- A família conta com algum tipo de ajuda destes grupos? (finaceira ou outrros recursos)?
(01)sim
(02)não
(99)não sabe
(88)nsa

26- A família recebe visitas dos agentes de saúde?

01- sim, regulamente

02- sim, irregularmente

04 - não

03- sim, só uma vez

27- A família recebe visitas da pastoral da criança?

01 - sim, regulamente

$02-\operatorname{sim}$, irregulamente

03 - não

99 - não sabe/não lembra

28- A família recebe a cesta básica do governo?
01 - sim, regularmente
03 - não
$02-\operatorname{sim}$, irregularmente
99 - não sabe

20.tamter

21.1.verd

21.2.leite

21.3.carne

21.4. legum

21.5. cere

22. plans

23. plansq

24.1. assom

24.2. sindc

24.3. grujo

24.4. gruig

24.5. grumul

24.6. gruou

25. ajudag

26. agens

27. past

28. prodea 


\section{As questões a sequir deverão ser respondidas pelo chefe do domicílio, seja homem ou mulher.}

29- O (a) senhor (a) estudou na escola?

$\left(C_{-}\right)$sim. até que série completou? ___ série__ grau

(00)não frequentou escola e não sabe ler/escrever

(88) não frequentou escola mas sabe ler e escrever

(99) não sabe/ não informa

30- No mês passado, quanto receberam as pessoas da casa?

pessoa 1: r\$__ _ _ _ _ _ _ _ por mês.

pessoa 2: r\$__ _ _ _ _ _ _ por mês

pessoa 3: r\$__ _ _ _ _ _ _ por mês

pessoa 4: r\$__ _ _ _ _ _ _ por mês

pessoa 5: r\$__ _ _ _ _ _ _ _ por mês

pessoa 6: r\$__ _ _ _ _ _ _ _ por mês

pessoa 7: r\$__ _ _ _ _ _ _ _ por mês

pessoa 8: $r \$ \_\_$_ _ _ _ _ _ por mês

$(88.888,88)$ não se aplica $\quad(88,88)$ não se aplica

$(99.999,99)$ não sabe/não lembra $\quad(99,99)$ não sabe/ não se aplica

31- A família tem outra fonte de renda de renda, como aluguel, mesada, pensão, etc?

1. $r \$$ por mês

2. $r \$$ por mês

3. $r \$$ por mês

$(88.888,88)$ não se aplica $(99.999,99)$ não sabe/não lembra
$(88,88)$ não se aplica $(99,99)$ não sabe/ não se aplica
29. estesc

30.1.rend1

30.2. rend2

30.3. rend3

30.4.rend4

30.5.rend5

30.6. rend6

30.7.rend7

30.8. rend8

31.1.rend9

31.2. rend10

31.3. rend11 
QUESTIONÁRIO DA MÃE/RESPONSÁVEL PELAS CRIANCAS DO DOMICÍLIO

Nome

mãe/responsável:

Entrevistador:

Data: /2001

Resultado da entrevista:

Códigos

01 - entrevista completa

02 - entrevista incompleta

03 - moradores ausentes

04 - adiada

05 - recusa total

06 - domicílio desocupado

77 - outra

(especificar)

ESTE QUESTIONÁRIO DEVERÁ SER RESPONDIDO PELA MÃE(S) OU PELA(S) SUBSTITUTA(S) DA MÃE DA(S) CRIANÇA(S) MENORES DE 5 ANOS QUE MORAM NA CASA. 


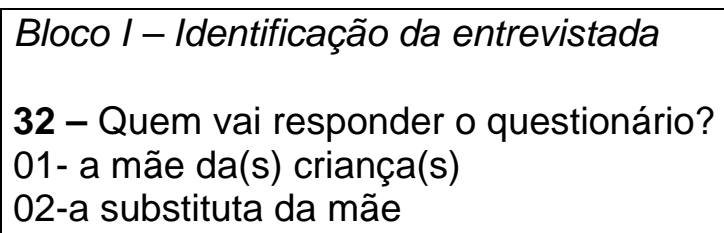

33- Idade mãe : anos / 88-não se aplica 99- não sabe/não lembra data nascimento:

Bloco II - Migração

34- Há quanto tempo a senhora mora nesta cidade? 01-menos de 1 ano 04 - desde que nasceu 02- de 1 a 5 anos 99 - não sabe /não lembra 03- mais de 5 anos 88 - não se aplica

Bloco III- Educação

35- A senhora estudou na escola?

( $)$ sim. até que série completou? série

$(\overline{00})$ não frequentou escola e não sabe ler/escrever

(88) não frequentou escola mas sabe ler e escrever

(99) não sabe/ não informa

\section{Bloco IV - Estado conjugal e história reprodutiva}

36- A senhora está casada ou mora com um companheiro?

01- sim

02- não

37- Há quanto tempo estão casados ou moram juntos?

00 - menos de 1 ano 88- não se aplica

38- O que a sra. faz para não engravidar?

(01) nada/não tem companheiro

(02) pílula, qual?

(03) diu

(04) diafragma

(05) laqueadura

(06) camisinha (companheiro)

(07) tabela

(08) vasectomia

( — outro:

39- Ao todo, quantas vezes ficou grávida? grau anos

99 - não sabe/não informa

32. entrm

33. idadm

34. Temom

35. estescm

36. econj

37. teconj

38. Faznen

(99) não sabe/não informa

39. vezgra 
40-Idade na primeira gravidez? anos

41- Quantos filhos nasceram vivos?

42- Dos filhos que nasceram vivos, algum filho morreu antes dos 5 anos?

(88)não se aplica (99)não sabe/ não lembra

43- Qual era a idade da senhora na última gravidez?

(99)não sabe/ não lembra

(considerar idade atual se estiver grávida)

Bloco V - Trabalho materno e história ocupacional

44 - A senhora está trabalhando fora de casa?

01 - sim, só um turno

03 - sim, sem turno definido

$02-\operatorname{sim}$, dois turnos

04 - não trabalha

45 - Qual é a sua ocupação ?

(01) faxineira, serviços gerais

(02) comércio

(03) agricultura

(04) serviços técnicos (escola, secretaria, etc)

(05) assistencial (igrejas)

(__) outros:

As questões seguintes serão aplicadas às mães que estão trabalhando, para as que não trabalham assinale a alternativa não se aplica.

46 - Há quanto tempo a senhora está neste trabalho?

01 - menos de 6 meses

02 - 6 meses a 1 ano

$03-1$ a 2 anos

04- de 3 anos a 4 anos

05 - há mais de 4 anos

88 - não se aplica

47- A senhora trabalha quantos dias na semana?

$$
88 \text { - não se aplica }
$$

dias/semana

\section{Bloco VI - Saúde materna}

- Nós gostaríamos de saber agora algumas informações sobre a saúde da senhora

48 - A senhora já foi internada alguma vez durante sua vida por motivo de doença (não incluir partos ou cirurgias para laquedura de trompa)? vezes

00 - nunca 88 - muitas vezes (não consegue contar) 99 - não sabe/não informa

49 - Depois do nascimento de dos seus filhos menores de cinco anos, a sra. foi internada alguma vez (não incluir partos ou cirurgias para laqueadura de trompa) ?

vezes
40. idprgra

41. quavi

42.quamac

43.idault

44. tram:

45. ocuma

46. tetram

47. Ditra

48. intimat1

49. intimat2 
Condições de Saúde e Nutrição de Crianças da Amazônia Ocidental Brasileira

\section{QUESTIONÁRIO 2 \\ CARACTERÍSTICAS DA CRIANÇA}

Identificação do Domíclio início (hs) : / término:

município (1- Assis Brasil 2-Acrelândia)

Número domicílio:

Número da criança:

Nome informante:

Endereço completo:

Ponto de referência:

Telefone:

Entrevistador:

Data: ___ _ _ I2001 (1 $1^{\mathrm{a}}$ visita $) \quad$ resultado da entrevista:

Data: _____ I2001 (2 $2^{\mathrm{a}}$ visita) resultado da entrevista:

(código)

Data: /2001 (3 $3^{\mathrm{a}}$ visita)

resultado da entrevista:

Códigos

01 - entrevista completa

02 - entrevista incompleta

03 - moradores ausentes

04 - adiada

05 - recusa total

06 - domicílio desocupado

77 - outra

Revisado pelo entrevistador? ( ) sim （ )não assinatura do entrevistador

Revisado pelo supervisor? ( ) sim ( )não assinatura do supervisor

\section{Confidencial}

as informações solicitadas neste questionário são confidenciais e só serão utilizadas para fins estatísticos este questionário deverá ser respondido pela mãe da criança menor de cinco anos selecionada para o estudo. caso esta não tenha mãe ou não more com ela, a responsável, substituta da mãe da crinaça é quem deverá responder as questões. 
Data da entrevista: 1 datent nome da criança:

ncri

\section{Bloco I- Características gerais da criança e da família da crianca}

01-Data de nascimento 1

(conferir na certidão, senão , no cartão da criança, evite a idade referida)

02-Sexo

01- masculino 02- feminino

03- Documento apresentado para fornecimento da data de nascimento? certidão de nascimento cartão da criança batistério cartão da maternidade / declaração de nascimento referido

04-Quem vai responder o questionário? 01-mãe (passe para a questão 12)

02- pai da criança

03- $\quad$ substituta da mãe

04- não parente (vizinha/amiga)

05- avó

06- tia

07- irmã

08- cunhada

09- prima

10- sogra

11- marido/companheiro

77-outro:

05-Há quanto tempo a senhora cuida de (nome da criança)?
01- desde que nasceu
04- de 1 a 2 anos
02- há mais de 4 anos
05- há menos de 1 ano
03- de 3 a 4 anos
88- não se aplica

99-não sabe/não lembra

06-Por que a mãe não mora com (nome da criança)?

01- por motivo de trabalho 06- por problemas financeiros

02- constituiu outra família

77- outro:

04- motivo de doença

88- não se aplica

01- não quis assumir o filho

99- não sabe/ não lembra

01. Idade

02. sexocri

03. doc

04. resq

05. temsub

06. motma1 
07-O pai de (nome da criança) mora com ela (e)?

07. morpai

01-sim

02-não, faleceu

03-não, outros motivos

99-não sabe/não informa

As questões de 22-33 só deverão ser respondidas quando o pai morar com criança ou para o substituto deste, quando existir.

08-O pai da criança estudou na escola?

$\left(L_{-}\right)$sim. até que série completou? ___érie__ grau

$(00)$ não frequentou escola e não sabe ler/escrever

(88) não frequentou escola mas sabe ler e escrever

(99) não sabe/ não informa

09 -O pai da criança está trabalhando?

01 - sim, só um turno $\quad$ 03- sim, sem turno definido

02 - sim, dois turnos $\quad 04$ - não trabalha

10-Qual é a ocupação do pai da criança?

(01) faxineiro, serviços gerais

(02) comércio

(03) agricultura

(04) serviços técnicos (escola, secretaria, etc)

(05) assistencial (igrejas)

(_ $)$ outros:

Vamos falar agora sobre (nome da criança)

11- Há quanto tempo a criança mora nesta cidade?

11. tempci

01- desde que nasceu

02- menos de 6 meses

03- de 6 meses a 1 ano

04- de 1 a 2 anos

\author{
05- de 2 a 3 anos \\ 06-mais de 3 anos \\ 99-não sabe \\ 88-não se aplica
}

08. estescp

09. tram:

10. ocupa

12- Em que cidade a criança morava antes?

nome cidade 1

88- não se aplica

99-não sabe/não lembra

13- $E$ antes desta cidade, a criança morou em outra (s)? qual (s)? nome cidade 2

nome cidade 3

88- não se aplica

99-não sabe/não lembra 


\section{Bloco Il- Cuidado materno (gestação e parto)}

Este bloco deverá ser respondido apenas pela mãe biológica das crianças

menores de dois anos. Se a criança for maior de dois anos ou a mãe biológica não estiver respondendo, passe para o próximo bloco.

\section{Gestação}

14-A senhora fez pré-natal durante a gestação de (nome da criança)?

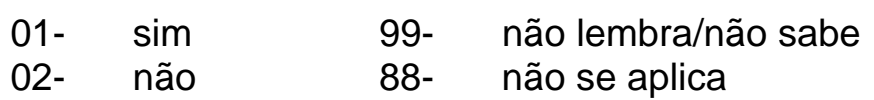

Se não ou não lembra/náo sabe, passe para a questão 21

15- Onde fez o pré-natal?

01- serviço de saúde público (posto de saúde/centro/maternidade/hospital)

99- não lembra/não sabe

02- médico convênio ou particular

88- não se aplica

14. pren

15. onpre

16-Em que mês da gestação fez o primeiro exame pré-natal? mês 99-não lembra/não sabe 88-não se aplica

17-Quantas consultas fez durante a gravidez? consultas 99-não lembra/não saber 88-não se aplica

18-Teve cartão de pré-natal (da gestante)?

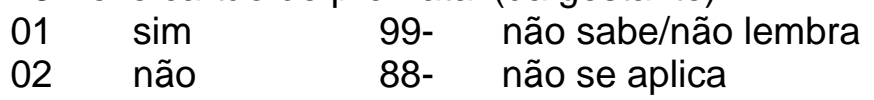

19-Durante o pré-natal, sua pressão arterial foi medida?
01- sim, em todas as consultas 99- não sabe/não lembra
02- sim, apenas em algumas 88- não se aplica
03- não, em nenhuma das consultas

20-Durante o pré-natal seu peso foi medido?

01- sim, em todas as consultas 99- não sabe/não lembra

02- sim, apenas em algumas 88- não se aplica

03- não, em nenhuma das consultas

21-Durante a gestação recebeu orientação sobre aleitamento materno ?

$\begin{array}{ll}\text { 01- sim } & \text { 99- não lembra/ não sabe } \\ \text { 02- não } & \text { 88- não se aplica }\end{array}$

22- Durante a gestação recebeu orientação sobre como evitar filhos após o parto? 01- sim 99- não lembra/ não sabe

02- não 88 naõ se aplica

16. prien

17. cons

18. cpren

19. prespre

20. pespre

21. oriam

22. orievp 
23-Tomou vacina antitetânica durante a gestação?

$\begin{array}{llrl}\text { 01- } & \text { sim } & 99- & \text { não sabe/não lembra } \\ \text { 02- } & \text { não, nunca tomou } & 88- & \text { não se aplica } \\ \text { 03- } & \text { não, já era imunizada } & & \end{array}$

24-Durante esta gravidez, a senhora apresentou algum dos seguintes problemas de saúde?
01)hemorragia
02)inchaçho nas pernas
03)pressão alta
04)anemia
05)açúcar no sangue
06)internação qualquer motivo
07)malária

(01) sim (02) não (99) não sabe

(01) sim (02) não (99) não sabe

(01) sim (02) não (99) não sabe

(01) sim (02) não (99) não sabe

(01) sim (02) não (99) não sabe

(01) $\operatorname{sim}$ (02) não

(01) sim

(02) não

(99) não sabe

(99) não sabe

(88) nsa

(88) nsa

(88) nsa

(88) nsa

(88) nsa

(88) nsa

(88) nsa

25- A senhora fumou durante a gestação ?

01- sim, algumas vezes

02- sim, sempre

03-fumava antes mas não fumou durante a gravidez

04-não

99- não lembra/ não sabe

26- A senhora tomou bebida alcoólica durante a gestação?

01- sim, algumas vezes

02- sim, sempre

03-bebia antes mas não bebeu durante a gravidez

04-não

99- não lembra/ não sabe

Parto

Vamos agora falar sobre o parto de (nome da criança)

27-- Onde (nome da criança) nasceu ?

01-em hospital / maternidade / casa de parto pública

02- em hospital ou maternidade particular ou convênio

03- em casa ( a própria casa, de outra peesoa ou da parteira)

88- não se aplica

99- não sabe / não lembra

28- Como foi o parto de (nome da criança) ?

$\begin{array}{ll}\text { 01- natural } & \text { 03-fórceps (tirado a ferro) } \\ \text { 02- cesária } & \text { 88- não se aplica }\end{array}$

29-(Nome da criança) é gêmeo ?

01- sim 02-não 99-não sabe 88- nsa

30- Quem fez o parto de (nome da criança)?

01- médico 05- pariu sozinha

02- enfermeira 06- outra pessoa(não profissional ou parteira)

03-auxiliar de enfermagem
23. vacit

24.1. sang

24.2. inch

24.3. pres

24.4. anem

24.5. açuc

24.6. intges

24.7. malges

25. fumog

26. alcog

27. onden

28. Parto

29. gêmeo

30. qparto 
04-parteira

88- não se aplica

31- Durante o parto ou logo depois (até 45 dias) a senhora apresentou algumas das seguintes complicações:
01)hemorragia
02)febre
03)convulsão
04)problema mental/emocional
(muita tristeza,perda do juízo)
05)pressão alta
06)internação qualquer motivo

(01) sim (02) não (99) não sabe (88) nsa

(01) sim (02) não (99) não sabe (88) nsa

(01) sim (02) não (99) não sabe (88) nsa

(01) sim (02) não (99) não sabe (88) nsa

(01) sim (02) não (99) não sabe (88) nsa

(01) sim (02) não (99) não sabe (88) nsa

\section{Bloco III-Outras informações e acesso aos serviços de saúde}

Aplicável a todas a as crianças

Peso ao nascer, vacinação e outras informações

32- Qual o peso de (nome criança) ao nascer: 8888- não se aplica 9999-não sabe/não lembra

gramas

33-Qual o comprimento (nome criança) ao nascer:

888- não se aplica 999-não sabe/não lembra $\mathrm{cm}$

34- A criança nasceu: (ler)

01-no tempo

02-antes do tempo

03-depois do tempo

99-não sabe

35- Se nasceu antes do tempo, quantas semanas antes?

semanas

88- não se aplica

99-não sabe/não lembra

$\rightarrow$ coletar no cartão (da criança ou da maternidade):

peso ao nascer (gramas)

comprimento (cm)

idade gestacional

88- não se aplica

99-não sabe/não lembra

Preencha o quadro abaixo, conforme o cartão da criança

\begin{tabular}{|c|c|c|c|c|c|}
\hline \multirow[t]{2}{*}{ vacina } & \multicolumn{3}{|c|}{ datas das vacinas } & \multirow[t]{2}{*}{ reforço } & \multirow{2}{*}{$\begin{array}{l}\text { n. }{ }^{\circ} \text { de doses de } \\
\text { campanha }\end{array}$} \\
\hline & $1^{a}$ dose & $2^{a}$ dose & $3^{a}$ dose & & \\
\hline \multicolumn{6}{|l|}{ tríplice } \\
\hline \multicolumn{6}{|l|}{ sabin } \\
\hline \multicolumn{6}{|l|}{ sarampo } \\
\hline \multicolumn{6}{|l|}{$\mathrm{mmr}^{*}$} \\
\hline \multicolumn{6}{|l|}{ bcg } \\
\hline hepatite b & & & & & \\
\hline
\end{tabular}

31.1. sangr

31.2. febr

31.3. conv

31.4. mental

31.5. press

31.6. interge

32.PNrefere

33. comrefe

34. inasc

35. inasca

32b. PN

33b. comp

35b. idgest 
*sarampo, caxumba, rúbéola

36- Não perguntar para a mãe, preencher após a entrevista:

Vacinação da criança está em dia: (01) sim

(02) não

(99) não tem cartão

37- (Nome da criança) fez uso de alguma vitamina ou fortificante nos últimos 30 dias?

01 - sim $\quad 02$ - não $\quad 99$ - não sabe / não lembra $\quad 88$ - nsa

$\left.L_{-}\right)$Se sim, qual?

38- (Nome da criança) fez uso de algum remédio para verme (lombriga) nos últimos 6 meses?

01 - sim $\quad 02$ - não $\quad 99$ - não sabe / não lembra 88 - nsa

Se não ou não lembra /não sabe passe para questão 40

39-- (Nome da criança) eliminou verme após o uso do remédio?

01 - sim $\quad 02$ - não $\quad 99$ - não sabe / não lembra 88 - nsa

40- Para os maiores de 3 anos - (nome da criança) já foi ou vai ao dentista ?

01 - sim, foi uma vez

04 - não, nunca foi

02 - sim, vai de 6 em 6 meses

99 - não lembra / não sabe

03 - sim, vai uma vez por ano

88 - nsa (<3 anos)

Acesso aos serviços de saúde e percepção materna da saúde infantil

41-(Nome da criança) é acompanhada no serviço de saúde?

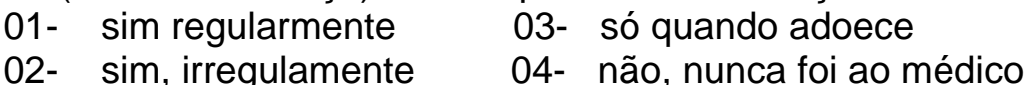

99 - não sabe

42- (Nome da criança) já foi considerada desnutrida no serviço de saúde?

$01-\operatorname{sim}$

03 - nunca foi ao serviço de saúde

02 - não

99 - não sabe / não lembra

43- (Nome da criança) está inscrita em algum dos programas de distribuição de alimentos ou algum outro?

$\begin{array}{llll}01 \text { - programa do leite (pad) } & \text { (01) sim } & \text { (02) não } & \text { (99) não sabe } \\ 02 \text { - pastoral da criança } & \text { (01) sim } & \text { (02) não } & \text { (99) não sabe }\end{array}$

02 - pastoral da criança

44- (Nome da criança) recebe (ou recebeu) do serviço público ou de outra instituição algum destes alimentos?
01) leite
(01) sim
(02) não
(01) sim
(02) não
02) óleo
(01) sim
(02) não
(99) não sabe
03) sopão
(01) sim
(02) não
05) outros:
(01) sim
(02) não
(99) não sabe
(99) não sabe
(99) não sabe
(99) não sabe

45 - Esse alimento é (ou era) recebido

01 - regulamente $\quad 99$ - não sabe / não lembra

02 - irregularmente $\quad 88$ - não se aplica
36. vadia1

37. vitam

38. reverme

39. eliver

40. dent

41. acomps

42. desnu

43. pascri

44.1. leite

44.2. óleo

44.3. sopa

44.4. muitim

44.5. outros

45. receba 
Bloco IV - Morbidades

Aplicável a todas as crianças

\section{Internações durante a vida}

46-(Nome da criança) já esteve internada alguma vez? (se não passe para a questão 48)

01- $\operatorname{sim}$ 02- não 99- não sabe/não informa

47- Se sim, indicar a causa da internação, o período de internação, o ano e o local onde a criança ficou internada (hospital e cidade)

1.Motivo:

2. período (dias):

3. ano:

4.nome hospital;

5.cidade:

1.motivo:

2. período (dias):

3. ano:

4. nome hospital;

5.cidade:

1.motivo:

2. período (dias):

3.ano:

4.nome hospital;

5.cidade:

1.motivo:

2. período (dias):

3.ano:

4. nome hospital;

5.cidade:

1.motivo:

2. período (dias):

3.ano:

4. nome hospital;

5.cidade:

1.motivo:

2. período (dias):

3.ano:

4. nome hospital;

5.cidade:

47.2. perint1

47.3. ano1

47.4. nomhos1

47.5. cidint1

47.6. motint2

47.7. perint2

47.8.ano2

47.9. nomhos 2

47.10. cidint 2

47.11. motint 3

47.12. perint3

47.13. ano3

47.14. nomhos 3

47.15.cidint3

47.16. motint4

47.17. perint 4

47.18. ano 4

47.19. nomhos 4

47.20.cidint4

47.21. motint5

47.22. perint5

47.23.ano5

47.24. nomhos 5

47.25.cidint5

47.26. motint6

47.27. perint6

47.28.ano6

47.29. nomhos 6

47.30.cidint6 


\section{Morbidade nos últimos 15 dias}

48-(Nome da criança) teve algum destes problemas de saúde nos último 15 dias?

1. diarréia

2. duração da diarréia

3. sangue nas fezes

sabe 4. febre

5. vômitos

6. chiado no peito

7. coriza

8. tosse seca

9. tosse com catarro claro

10. tosse com catarro esverdeado

11. tosse com catarro sanguinolento

12. perda de apetite

13. eliminação de vermes

14. abatimento/tristeza

15. problema de ouvido

16. problema de garganta

17. dor de dente

18. malária dias

(01) sim (02) não

$$
\text { (01) } \operatorname{sim}
$$

(01) sim

(01) sim

(01) sim

(01) sim

(01) sim

(01) sim

(01) sim

(01) sim

(01) sim

(01) sim

(01) sim

(01) sim

(01) sim

(01) sim

(01) sim
(02) não

(02) não

(02) não

(02) não

(02) não

(02) não

(02) não

(02) não

(02) não

(02) não

(02) não

(02) não

(02) não

(02) não

(02) não

(02) não
(99) não sabe (99) não sabe (99) não

(99) não sabe (99) não sabe (99) não sabe (99) não sabe (99) não sabe (99) não sabe (99) não sabe (99) não sabe (99) não sabe (99) não sabe (99) não sabe (99) não sabe (99) não sabe (99) não sabe (99) não sabe

48. 1. diarr

48. 2. dudia

48.3. sanfe

48.4.febre

48.5.vomit

48.6. chipe

48.7. coriz

48.8. tosse

48.9. tocac

48.10.tocae

48.11. tocas

48.12. peape

48.13. verme

48.14.abati

48.15. ouvid

48.16. garga

48.17. dorden

48.18. malar1

49. psesau quinze dias a senhora procurou algum serviço de saúde?

01- sim (passe para a questão 51) 88- não se aplica

02- não

99-não sabe/não lembra

50-Se não, porque não procurou o serviço de saúde? pode ser marcada mais de uma alternativa.

01- não achou que seria necessário

(01) sim (02) não (99) nsa

02- teve dificuldade financeira

(01) $\operatorname{sim}$

(02) não

(99) nsa ou de trabalho

03- não tem médico no serviço local

(01) sim (02) não (99) nsa

04- o atendimento demora

(01) sim (02) não (99) nsa

05- o serviço não resolve o problema

(01) sim

(02) não (99) nsa

51- O serviço de saúde era:

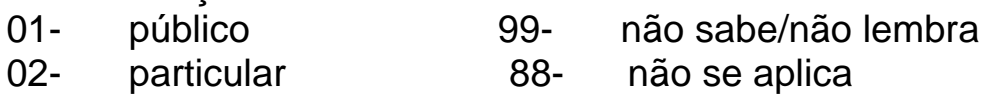

52-No serviço de saúde procurado foi prescrito algum medicamento para (nome da criança)?

01- sim

99- não lembra / não sabe

02- não

88- não se aplica

53-Se sim, o medicamento foi adquirido?

01- sim 99- não lembra/ não sabe

02- não

88- não se aplica

50.1. nasen

50.2. tedift

50.3. names

50.4. ated

50.5.narep

51. sesau

52. presc1

53. presc 2 
54-Como o medicamento foi adquirido?

01- foi dado pelo próprio serviço de saúde

02- foi comprado

03- doado

04- na farmácia, mas foi pago pela prefeitura

55-- A senhora ficou satisfeita com o atendimento no serviço de saúde?
01- $\operatorname{sim}$
02- não
88- não se aplica

56- Para a criança que apresentou diarréia nos últimos 15 dias: quando (nome da criança) estava com a diarreia, o que a senhora usou para trata-la?
01- soro caseiro
(01)sim (02)não (99)não sabe
02- soro industrializado
(01)sim (02)não
(99)não sabe
(88)nsa
(01)sim (02)não (99)não sabe
(88)nsa
03- água
04- água de côco
(01)sim (02)não (99)não sabe
(88)nsa
(01)sim (02)não
(99)não sabe
(88)nsa
(01)sim (02)não
(99)não sabe
(88)nsa
(01)sim (02)não
(99)não sabe
(88)nsa
(01)sim (02)não
(99)não sabe
(88)nsa
(01)sim (02)não
(99)não sabe
(88)nsa
(01)sim (02)não
(99)não sabe
(88)nsa
(01)sim (02)não
(99)não sabe
(88)nsa
(01)sim (02)não
(99)não sabe
(88)nsa
(88)nsa
12- medicamento

57-(Nome da criança) precisou ser internada por causa da diarréia?
(01) $\operatorname{sim}$
( 02 )não
(99 )não sabe/não lembra
( 88 )nsa

58- Para as crianças que apresentaram malária nos últimos 15 dias: que espécie d plasmódio foi responsável pela malária?
01- plamodium falciparum
99-não sabe/não lembra
02- plasmodium vivax
88- não se aplica
03- mista (ambas espécies)

59- A criança tomou remédio para malária nos últimos 15 dias?

01-sim

02-não

99-não sabe /não lembra

88-não se aplica

60- Se tomou, poderia dizer qual o nome do remédio?

01-cloroquina

02-primaquina

03-mefloquina

04-quinino

05-doxiciclina ou tetraciclina

06-artesunato

07-outros

99-não sabe/não lembra

88-não se aplica

(pedir a mãe, se possível, para ver a caixa do remédio)
54. aquis

55. tend

56.1. sorca

56.2. orin

56.3. água

56.4. aguac

56.5. aguar

56.6. cha

56.7.suco

56.8. excali

56.9. exletv

56.10. exletm

56.11.aliobs

56.12. medic

57. intidia

58. plasma 1

59. remal1

60. nremal1 
Morbidade últimos 12 meses

61- A criança teve malária nos últimos 12 meses?

01-sim 02-não 99-não sabe/não lembra

61. malar2

62- Se sim, onde foi feito o diagnóstico?

01- posto funasa/sucam na cidade onde mora

02- posto funasa/sucam em outra cidade

03- laboratório privado

04- outros:

99-não sabe/não lembra

88-não se aplica

63- Que espécie de plasmódio foi diagnosticada no último episódio de malária?

04- plamodium falciparum 99-não sabe/não lembra

05- plasmodium vivax 88- não se aplica

06- mista (ambas espécies)

64- A criança tomou remédio para malária no último episódio?

01-sim

02-não

99-não sabe /não lembra

88-não se aplica

65- Se tomou, poderia dizer qual o nome do remédio?

01-cloroquina

02-primaquina

03-mefloquina

04-quinino

05-doxiciclina ou tetraciclina

06-artesunato

07-outros

99-não sabe/não lembra

88-não se aplica

(pedir a mãe, se possível, para ver a caixa do remédio)

66- Durante os últimos 12 meses a criança apresentou chiado no peito?

66. chia12

01-sim

02-não

99-não sabe/não lembra

67- Por causa deste chiado, o médico já disse que (nome criança) tem asma?

01-sim

02-não

99-não sabe/não lembra

88-não se aplica

63. plasma2

64. remal2

65. nremal2

62. locdi

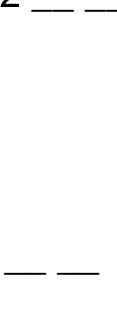


68- A criança teve pneumonia nos últimos 12 meses?

01-sim

02-não

99-não sabe/não lembra

\section{Bloco V- História alimentar da criança}

69 - (Nome da criança) mamou no peito?

01 - sim 02 - não $\quad 99$ - não lembra/não sabe

70- A criança mama no peito?

01- $\quad$ Sim

99- não sabe

02- não

71- Se a criança mamou no peito, até que idade (nome criança) recebeu só o leite materno (LM), sem nenhum outro alimento (nem água ou chás) ?
1.
dias
888 - ainda recebe só LM
2. meses
999 - não sabe / não lembra

68. pneu12

69. nmamou

70. mampei

72- Se a criança mama no peito, recebe outro alimento que não o leite de peito? 01-chá
(01) $\operatorname{sim}$
(02) não
(01) sim
(02) não
(99) não sabe
02-água
(01) sim (02) não
(99) não sabe
03-leite vaca/pó
(01) sim (02) não (99) não sabe
(01) sim (02) não (99) não sabe
(99) não sabe
04-outros

72.1. chá

72.2. água

72.3.leitev

72.4. outroa

73- Quando (nome da criança) recebeu outro tipo de leite diferente do LM?

1. dias

(999) não lembra / não sabe

2. meses

(888) ainda não recebeu

3. anos

73.a. quando

73.1. leitd

73.2. leitem

73.3. leitea

74- Com que idade (nome da criança) deixou de receber o LM? dias (888) - ainda mama semanas (999) - não lembra / não sabe meses

74a. ideld

74b. idels

74c. idelm

\section{Bloco VI- Dados antropométricos e de Hemoglobina}

Data do dexame

75. Peso

1.peso $1=$

2.peso $2=$ $\mathrm{kg}$ 
76. Comprimento

1.comprimento/estatura $1=$ $\mathrm{cm}$

2. comprimento/estatura $2=$

$\mathrm{cm}$
76.1. compc1

76.2.compc2

77. hemog

77. Valor da hemoglobina

$\mathrm{hb}=$ $g / d l$

resultado: ( ) normal

( ) anêmico (<11 mg/dl) 


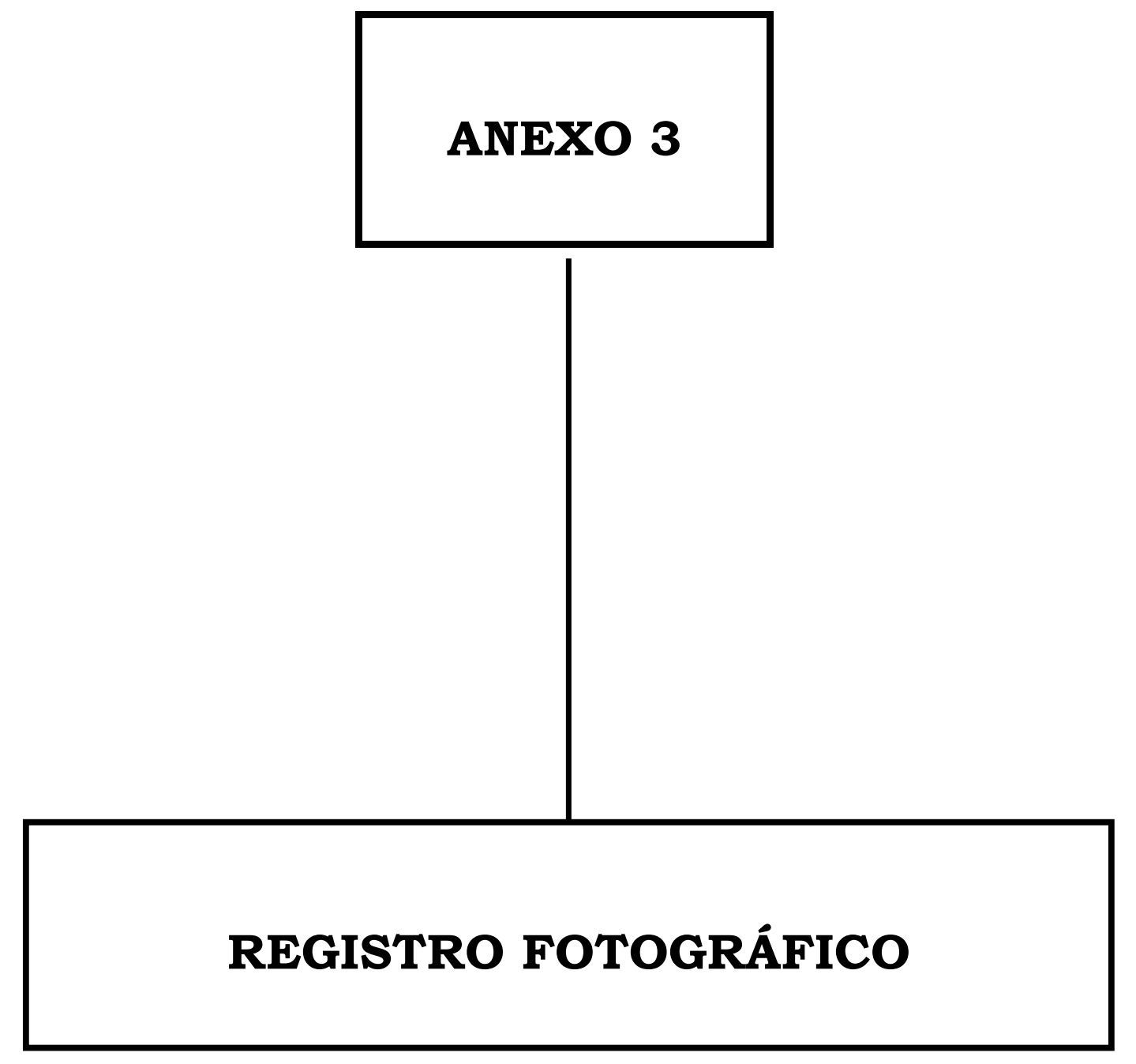




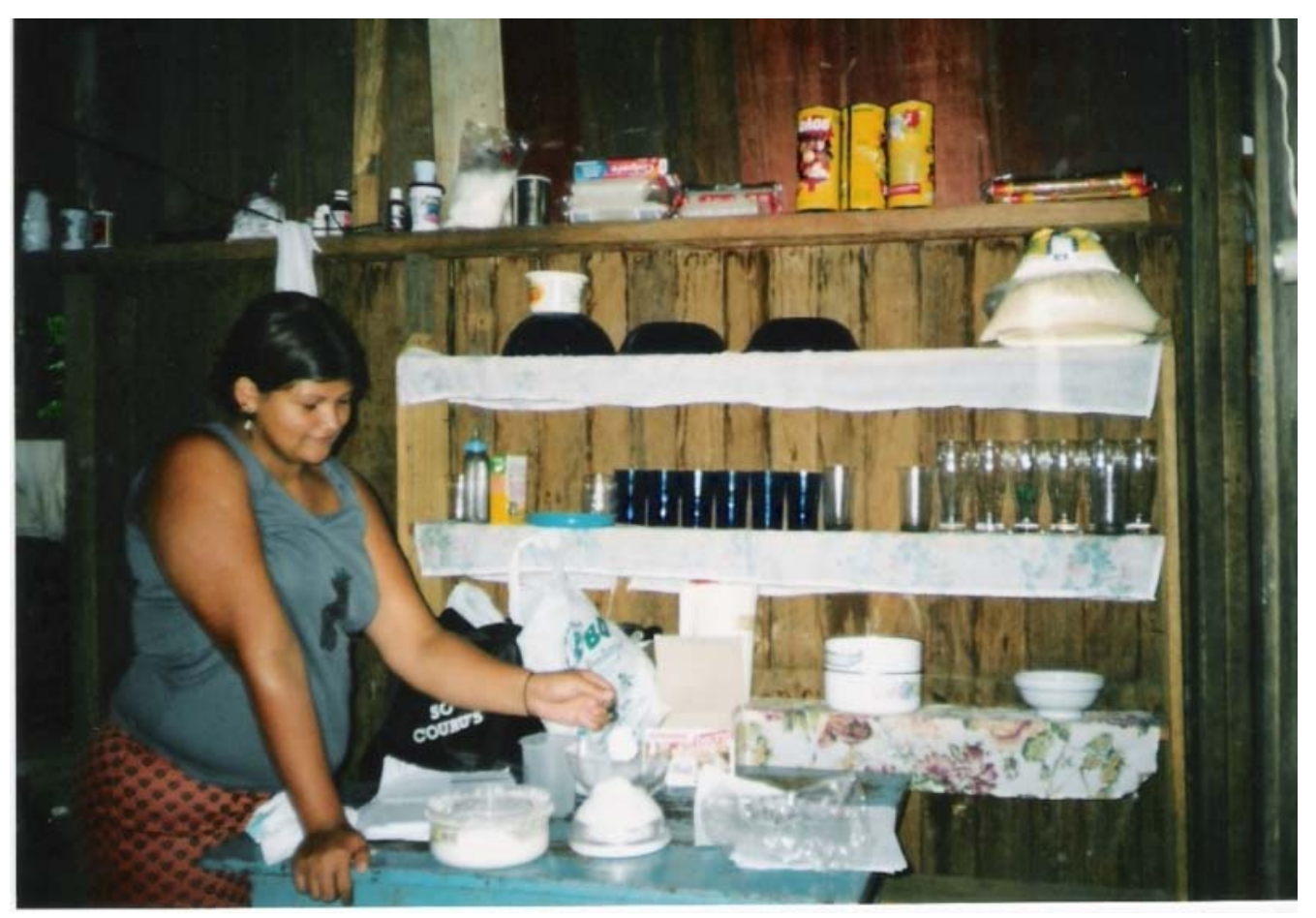


